INTERNATIONAL

CENTER FOR

PUBLIC POLICY
International Center for Public Policy

Working Paper 20-05

April 2020

The Politics of Fiscal Federalism: Building a Stronger Decentralization Theorem

Raúl A. Ponce-Rodríguez

Charles R. Hankla

Jorge Martinez-Vazquez

Eunice Heredia-Ortiz 



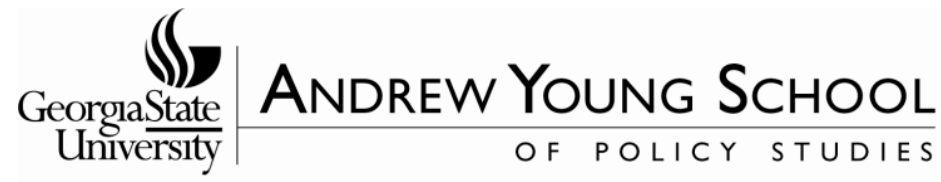

International Center for Public Policy

Working Paper 20-05

\section{The Politics of Fiscal Federalism: Building a Stronger Decentralization Theorem}

Raúl A. Ponce-Rodríguez

Charles R. Hankla

Jorge Martinez-Vazquez

Eunice Heredia-Ortiz

\section{April \\ 2020}

International Center for Public Policy

Andrew Young School of Policy Studies

Georgia State University

Atlanta, Georgia 30303

United States of America

Phone: (404) 413-0235

Fax: (404) 651-4449

Email: paulbenson@gsu.edu

Website: http://icepp.gsu.edu/

Copyright 2020, the Andrew Young School of Policy Studies, Georgia State University. No part of the material protected by this copyright notice may be reproduced or utilized in any form or by any means without prior written permission from the copyright owner. 


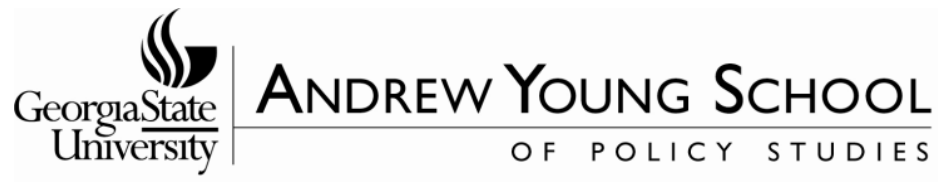

\section{International Center for Public Policy Andrew Young School of Policy Studies}

The Andrew Young School of Policy Studies was established at Georgia State University with the objective of promoting excellence in the design, implementation, and evaluation of public policy. In addition to four academic departments, including economics and public administration, the Andrew Young School houses eight leading research centers and policy programs, including the International Center for Public Policy.

The mission of the International Center for Public Policy (ICePP) at the Andrew Young School of Policy Studies is to provide academic and professional training, applied research, and technical assistance in support of sound public policy and sustainable economic growth in developing and transitional economies.

ICePP is recognized worldwide for its efforts in support of economic and public policy reforms through technical assistance and training around the world. This reputation has been built serving a diverse client base, including the World Bank, the U.S. Agency for International Development (USAID), the United Nations Development Programme (UNDP), finance ministries, government organizations, legislative bodies, and private sector institutions.

The success of ICePP reflects the breadth and depth of its in-house technical expertise. The Andrew Young School's faculty are leading experts in economics and public policy and have authored books, published in major academic and technical journals, and have extensive experience in designing and implementing technical assistance and training programs. Andrew Young School faculty have been active in policy reform in over 40 countries around the world. Our technical assistance strategy is not merely to provide technical prescriptions for policy reform, but to engage in a collaborative effort with host governments and donor agencies to identify and analyze the issues at hand, arrive at policy solutions, and implement reforms.

ICePP specializes in four broad policy areas:

- Fiscal policy (e.g., tax reforms, public expenditure reviews)

- Fiscal decentralization (e.g., reform, intergovernmental transfer systems, urban finance)

- Budgeting and fiscal management (e.g., local, performance-based, capital, and multiyear budgeting)

- Economic analysis and revenue forecasting (e.g., micro-simulation, time series forecasting)

For more information about our technical assistance activities and training programs, please visit our website at icepp.gsu.edu or contact us at paulbenson@gsu.edu. 


\title{
The Politics of Fiscal Federalism: Building a Stronger Decentralization Theorem
}

\author{
Raúl A. Ponce-Rodríguez, Charles R. Hankla, \\ Jorge Martinez-Vazquez, and Eunice Heredia-Ortiz ${ }^{1,2}$
}

April 2020

\begin{abstract}
We explore how party structures can condition the benefits of decentralization in modern democracies. In particular, we study the interaction of two political institutions: democratic (de)centralization (whether a country has fiscally autonomous and elected local governments) and party (non)integration (whether power over local party leaders flows upwards through party institutions, which we model using control over candidate selection). We incorporate these institutions into our strong decentralization theorem, which expands on Oates (1972) to examine when the decentralized provision of public services will dominate centralized provision even in the presence of inter-jurisdictional spillovers. Our findings suggest that, when externalities are present, democratic decentralization will be beneficial only when parties are integrated. In countries with non-integrated parties, we find that the participation rules of primaries have implications for the expected gains from democratic decentralization. Under blanket primaries, Oates' conventional decentralization theorem holds but our strong decentralization theorem does not. By contrast, when primaries are closed, not even Oates' conventional decentralization theorem holds.
\end{abstract}

Keywords: decentralization, fiscal federalism, formal theory, political parties, public goods

\footnotetext{
${ }^{1}$ Ponce-Rodríguez: Department of Economics, Universidad Autónoma de Ciudad Juárez; Hankla: Department of Political Science, Georgia State University; Martinez-Vazquez: Department of Economics, International Center for Public Finance, Georgia State University; Eunice Heredia-Ortiz: Development Alternatives Inc., DAI

${ }^{2}$ The order of authors has been drawn randomly. We would like to thank Roger Myerson, Irfan Nooruddin, Craig Volden, Katrina Kosec, Emmanuel Haruna, Kyle Hanniman, and participants in the World Bank's 2018 Conference in Development Economics for their helpful feedback. Our thanks also go the International Center for Public Policy at Georgia State's Andrew Young School of Policy Studies for financial support. Finally, we would like to thank the members of the Deil Wright Awards committee for naming a much earlier version of this work the best paper on federalism presented at the 2011 American Political Science Association Convention in Seattle.
} 


\section{Introduction}

In the last few decades, numerous countries - China, Indonesia, South Africa, India, the United Kingdom, and many others - have engaged in decentralization reforms. These reforms, at least in the developing world, have been supported both by the aid dollars of multilateral agencies such as the World Bank and USAID, and by the research findings of many scholars. Central to these positive scholarly judgments is the "decentralization theorem," which was developed by Oates (1972) and states that " . . . in the absence of cost-savings from the centralized provision of a (local public) good and of inter-jurisdictional externalities, the level of welfare will always be at least as high (and typically higher) if Pareto-efficient levels of consumption are provided in each jurisdiction than if any single, uniform level of consumption is maintained across all jurisdictions" (p.54).

However, as the process of decentralization has continued apace, some scholars have begun to question whether devolving authority to regional and local governments is a universal good. Among other things, they have pointed out that Oates, in developing his theorem, assumes not only the absence of economies of scale and externalities, but also that policies are implemented by benevolent welfare-maximizing governments. While this latter assumption may be useful for creating a simple and elegant theory of decentralization, it hardly accords with empirical realities. More to the point, it begs the question of how different political processes and institutions might shape the fiscal choices made by policy makers, and, with them, the outcomes of fiscal federalism.

In this paper we seek to answer that question by analyzing the interaction of two particular political institutions: democratic (de)centralization (whether a country has fiscally autonomous and elected local governments) and party (non)integration (whether power over 
local party leaders flows upwards through party institutions to leaders at the national level, which we model using candidate selection procedures). ${ }^{1}$ We incorporate these institutions into a rigorous and formal extension of Oates (1972), which we term our strong decentralization theorem.

Our findings suggest that, when public goods have externalities, a move towards democratic decentralization will only produce the benefits predicted by Oates if parties are integrated. When local governments are elected and autonomous, their leaders possess the accountability necessary to incentivize public goods provision, but when national party leaders also control access to the ballot, local leaders have strong reasons to provide the efficient level of goods even when their benefits spillover across jurisdictions. Put differently, democratic (de)centralization affects public spending because local elections and nationwide elections create different incentives for the officials who design public policy. Upward accountability through integrated party mechanisms can influence these incentives.

Narrowing our focus to non-integrated parties, we also study how the institutions of primary elections shape decisions over public spending. We find that the participation rules of primaries, whether closed or blanket, have important implications for the expected gains from democratic decentralization. Blanket primaries are an extreme form of open primary in which the top two candidates, regardless of party, compete in the general election. ${ }^{2}$ Under such system, democratic decentralization only produces the expected benefits when inter-jurisdictional spillovers are absent. By contrast, when primaries are closed, not even Oates' conventional

\footnotetext{
${ }^{1}$ Note that, in Ponce et al. 2018, we use the term "party (de)centralization" for a similar concept. As we explain later in this paper, we adopt the term "party (non)integration" here because it corresponds more closely to our intended meaning and is consistent with the use of the term in our recent book, Hankla et al. 2019.

${ }^{2}$ See the National Council of State Legislatures for more on types of primary elections: http://www.ncsl.org/research/elections-and-campaigns/primary-types.aspx.
} 
decentralization theorem holds, meaning that democratic decentralization will produce no consistent benefits vis-à-vis centralized provision. This is because, in a closed primary system, parties will hew too closely to the specific preferences of their local co-partisans rather than to the aggregate interests of all constituents.

This article contributes to the extensive literature on decentralization in two important ways. First, it significantly expands the main theoretical construct in fiscal decentralizationOates's decentralization theorem — by showing that under the right political institutions, the fiscally decentralized provision of local public goods can be more efficient even in the presence of inter-jurisdictional externalities. It also shows that under certain political institutions, Oates's decentralization theorem does not continue to hold. Second, and more generally, the paper clearly demonstrates that different forms of decentralization—-fiscal versus democratic versus party - are closely intertwined and cannot be analyzed separately, as has been previously done in most of the literature.

Given the extensive variation in party organization that exists in the real world, these findings are of great empirical significance. Of the 157 countries that we have coded for our empirical work (see Hankla et al. 2019; Ponce et al. 2018), 106 were characterized by some degree of democratic decentralization. Of these 106, sixty-seven countries have had integrated parties for at least some years and forty-nine have consistently had non-integrated parties

We structure the rest of the article as follows: The second section reviews the relevant previous literature. The third section contains a summary and detailed explanation of the main findings of our theory. The fourth section includes a benchmark model in which local public goods are efficient and match the heterogeneous preferences over public spending from voters. The fifth section incorporates the analysis of party integration and democratic centralization. The 
sixth section studies the case of party integration and democratic decentralization. The seventh section contains the introduction of our analysis of non-integrated parties. The eight section considers the case of nonintegrated parties and democratic centralization. The ninth section studies non-integrated parties and democratic decentralization. The tenth section develops a comparative analysis between democratic centralization versus decentralization in economies with non-integrated parties. The final section concludes.

\section{Literature Background}

There has been considerable previous research on the role of political institutions in public goods delivery, but most of it has concerned the national level. In this vein, scholars have investigated the impact of a number of specific institutions (e.g., electoral systems, legislativeexecutive relations, legislative and coalition party fragmentation) on policy outcomes such as government spending, free trade, balanced budgets, and economic growth (see Persson and Tabellini 2003, O’Halloran 1994, Nielson 2003, Haggard and Kaufman 1995, Hallerberg and Marier 2004, Roubini and Sachs 1989, and Volkerink and de Haan 2001). Work on the influence of political institutions on subnational public goods delivery has been much sparser, as we discuss below.

Researchers focused on decentralization, for their part, have examined the relationship between the organization of parties, on the one hand, and the devolution of state power, on the other. For example, Chhibber and Kollman (2004) make the case that countries decentralizing authority to the subnational level are likely to have more localized party systems, while Fabre et al. (2005) find that such countries will also be characterized by more decentralized parties.

Perhaps William Riker is the most prominent scholar to have taken up this question. He argues in his 1987 book that the American "decentralized party system is the main protector of 
the integrity of states in our federalism" (p. 221). ${ }^{3}$ By contrast, Filippov, Ordeshook, and Shvetsova (2004) emphasize the benefits of more integrated parties, making the case that party systems, which successfully link the national and sub-national levels of government, are the best guarantors of a stable federal system. Myerson (2006) concurs with the latter authors, arguing that regional and local elections provide opportunities for potential national candidates to prove themselves at the sub-national level.

Oates' (1972) decentralization theorem has also inspired considerable work in the last few decades. While its assumption of benevolent public officials has been confronted in the "second generation" of research on decentralization, however, few scholars have examined which political institutions support the social welfare gains expected from the theorem. ${ }^{4}$ In particular, second generation scholars have tended to focus on the problems of assignment and soft budget constraints, and much less on the relationship between specific political institutions at the subnational level and the efficient provision of local public goods in fiscally decentralized systems.

Despite these limitations, recent work on the political economy of fiscal federalism highlights the need to examine more closely how political institutions can influence the expected gains from decentralization (see Lockwood 2015). For instance, Lockwood (2002) uses a model of legislative bargaining to show that welfare is not increasing with higher spillovers under centralization, which is one of the main advantages of centralization suggested by Oates (1972). Lockwood (2008) studies whether the decentralization theorem holds when collective choices are made by majority rule and lobbying, and Bordignon et al. (2008) characterize conditions in

\footnotetext{
${ }^{3}$ See also Volden 2004 for an excellent summary of Riker's thought on Federalism.

${ }^{4}$ For more on second generation research on fiscal federalism, see Weingast (2014), Weingast (2009), and Oates (2005).
} 
which lobbying through campaign contributions induces a decentralized provision that is not Pareto efficient when politicians become too greedy.

Even more to the point, Besley and Coate (2003), in a legislative model, show that local public goods are not automatically Pareto efficient since public spending maximizes the utility of a median voter instead of a social welfare function. This outcome means that the decentralization theorem identified by Oates (1972) is not necessarily compatible with the electoral incentives of politicians. However, in spite of their focus on the role of legislatures in fiscal decentralization, Besley and Coate (2003) do not consider how the structures of political parties influence public spending behavior. In this paper, we develop such an analysis.

Other contributions in political economy have focused on providing rationales for the superiority of fiscal decentralization that are distinct from the one provided by Oates (1972). For instance, scholars have argued that fiscal decentralization is preferable because of its impact on corruption (Bardhan and Mookherjee 2000), , accountability (Seabright 1996), and, under certain conditions, government capture (Bardhan and Mookherjee 2002).

Enikolopov and Zhuravskaya (2007) is one rare study that focuses on the political and institutional conditions under which decentralization can deliver on its promises. These scholars argue convincingly that fiscal decentralization produces better outcomes in the presence of party integration. That said, they are not interested in democratic decentralization (i.e. elections) as we are here, and their paper is entirely empirical, with no formal component.

Building on all of this prior work, we demonstrate in this paper that the decentralization theorem, which lies at the heart of the fiscal federalism literature, is dependent on the structure of political institutions. Local elections and certain forms of party institutions, we argue, must be in place before decentralization can deliver on its promises. 


\section{Brief Introductory Tour to the Theory}

As noted above, the main goal of this paper is to create a rigorous and formal extension of Oates' influential "decentralization theorem." Of particular interest for us is the interaction between democratic (de)centralization and party (non)integration in the provision of local public goods. Under democratic decentralization, local public goods are provided by democratically elected local governments, while under democratic centralization they are provided by the national government.

Our notion of what constitutes an integrated party is the same regardless of the electoral system used in a country. For us, a party is integrated when power over local party officials flows upwards through party institutions to leaders at the national level. This concept, more fully defined in Hankla et al. (2019), encompasses a number of characteristics. ${ }^{5}$ For example, integrated parties are governed by strong institutions rather than personalist leaders, and they are present at all tiers of the polity. For modeling simplicity, however, we focus on what is perhaps the most salient feature of an integrated party—-that its national leaders control access to the party name in local elections. When local politicians can run for office using the name of a party without the permission and oversight of party leaders in the capital, the party cannot be considered integrated.

For space reasons, we focus our formal analysis in this paper on majoritarian, singlemember-jurisdiction systems, defining non-integrated parties as those that hold blanket or closed primaries (modeled separately) to choose candidates, as opposed to those having national party

\footnotetext{
${ }^{5}$ The models presented here build on those in Hankla et al. (2019), but here we introduce significant improvements including the nature of local public goods not being homogeneous and the analysis of majoritarian electoral systems with blanket and closed primary elections.
} 
leaders nominate them. ${ }^{6}$ While we understand that many non-integrated parties practice free candidate nomination procedures (i.e., by collecting signatures or paying a fee) rather than primaries, we believe these decentralized structures will have many of the same effects as primaries (see Carey and Shugart 1995).

In the majoritarian system models that are our focus here, we find that both the conventional decentralization theorem (which assumes away spillovers) and our new strong decentralization theorem (which allows for spillovers) hold-under democratic decentralization - when parties are integrated. In other words, we find that, when integrated national parties are active in local politics, locally elected governments will outperform central governments in providing public goods. This pattern will hold even in the presence of interjurisdictional spillovers.

In such situations, democratic decentralization creates local governments that are accountable to their voters' preferences, while the vertical responsibility within integrated parties incentivizes these local governments to finance the efficient provision of local goods and services, even those with benefits that spill across jurisdictions. This is the key implication of our strong decentralization theorem.

The situation is different when parties are non-integrated. In this case, it is necessary to consider the structure of primary elections in order to predict varying incentives for the provision of public goods and to determine whether democratic decentralization dominates centralization. For instance, we find that, under blanket primaries, our strong theorem is not satisfied but the

${ }^{6}$ See Hankla et al. (2019) for a previous analysis of systems using proportional representation, and Ponce et al. (2018) for an empirical test of our arguments. Note also that the model assumes that parties possess meaningful organizational structures and are not purely dominated by personalist "bosses." It also assumes competitive elections at the local level. 
conventional decentralization theorem is. Primary elections do not create the necessary incentives for local leaders to internalize spillovers, which mean that the strong decentralization theorem does not generally hold for democracies with nonintegrated parties. However, systems with blanket primaries are an exception. Here, local public goods with no spillovers are Pareto efficient and the benefits of policy differentiation are captured. By contrast, while central governments also provide Pareto efficient local public goods, they are not able to maximize the gains associated with the heterogeneity of preferences.

By contrast, when parties are non-integrated and primaries are closed, neither the strong nor the conventional decentralization theorem holds. For countries with such nominating institutions, parties operating under both democratically centralized and decentralized structures will lack incentives to provide the efficient level of local public goods. This is because the participation rules of closed primaries allocate voting rights only to members of a specific party rather than to the electorate in general. For this reason, parties operating under both structures of government have political incentives to target goods only to those voters who count. This intuition suggests why local public goods provision might not be efficient and might not successfully maximize the gains expected from matching policy with the heterogeneous preferences of voters.

These findings have significant implications for the scholarly understanding of decentralization among both political scientists and economists. Most obviously, they show that political institutions mediate the effects of the decentralized provision of public goods to an extent not previously realized. In addition, our findings contribute to the theory of fiscal federalism and help make sense of the mixed results that characterize the empirical scholarship on the actual impact of decentralization on service delivery, economic growth and other 
dimensions (see, for example, Martinez-Vazquez et al. 2016). Additionally, for development practitioners, they have the potential to encourage a deeper examination of the types of political institutions that may be necessary for decentralization reforms to produce fuller positive results.

\section{The Benchmark and Definitions}

We begin by characterizing the set of local public goods that maximize society's surplus from public goods. This approach to benchmarking our results allows us to compare them to those in the normative analysis of Oates (1972) and the more recent political economy analyses of Besley and Coate (2003) and Lockwood (2015).

Consider an economy composed of jurisdictions $i=\{1,2\}$ with a corresponding population of $n_{i}$ in each jurisdiction. Moreover, we assume $n_{1} \neq n_{2}$. Following most of the literature and for simplicity of the analysis, in our economy individuals do not have mobility across jurisdictions. The utility of an individual $h$ in jurisdiction 1 is $v_{h 1}\left(\alpha_{h 1}, g_{1}, g_{2}\right)=$ $\alpha_{h 1}\left[\ln \left(g_{1}\right)+k_{2} \ln \left(g_{2}\right)\right]$ where $g_{1}$ and $g_{2}$ are public goods provided by jurisdictions 1 and 2 and $\alpha_{h 1}>0$ is a parameter of intensity of preferences for public goods consumed by a resident $h$ of jurisdiction 1 . The parameter $k_{2} \in[0,1]$, measures the extent of inter-regional spillovers of $g_{2}$ over residents of jurisdiction 1 . For local public goods without spillovers $k_{2}=0$, and when jurisdiction 2 provides a nationwide pure public good, $k_{2}=1$. A similar expression is given by an individual $h$ living in jurisdiction 2 such that $v_{h 2}\left(\alpha_{h 2}, g_{2}, g_{1}\right)=\alpha_{h 2}\left[\ln \left(g_{2}\right)+k_{1} \ln \left(g_{1}\right)\right]$. In this economy, preferences are heterogeneous within and across districts. Hence, for individuals $h$ and $h^{\prime}: h \neq h^{\prime}, \alpha_{h 1} \neq \alpha_{h \prime 1} \neq \alpha_{h 2} \neq \alpha_{h \prime 2}$. In our model, the size of spillovers between jurisdictions is asymmetric therefore $k_{1} \neq k_{2}$. The marginal cost of producing a public good in all jurisdictions is $q$. The nationwide net social welfare for this economy is given by $N S$ : 


$$
N S W=\sum_{h=1}^{n_{1}} v_{h 1}\left(\alpha_{h 1}, g_{1}, g_{2}\right)+\sum_{h=1}^{n_{2}} v_{h 2}\left(\alpha_{h 2}, g_{2}, g_{1}\right)-q\left(g_{1}+g_{2}\right)
$$

Proposition 1 characterizes a set of local public goods that are Pareto efficient and maximize the gains attributed to matching the size of local public spending to the heterogeneous preferences of individuals across jurisdictions.

Proposition 1. The Pareto efficient local public goods $\widehat{\boldsymbol{g}}^{*}=\left[\hat{g}_{1}^{*}, \hat{g}_{2}^{*}\right]$ that maximize the gains from inter-regional policy differentiation are given by:

$$
\left[\hat{g}_{1}^{*}, \hat{g}_{2}^{*}\right]=\left[\frac{\alpha_{1}+k_{1} \alpha_{2}}{q}, \frac{\alpha_{2}+k_{2} \alpha_{1}}{q}\right]
$$

Where $\alpha_{1}=\sum_{h=1}^{n_{1}} \alpha_{h 1}$ is the aggregate intensity of preferences for local public goods of all residents in district 1 and $\alpha_{2}=\sum_{h=1}^{n_{2}} \alpha_{h 2}$ is the corresponding aggregate intensity of preferences of all residents of district 2 .

\section{Proof}

Find $\frac{\partial N S W}{g_{1}}=\frac{\sum_{h=1}^{n_{1}} \alpha_{h 1}}{\hat{g}_{1}^{*}}+k_{1} \frac{\sum_{h=1}^{n_{2}} \alpha_{h 2}}{\hat{g}_{1}^{*}}-q=0$ and $\frac{\partial N S W}{g_{2}}=\frac{\sum_{h=1}^{n_{2}} \alpha_{h 2}}{\hat{g}_{2}^{*}}+k_{2} \frac{\sum_{h=1}^{n_{1}} \alpha_{h 1}}{\hat{g}_{2}^{*}}-q=0$ rearrange terms to obtain the result in (2).

In (2), local public goods with and without spillovers in each jurisdiction, $\hat{g}_{i}^{*}$ for $i=1,2$, are provided at the point in which the nationwide marginal social benefits of $\hat{g}_{i}^{*}$ in both jurisdictions are equivalent to the social marginal costs, $q$, of producing the local public good in jurisdiction $i$, therefore, $\widehat{g}_{i}^{*}$ is Pareto efficient. For instance, the nationwide marginal social benefits of $\hat{g}_{1}^{*}$ include the marginal utility gains of all residents of jurisdiction $1, \frac{\sum_{h=1}^{n_{1}} \alpha_{h 1}}{\hat{g}_{1}^{*}}$, and due to inter-regional spillovers, the marginal utility gains of all residents of jurisdiction $2, k_{1} \frac{\sum_{h=1}^{n_{2}} \alpha_{h 2}}{\hat{g}_{1}^{*}}$. 
Therefore, $\hat{g}_{1}^{*}$, depends positively on the intensity of preferences of all residents of jurisdiction 1 , which are given by $\alpha_{1}=\sum_{h=1}^{n_{1}} \alpha_{h 1}$, the intensity of preferences of all residents of jurisdiction 2 ,

which are given by $\alpha_{2}=\sum_{h=1}^{n_{2}} \alpha_{h 2}$, the extent of inter-regional spillovers (if $k_{1}>0$ ), and negatively on the marginal cost of the public good $q$. The heterogeneity of preferences of individuals across jurisdictions implies that in general $\hat{g}_{1}^{*} \neq \hat{g}_{2}^{*}$.

\section{Party Integration in a Democratically Centralized Government}

In this section, we introduce a model of electoral competition in a democracy characterized by party integration (modeled as party leaders controlling the nomination of candidates participating in elections) and democratic centralization (modeled as voters electing an official to run the central government and with no local elections). We assume that if systems are democratically centralized then they are also fiscally centralized. Similarly, democratically decentralized systems, i.e., those with elected subnational governments, are also fiscally decentralized, with subnational officials having autonomy over spending and taxing decisions in their respective jurisdictions.

In our economy, there are two parties, $P=\{A, B\}$. The parties' problem is to aggregate the heterogeneous and conflicting views of voters over public spending into a policy platform that maximizes the parties' probabilities of winning the election. We characterize the political equilibrium of this economy throughout a sequential game of complete and perfect information in which all actions of all players in each stage of the game are common knowledge. In the first stage of the game, candidates announce policies seeking their party's nomination and party leaders nominate the candidate that will run in the general election. Party leaders nominate a candidate by selecting a candidate $j=\{1,2\}$ to the nomination set $N S_{P}$ with $P=\{A, B\}$. In the 
second stage, voters observe the parties' policies and vote. In the third stage, the winning candidate takes all, forms the government, and implements policy.

In the first stage, two candidates $j=\{1,2\}$ in each party seek the nomination of their parties. For an economy with party integration, party leaders have full command over policy making by nominating only those candidates who adopt the ideal policy of party leaders. In our economy, the two parties compete in the election to form the government in a majoritarian electoral system with single member jurisdictions. Under a central government, local public goods are provided by a single government that represents voters of all jurisdictions. The government finances its expenditures through a uniform tax on residents of all jurisdictions $\tau$ satisfying the budget constraint $\tau\left(n_{1}+n_{2}\right)=q\left(g_{1}+g_{2}\right)$, where $\tau\left(n_{1}+n_{2}\right)$ is the tax revenue and $q\left(g_{1}+g_{2}\right)$ is the nationwide spending in local public goods. We assume the central government provides a uniform local public good. ${ }^{7}$

In the second stage of the game, voters observe the parties' policies and vote. Voting is sincere and all individuals vote. ${ }^{8}$ Denote $\Psi_{A h 1}\left(\alpha_{h 1}\right)$ as the net payoff received by a voter with preference $\alpha_{h 1}$ in jurisdiction 1 from party A relative to that of party B where $\Psi_{A h 1}\left(\alpha_{h 1}\right)=$ $\left\{v_{A h 1}\left(\alpha_{h 1}, g_{A 1}, g_{A 2}\right)-\tau_{A}+\sigma_{A h 1}\right\}-\left\{v_{B h 1}\left(\alpha_{h 1}, g_{B 1}, g_{B 2}\right)-\tau_{B}+\sigma_{B h 1}\right\}$ and where $v_{A h 1}\left(\alpha_{h i}, g_{A 1}, g_{A 2}\right)$ is the welfare of voter when party A selects spending policies $g_{A 1}, g_{A 2}$,

\footnotetext{
${ }^{7}$ The assumption of uniform central provision is quite standard in the literature. It is now agreed that central governments may provide heterogeneous services but that the central government may also have less information (Cremer and Palfrey 1996) and fewer incentives. Moreover, although federations may lead to horizontal fiscal externalities (Wilson 1999), and citizens could benefit from a coordinated central policy, this could also lead to less accountability and efficiency (Seabright 1996). Related to this same issue, Tomassi and Weinschelbaum (2003) characterize a tradeoff between externalities and accountability in which decentralization might be preferred even if preferences are identical. In summary, assuming that the central government provides uniform public goods could be interpreted as just convenient shorthand for assuming that centralized and decentralized governments have different mechanisms to match local preferences and needs with policy.

${ }^{8}$ The assumption of sincere voting seeks to simplify the analysis and it ignores strategic voting behavior such as credible threats of some coalition of voters who might abstain from voting for the nominated candidate in the general election if the candidate changes the policy position he previously announced.
} 
$v_{B h 1}\left(\alpha_{h i}, g_{B 1}, g_{B 2}\right)$ is the welfare when party B selects spending policies $g_{B 1}, g_{B 2}$, and $\tau_{A}$ and $\tau_{B}$ are taxes on residents of all jurisdictions under parties A and B. We follow McKelvey and Patty (2006), and Coughlin (1992) in assuming that the net payoff $\Psi_{A h 1}\left(\alpha_{h 1}\right)$ also depends on stochastic factors $\sigma_{A h 1}$ and $\sigma_{B h 1}$. Voter type $\alpha_{h 1}$ in jurisdiction 1 votes for party $A$ if $\Psi_{A h 1}\left(\alpha_{h 1}\right)>0$, for party $B$ if $\Psi_{A h 1}\left(\alpha_{h 1}\right)<0$, and flips a fair coin if $\Psi_{A h 1}\left(\alpha_{h 1}\right)=0$. An equivalent interpretation is given to $\Psi_{A h 2}\left(\alpha_{h 2}\right)$ which is the net payoff received by a voter with preference $\alpha_{h 2}$ in jurisdiction 2 from party A relative to that of party B.

Define $\varepsilon_{h 1}=\sigma_{B h 1}-\sigma_{A h 1}=\left\{v_{A h 1}\left(\alpha_{h 1}, g_{A 1}, g_{A 2}\right)-\tau_{A}\right\}-\left\{v_{B h 1}\left(\alpha_{h 1}, g_{B 1}, g_{B 2}\right)-\tau_{B}\right\}$

and assume $\varepsilon_{h 1} \in\left[\underline{\varepsilon}_{h 1}, \bar{\varepsilon}_{h 1}\right]$, then probability that a voter type $\alpha_{h 1}$ votes for party $A$ in jurisdiction $i$ is $F_{A h 1}=\int_{\underline{\varepsilon}_{h 1}}^{\bar{\varepsilon}_{h 1}} f_{A h 1}\left(\varepsilon_{h 1}\right) d \varepsilon_{h 1}$, where $f_{A h 1}\left(\varepsilon_{h 1}\right)$ is a continuous probability distribution over $\varepsilon_{h 1}$. The expected vote of party $A$ in jurisdiction 1 is $\phi_{A 1}=\sum_{h=1}^{n_{1}} F_{A h 1}\left(\varepsilon_{h 1}\right)$ and the nationwide expected vote of party $A$ is $\phi_{A}=\sum_{i=1}^{2} \phi_{A i}$ and that of party B is $\phi_{B}=\sum_{i=1}^{2} \phi_{B i}$. Define $\pi_{A}: \rho_{A} \rightarrow[0,1]$ as a continuous cumulative distribution over the plurality of the party, $\rho_{A}=\phi_{A}-\phi_{B}$, where $\rho_{A} \in\left[\underline{\rho}_{A}, \bar{\rho}_{A}\right]$ and $\pi_{A}=\int_{\underline{\rho}_{A}}^{\bar{\rho}_{A}} w_{A}\left(\rho_{A}\right) d \rho_{A}$, where $w_{A}\left(\rho_{A}\right)$ is the probability distribution over the party's plurality. Following our previous discussion, we define $\pi_{B}$ as the probability that party $B$ wins the election. We follow the previous literature (see, for example, Coughlin 1992) and assume $\pi_{A}$ is strictly concave on $g_{A 1}, g_{A 2}$ and $\pi_{B}$ is strictly concave on $g_{B 1}, g_{B 2} \cdot$

In the third stage, we define $\boldsymbol{\Omega}$ as a non-decreasing cumulative distribution of the sequence, $\left\{\Psi_{A h i}\left(\alpha_{h i}\right)\right\}_{\forall h, \forall i}$, hence $\boldsymbol{\Omega} \in[\mathbf{0}, \mathbf{1}]$.Therefore, if there exists a majority of individuals voting for party A then $\boldsymbol{\Omega}\left(\forall \alpha_{h i}: \Psi_{A h i}\left(\alpha_{h i}\right)>0\right)>1 / 2$ and party $A$ wins the election and 
implements its policy platform. ${ }^{9}$ Otherwise, party $B$ wins the election and implements its policy platform.

The Subgame Perfect Nash Equilibrium of our political process is constituted by the policy platforms of candidates seeking nomination $g_{P i}^{*}$ for $P=\{A, B\}$ and $i=\{1,2\}$, the nomination choices of party leaders $N S_{P}$ for both parties, and the individuals' choices of the vote in all jurisdictions $\Psi_{A h i}\left(\alpha_{h i}\right) \frac{\geq}{<} 0$ for all voters in all districts. For a formal definition of the equilibrium, see Definition 1 in the appendix. On what follows, the equilibrium provision of local public goods is characterized in Lemma 1. In our economy, parties converge in their policy platforms since they maximize a continuous and strictly concave probability function of winning the election based on a common system of beliefs and strategy policy set. ${ }^{10}$ In this section, and with the purpose of differentiating the outcome from this section with upcoming sections of the paper, we define the equilibrium policy as $g_{c}^{*}$. Formally, our main result of this section is the following.

Lemma 1. Local public goods with and without spillovers are Pareto efficient for an economy with a majoritarian electoral system, single member jurisdictions, a democratically centralized government and integrated parties. All parties converge in providing a uniform local public good across jurisdictions, $g_{1}^{*}=g_{2}^{*}=g_{c}^{*}$ where $g_{c}^{*}$ is defined as follows: ${ }^{11}$

$$
g_{c}^{*}=\frac{\hat{g}_{1}^{*}+\hat{g}_{2}^{*}}{2}
$$

\footnotetext{
${ }^{9}$ Note that $\boldsymbol{\Omega} \in[\mathbf{0}, \mathbf{1}]$ is a non-decreasing cumulative distribution of the sequence $\left\{\Psi_{A h i}\left(\alpha_{h i}\right)\right\}_{\forall h, \forall i}$, hence, given some policies $g_{A 1}, g_{A 2}$ of party A and policies $g_{B 1}, g_{B 2}$ of party B, if $\boldsymbol{\Omega}\left(\forall \alpha_{h i}: \Psi_{A h i}\left(\alpha_{h i}\right)>0\right)=0.3$ then $30 \%$ of voters vote for party $\mathrm{A}$ and $70 \%$ for party $\mathrm{B}$.

${ }^{10}$ For a formal proof of convergence in probabilistic voting models with homogeneous parties see Coughlin (1992).

${ }^{11}$ Because all candidates of all parties converge in selecting their policy platforms, in Lemma 1 we have drop the subscripts associating policy with candidates and parties.
} 
Where

$$
\left[\hat{g}_{1}^{*}, \hat{g}_{2}^{*}\right]=\left[\frac{\alpha_{1}+k_{1} \alpha_{2}}{q}, \frac{\alpha_{2}+k_{2} \alpha_{1}}{q}\right]
$$

\section{Proof}

See the appendix.

Lemma 1 says $g_{c}^{*}$ is a Pareto efficient provision of local public goods since the institution of democratic centralization provides voting rights to residents of all jurisdictions and parties have electoral incentives to take into account the marginal benefits and costs of public goods of all residents of all jurisdictions. As a result, parties select a policy in which the nationwide social marginal benefits of public goods are equal to the society's marginal costs. In addition, since the central government provides a uniform public good across jurisdictions then democratic centralization and party integration create incentives for politicians to provide a local public

good, $g_{c}^{*}$, in all jurisdictions that is given by $g_{c}^{*}=\frac{\hat{g}_{1}^{*} \hat{g}_{2}^{*}}{2}$, where $g_{c}^{*}$ corresponds to the average of the socially optimal provision of public goods in jurisdiction 1 and 2 , that is, $\hat{g}_{1}^{*}$ and $\hat{g}_{2}^{*}$.

\section{Party Integration and Democratic Decentralization}

In this section, we consider the case of party integration and democratic decentralization (i.e. local government elections with fiscal decentralization). To anticipate the results that follow below, this section has two main findings. First, we show that party integration in a system of local governments leads to Pareto efficient local public goods with and without inter-regional spillovers. This finding that local elections might lead to Pareto efficient local public goods with inter-regional spillovers is different to the findings of most political economy models in the literature (see for instance Besley and Coate 2003 and many others). Second, local public spending is differentiated to match the heterogeneous spending policies demanded by voters 
across jurisdictions. Third, we show that, under party integration, democratic decentralization dominates democratic centralization.

To prove these claims, we develop again a sequential game of complete and perfect information with local elections. In the first stage of the game, candidates announce policies seeking their party's nomination and party leaders nominate the candidate that will run in the local election of jurisdictions 1 and 2. In the second stage, voters observe the parties' policies and vote in the local election of their jurisdiction. In the third stage, the winning candidate in the local election takes all, forms the government and implements policy.

In a federation with integrated parties, party leaders want to win multiple local elections and nominate candidates who propose policies that maximize the party's joint probability of winning elections in jurisdictions 1 and $2 .{ }^{12}$ In this case, party leaders have full command on policy making by nominating only those candidates who adopt the ideal policy of party leaders. Party Leaders nominate a candidate by selecting a candidate $j=1,2$ in jurisdictions 1 and 2 to the nomination set $N S_{P}$ for parties $P=\{A, B\}$.

Two parties compete in the local election of each jurisdiction to form the local government. For the analysis that follows, we define the joint probability of party $A$ of winning local elections in jurisdictions 1 and 2 by $\pi_{L A}=\pi_{L A}\left(\rho_{L A 1}, \rho_{L A 2}\right)$ where $\pi_{L A}$ is a function of the pluralities of the party in both jurisdictions, $\rho_{L A 1}$ and $\rho_{L A 2}$, where $\rho_{L A i}=\phi_{L A i}-\phi_{L B i}$, and $\phi_{L A i}=\sum_{h=1}^{n_{1}} F_{L A h i}\left(\varepsilon_{h i}\right)$ is the number of votes that party $A$ expects to receive in the local election of jurisdiction $i$ and $F_{L A h i}\left(\varepsilon_{h i}\right)$ is the marginal probability that a voter type $\alpha_{h}^{i}$ votes for

\footnotetext{
${ }^{12}$ In the previous section, under democratic centralization, parties design spending policies to maximize the parties' probability of winning a single national election in which voters from all jurisdictions vote. In this section, under democratic decentralization, parties with nationwide presence, design policies to maximize the joint probability of winning all local elections.
} 
party $A$ in the local election of jurisdiction $i$ (a similar interpretation is given to $\phi_{L B i}$ ). A similar expression is given for the probability of party B of winning the local election $\pi_{L B}$. We assume that $\pi_{L A}$ and $\pi_{L B}$ are continuous and strictly concave function of public goods in jurisdictions 1 and 2 .

In the second stage of the game, voters observe the parties' policies and vote. All individuals vote and voting is sincere. For the case $i=1$, we define $\Psi_{A h 1}\left(\alpha_{h 1}\right)$ as the net payoff received by a voter with preference $\alpha_{h 1}$ in jurisdiction 1 from party A relative to that of party B where $\Psi_{A h 1}\left(\alpha_{h 1}\right)=\left\{v_{A h 1}\left(\alpha_{h 1}, g_{A 1}, g_{A 2}\right)-\tau_{A 1}+\sigma_{A h 1}\right\}-\left\{v_{B h 1}\left(\alpha_{h 1}, g_{B 1}, g_{B 2}\right)-\tau_{B i}+\sigma_{B h 1}\right\}^{13}$ In a system of local governments, politicians pay for local public goods by setting a head tax on residents of their respective jurisdiction $i=\{1,2\}$ with $\tau_{A i}=\frac{q g_{A i}}{n_{i}}$. In addition, the net payoff $\Psi_{A h 1}$ also depends on stochastic factors determined by $\sigma_{A h 1}$ and $\sigma_{B h 1}$. Voter type $\alpha_{h 1}$ votes for party $A$ in the local election of jurisdiction $i$ if $\Psi_{A h 1}\left(\alpha_{h 1}\right)>0$; if $\Psi_{A h 1}\left(\alpha_{h 1}\right)<0$ he or she votes for party $B$, and the voter flips a fair coin if $\Psi_{A h 1}\left(\alpha_{h 1}\right)=0$.

In the third stage, in the local election of jurisdiction $i$, if there exists a majority of individuals voting for party $A$ then $\boldsymbol{\Omega}_{\boldsymbol{i}}\left(\forall \alpha_{h i}: \Psi_{A h i}\left(\alpha_{h i}\right)>0\right)>1 / 2$ then party $A$ wins the election and $g_{L A i}^{*}$ is implemented, otherwise party $B$ wins and $g_{L B i}^{*}$ is implemented.

The subgame perfect Nash equilibrium of the political process with local elections is constituted by policy platforms of candidates $J=\{1,2\}$ seeking nomination from their parties in their respective jurisdictions, the nomination choices of party leaders $N S_{L P i} \forall P, \forall i$, that is to say, party leaders nominate a candidate that will run with the party label in each local election, and

\footnotetext{
${ }^{13}$ Notice that from the perspective of politicians in jurisdiction 1, the welfare of the voter associated with local spending is $v_{A h 1}\left(\alpha_{h 1}, g_{A 1}, g_{A 2}\right)$ and $g_{A 1}$ is a choice variable but $g_{A 2}$ is exogenous and determined by the policy maker of jurisdiction 2 .
} 
the individuals' choices of the vote in their respective local election. For a formal characterization of this equilibrium, see Definition 2 in the appendix. In this economy, all candidates of all parties converge in their policy platforms since they maximize a continuous and strictly concave probability function of winning multiple elections based on a common system of beliefs and strategy policy set. Lemma 2 characterizes the equilibrium spending policies for this economy and Theorem 1 shows that if parties are integrated then democratic decentralization dominates democratic centralization.

Lemma 2. Party integration and democratic decentralization lead to a set of Pareto efficient local public goods with and without spillovers, $\mathbf{g}_{\mathbf{L}}^{*}=\left[g_{L 1}^{*}, g_{L 2}^{*}\right]$. At the equilibrium, $g_{L 1}^{*}, g_{L 2}^{*}$, satisfy the following :

$$
\left[g_{L 1}^{*}, g_{L 2}^{*}\right]=\left[\frac{\alpha_{1}+k_{1} \alpha_{2}}{q}, \frac{\alpha_{2}+k_{2} \alpha_{1}}{q}\right] \text { (5) }
$$

\section{Proof}

See the appendix.

Lemma 2 says that parties have electoral incentives to choose a policy that maximizes the joint probability of winning all local elections. Lemma 2 shows that this policy is equivalent to choosing a policy that maximizes an anonymous utilitarian nationwide social welfare function subject to the constraint that the local public good of the jurisdiction is financed by the residents of the jurisdiction. To see this, note the equivalence between the results in expressions (2) and (5) implying $g_{L i}^{*}=\hat{g}_{i}^{*} \forall i$. In (5), parties have electoral incentives to provide local public goods with and without spillovers at the point in which the nationwide marginal social gains, constituted by the sum of the marginal utility gains of all voters in jurisdiction $i$ plus the marginal utility gains of all voters in the other jurisdiction (that are associated with the effect of 
spillovers from $g_{L i}^{*}$, are equal to the nationwide social marginal costs of the public good. At $g_{L i}^{*}>0 \forall i$, the nationwide aggregate surplus from local public goods is maximized. The heterogeneity of preferences of individuals across jurisdictions implies that $g_{L 1}^{*} \neq g_{L 2}^{*}$.

The decentralized provision of local public goods with and without spillovers is Pareto efficient because the political process is centralized and national parties seek to win elections in all jurisdictions and recognize that the inter-regional externalities of local public goods create an interdependence between the parties' expected votes in the elections of jurisdictions 1 and 2 . Thus, parties have electoral incentives to coordinate local policies and propose spending policies that internalize the inter-regional spillovers in order to maximize the party's joint probability of winning the elections in all jurisdictions. In addition, if parties are integrated, local governments maximize the gains from differentiating local public goods according to the heterogeneous preferences of voters across jurisdictions.

\section{Figure 1. Public Goods With Party Integration and Democratic (De)Centralization}

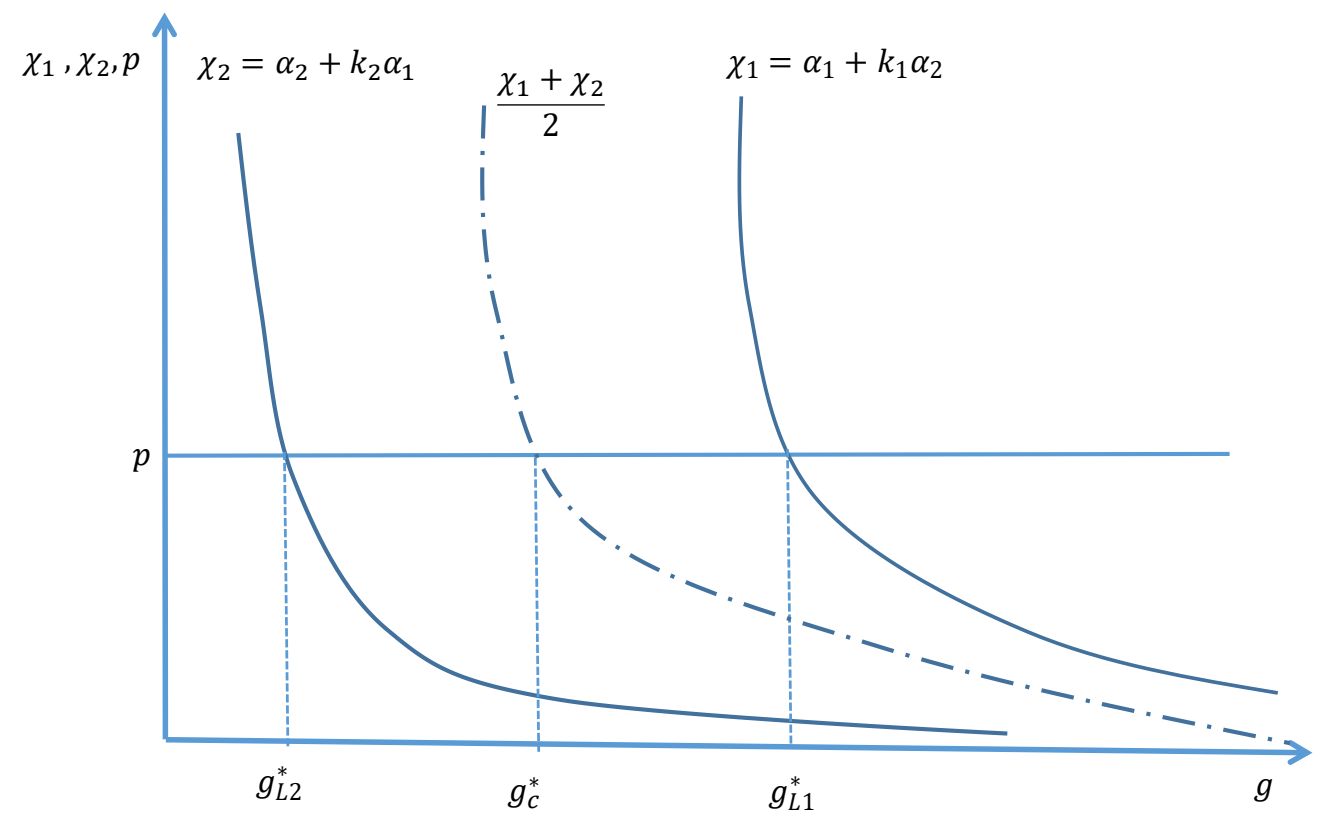


To contrast the outcomes between democratic centralization and decentralization with party integration, in Figure 1, we show the allocation under democratic decentralization given by $g_{L 1}^{*}, g_{L 2}^{*}$ and $g_{c}^{*}$ which is the equilibrium policy under democratic centralization. In Figure $1, p$ is the party's electoral costs of public goods, and $\chi_{1}$ and $\chi_{2}$ represent the party's electoral gains from the provision of public goods in jurisdictions 1 and 2 in economies with party integration and democratic decentralization. The expected votes in jurisdiction $1, \chi_{1}$, is equivalent to the marginal utility gains of all voters in jurisdiction 1 plus the marginal utility gains of all voters of jurisdiction 2. A similar interpretation is given to $\chi_{2}$, and without loss of generality, we assume $\chi_{1}>\chi_{2}$. In contrast, for an economy with party integration and democratic centralization, $\frac{\chi_{1}+\chi_{2}}{2}$, represents the parties' nationwide expected proportion of votes in a nationwide election from policy platform $g_{c}^{*}$, which, is also equivalent to the average nationwide marginal utility gains of providing $g_{c}^{*}$.

Figure 1 shows the loss of welfare associated with a move from democratic decentralization to centralization under party integration. A move from $g_{L 2}^{*}$ to $g_{c}^{*}$ implies that, from the perspective of residents of jurisdiction 2 , public spending is too high which leads to a loss of welfare for residents of that jurisdiction. Similarly, a move from $g_{L 1}^{*}$ to $g_{c}^{*}$ implies that, from the perspective of residents of jurisdiction 1 , public spending is too low which also leads to a loss of welfare for residents of that jurisdiction. More formally, in Theorem 1, our strong Decentralization Theorem shows that democratic decentralization welfare dominates centralization even in the presence of spillovers. 
Theorem 1. "Strong Decentralization Theorem." If parties are integrated, then the provision of local public goods with and without inter-regional spillovers by a system of democratically elected local governments welfare-dominates the democratically centralized provision.

\section{Proof}

See the appendix.

Theorem 1 says that the nationwide welfare of voters is maximized when local public goods with and without inter-regional spillovers are provided by a system of local governments. This outcome is a stronger version of the decentralization theorem proposed by Oates (1972), since democratic decentralization dominates democratic centralization even if local public goods show inter-regional spillovers.

Note, first, that local public goods with and without inter-regional spillovers are Pareto efficient under both a central government and a system of local governments. Second, by matching the individuals' demand for heterogeneous public spending across jurisdictions, the decentralized provision maximizes the gains associated with inter-regional policy differentiation. Since the central government does not maximize the gains from differentiating local public goods to match local preferences, democratic decentralization is welfare superior to democratic centralization.

For reasons of space and mathematical simplicity, we have assumed that the central government is constrained to provide uniform local public goods. However, in Hankla et al (2019), we relax this assumption and identify conditions to show that our analysis is robust. Decentralization dominates centralization even when the central government can differentiate across jurisdiction in the provision of public goods. 


\section{Non-Integrated Parties}

We turn our analysis to the provision of local public goods in a democracy with a majoritarian electoral system, single member jurisdictions, and non-integrated parties. In contrast to the case of integrated parties in which the decision to nominate candidates can rely on a small group of politicians (or even a single politician) inside a party, the nomination process in the case of non-integrated parties is determined by a primary election in which residents first vote to nominate a candidate while later in the general election voters elect a public official. In this setting, we study how the political institutions of primaries create incentives for parties to represent into policy platforms either the interests of a broad set of voters in the electorate or else the preferences of a minority coalition of voters.

Proponents of non-integrated parties argue that primary elections promote the political participation of voters and the representation of their interests in the policies eventually implemented by the government. However, the participation rules of primaries might actually limit both the voters' participation in elections and their effective political influence on policy design. Primary elections can be blanket, open and closed (see Kaufman, Gimpel and Hoffman 2003). In blanket primaries, voters of any affiliation may vote in the primary and voters are given a ballot listing all candidates of all parties (see Keefe 1998). In contrast, in closed primaries only those voters affiliated with a party (probably partisan voters) can vote in the party's primary.

Blanket primaries provide the whole electorate with the opportunity to nominate candidates and parties have incentives to consider the whole distribution of voters' views while designing policy. However, in closed primaries candidates have electoral incentives to weigh (discount) heavily the preferences over policy of those voters who can (not) participate in the primary election. Hence, parties might have electoral incentives to implement the ideal policy of 
primary voters. This might be considered socially undesirable because, in this case, public spending does not maximize the society's net fiscal incidence associated with public goods but the net surplus from public goods for a minority coalition of voters (the primary voters). ${ }^{14}$

The main results of this section are: first, the strong decentralization theorem does not hold for economies with non-integrated parties. We also find that the specific institutions of primaries might (not) lead to the expected benefits of democratic decentralization. In particular, Oates' conventional decentralization theorem (which assumes no spillovers) holds only for economies with blanket primaries. If primaries are closed then the decentralization theorem, in general, does not hold. Local leaders will be too beholden to their co-partisans rather than to the overall interests of their constituents. These are important and novel results. In summary, in this section we clearly show that the political institutions of non-integrated parties may also matter considerably in determining the gains from decentralization.

\section{Non-Integrated Parties and Democratic Centralization}

In this section we analyze a model with non-integrated parties (an economy in which nominations are determined through a primary election) and democratic centralization (voters elect public officials only for the central government). Corresponding to the latter, the economy is also fiscally centralized. That is, local public goods are provided and taxes levied by a single government that represents voters of all jurisdictions. The government finances its expenditures through a tax on residents of all jurisdictions.

\footnotetext{
14 The net fiscal incidence or fiscal surplus of local public goods reflects the following tradeoff: on the one hand, an increase of public spending leads to higher utility for voters (this is the marginal social benefit). On the other hand, higher spending requires higher taxes and lower consumption of private goods (this is the marginal social cost), see Martinez-Vazquez (1982).
} 
We consider a sequential game of complete and perfect information with a primary and a general election to form the central government. In the first stage, two individuals, denoted by $j=\{1,2\}$ in each party seek the nomination of their party by declaring their binding policy platforms over public spending. In the second stage, all voters observe the candidates' policies but only qualified voters vote in the primary election. ${ }^{15}$ In our economy, under a closed primary the right to vote is limited only to voters affiliated with the party. In contrast, in blanket primaries voters are given a ballot listing all candidates of all parties (see Keefe 1998) and voters vote in the primary of each party.

To model the right to vote in primary elections, and for simplicity of the analysis, we assume Nature moves and selects a set of voters who can participate in the primary. Hence, in each jurisdiction, Nature selects the distribution of qualified voters to participate in the primary of party $P .{ }^{16}$ The distribution of qualified voters selected by Nature is given by $\left\{\alpha_{P 1 i}, \alpha_{P 2 i} \ldots \ldots \ldots \alpha_{P m_{i} i}\right\}$ where $\alpha_{P h i}$ identifies a voter with some preference for public goods, the subscript $P$ shows the label of the party of the primary in which the voter will be participating and qualified voters are indexed by $h=1,2 \ldots . m_{i}$ where $m_{i}$ is the number of voters participating in the primary election of jurisdiction $i .{ }^{17}$ In a blanket primary, all voters are given a ballot listing all candidates of all parties (see Keefe 1998) and voters vote in the primary of

\footnotetext{
${ }^{15}$ The assumption that, in the first stage candidates announce a binding policy platform is for simplicity of the analysis and it ignores dynamic inconsistency issues such as the possibility that candidates might announce different policies in the primary and general elections to please, respectively, primary and general election voters.

${ }^{16}$ In our model, the move by Nature could be interpreted as a move by an exogenous player with no strategic interest in the outcome of the game.

${ }^{17}$ In the real world, the number of primary voters participating in the closed primary of each party will be different. Here, however, we assume that $m_{i}$ voters participate in the primary of each party. This assumption helps to simplify our models and, at the same time, it does not change the main results of our analysis.
} 
each party, therefore $m_{i}=n_{i}$ where $n_{i}$ is the number of residents of jurisdiction $i$. In a closed primary, only $m_{i}<n_{i}$ qualified voters participate in the primary of one party.

In the third stage of the game, the candidate who receives the majority of votes across all jurisdictions wins the primary and obtains the nomination of his or her party. In the fourth stage, the general election takes place and all voters in the electorate vote from the set of nominated candidates to elect a public official. Voting is sincere at the different stages of the electoral contest. In the fifth stage, votes are counted and the party with a majority of votes wins the general election, forms the government and implements its proposal on public spending.

In the first stage of the game, candidates $j=\{1,2\}$ of party $P=\{A, B\}$ announce spending platforms to maximize, $\Phi_{j P}$, which is the candidates' joint probability of winning the nationwide primary and general elections. We assume $\Phi_{j P}$ is continuous and strictly concave on spending on public goods. Hence, candidates of, let's say party A, propose a policy platform that is sequentially rational and, therefore, their policy platform must consider two different states that might be played next: candidates might compete in the general election against candidate 1 or 2 of party $B$.

Define $\Phi_{j P}=\int_{\underline{\rho}_{0}}^{\bar{\rho}_{0}} \int_{\underline{\rho}_{1}}^{\bar{\rho}_{1}} \int_{\underline{\rho}_{2}}^{\bar{\rho}_{2}} w_{j P}\left(\rho_{j P 0}, \rho_{j P 1}, \rho_{j P 2}\right) d \rho_{j P 0} d \rho_{j P 1} d \rho_{j P 2}$ as the joint cumulative probability that candidate $j$ of party $P$ wins the primary and general elections where $w_{j P}=\partial \Phi_{j P} / \partial \rho_{j P 0} \partial \rho_{j P 1} \partial \rho_{j P 2}>0$ is the joint probability distribution function and $\rho_{j P 0}$ is the nationwide plurality in the primary election of candidate $j$ of party $P$ versus that of the other candidate running in the primary and $\rho_{j P 1}$ is the nationwide plurality in the general election for the state in which candidate $j$ of party $P$ runs against candidate 1 of the competing party. A 
similar interpretation is given to $\rho_{j P 2}$. In each case, the pluralities $\rho_{j P s}$ are defined in the interval $\rho_{j P s} \in\left[\underline{\rho}_{s}, \bar{\rho}_{s}\right]$ for $s=\{0,1,2\} .^{18,19}$

For the case of party $P=A$, each of the nationwide pluralities are given by the difference of the expected votes between party A, $\phi_{j A s}$, and party B, $\phi_{j B s}$, that is, $\rho_{j A s}=\phi_{j A s}-\phi_{j B s}$ for the states $s=\{01,2\}$ and the nationwide sum of expected votes in the primary (for the case $s=$ $0)$ is $\phi_{j A 0}+\phi_{j B 0}=m_{1}+m_{2}$ and in the general election is $\phi_{j A s}+\phi_{j B s}=n_{1}+n_{2}$ for $s=1,2$. The expected votes of candidate $j$ of party A in the nationwide primary election is $\phi_{j A 0}=$ $\sum_{i=1}^{2} \phi_{j A 0 i}$, and $\phi_{j A 1}=\sum_{i=1}^{2} \phi_{j A 1 i}$ is the expected votes of candidate $\mathrm{j}$ of party $\mathrm{A}$ in the general election in the event this candidate faces candidate 1 of party $B$ and $\phi_{j A 2}=\sum_{i=1}^{2} \phi_{j A 12}$ is the corresponding nationwide expected vote of candidate $j$ of party $A$ when this candidate faces candidate 2 of party $B$.

The expected vote of candidate $j$ of party $A$ in the primary of jurisdiction $i$ is $\phi_{j A 0 i}=$ $\sum_{h=1}^{m_{i}} F_{j A 0 i}\left(\varepsilon_{j A 0 i}\right) \forall i$, where $F_{j A 0 i}\left(\varepsilon_{J A 0 i}\right)=\partial^{2} F_{j A i}\left(\Psi_{j A 0 i}, \Psi_{j A 1 i}, \Psi_{j A 2 i}\right) / \partial \Psi_{j A 1 i} \partial \Psi_{j A 2 i}$ is the continuous marginal probability that a voter type $\alpha_{A h i}$ in jurisdiction i votes for candidate $j$ of party $A$ in the primary, and $F_{j A i}=F_{j A i}\left(\Psi_{j A 0 i}, \Psi_{j A 1 i}, \Psi_{j A 2 i}\right)$ is the joint probability that the voter type $\alpha_{A h i}$ votes for candidate $j$ of party $A$ in the primary and the general election. Similarly, the sum of expected votes for candidate $j$ of party $A$ in the general election from jurisdiction $i$ is $\phi_{j A s i}=\sum_{h=1}^{n_{i}} F_{j A s i}\left(\varepsilon_{J A s i}\right) \forall i$ for $s=\{1,2\}$ where $F_{j A s i}$ is the corresponding marginal probability

\footnotetext{
${ }^{18}$ Note that $\rho_{j P s}$ is the plurality of candidate $j$ of party $P$ in state $s=\{0,1,2\}$. When $s=0$ then candidate $j$ is competing in the primary election. In the event that candidate $j$ obtains the nomination then this candidate must consider two different states that might be played in the general election: candidates might compete against candidate $s=1$ or $s=2$ of the opposite party.

${ }^{19}$ It is not restrictive to assume $\rho_{j P s} \in\left[\underline{\rho}_{s}, \bar{\rho}_{s}\right]$ since, in general, this interval can take a wide range of values if $\underline{\rho}_{s} \rightarrow$ $-\infty$ and $\bar{\rho}_{s} \rightarrow+\infty$.
} 
that a voter type $\alpha_{h i}$ in jurisdiction i votes for $j$ of party $A$ if he or she faces candidates $s=1$ or $s=2$ of party $B$ in the general election. ${ }^{20}$

The joint probability that a voter with preference $\alpha_{A h i}$ in jurisdiction $i$ votes for candidate $j$ of party $A$ in the primary and the general election is $F_{j A i}\left(\Psi_{j A 0 i}, \Psi_{j A 1 i}, \Psi_{j A 2 i}\right)$, which is assumed to be continuous and non-decreasing with $\Psi_{j A 0 i}, \Psi_{j A 1 i}$, and $\Psi_{j A 2 i}$. Recall $\Psi_{j A 0 i}$ is the individual's net payoff for voter with preference $\alpha_{h i}$ in jurisdiction $i$ from voting for candidate $j$ of party A instead of the competing candidate of the same party in the primary, and $\Psi_{j A 1 i}$ and $\Psi_{j A 2 i}$ are the net payoffs of voting for candidate $j$ of party $A$ instead of candidates 1 or 2 of party $B$ in the general election. If $\Psi_{j A 0 i}>0, \Psi_{j A 1 i}>0, \Psi_{j A 2 i}>0$, a voter type $\alpha_{A h i}$ in jurisdiction $i$ votes for candidate $j$ of party $A$ in the nationwide primary and general elections.

We characterize the electoral equilibrium for this economy in Definition 3 (see the appendix) and the equilibrium level for public goods (the main result of this section) in Lemma 3. Candidates facing sequential primary and general election face several tradeoffs: The first tradeoff is between the ideal policies of primary voters versus the socially optimal policies in each jurisdiction. ${ }^{21}$ Since candidates have incentives to choose a policy that maximizes their joint probability of winning the primary and general election, candidates need to choose a policy that reflects a compromise between the ideal policies of primary voters and a linear combination of the policies that maximize the nationwide welfare. If the ideal policies of primary voters are not middle of the road policies, and primary voters have a significant electoral weight, then

\footnotetext{
${ }^{20}$ Our notation means that a voter type $\alpha_{A h i}$ has the right to vote in the primary of party $\mathrm{A}$ in the second stage of the game while the same voter, now characterized by $\alpha_{h i}$ has the right to participate in the general election (which is not conditioned to the election organized by a certain party) that takes place in the fourth stage of the game.

${ }^{21}$ A nationwide general election gives voting rights to residents of all jurisdictions. For this reason, in our economy, the ideal policies of general election voters are equivalent to the socially optimal policies.
} 
candidates might have incentives to design polarized policies with too much or too little government spending.

The second tradeoff that candidates also need to take into account is the distribution of votes in each jurisdiction. Hence, there is a tradeoff between the ideal policy of voters of jurisdiction 1 versus the policy of voters of jurisdiction 2 . This particular tradeoff might also create incentives for politicians to focalize local public goods and concentrate a significant amount of resources in jurisdictions that have significant electoral influence. If local public goods are focalized in some jurisdiction then the scope of net benefits of public goods might be greatly diminished (that is, local public goods might not be designed to benefit a broad portion of voters but to benefit a minoritarian coalition of voters).

For the analysis that follows, we define the following concepts: Let $G_{j P c}^{*}$ be the equilibrium policy of candidate $j$ of party $P$ under non-integrated parties and democratic centralization. We also denote $G_{P 01}^{*}$ and $G_{P 02}^{*}$ as the ideal policies of voters participating in the nationwide primary election of party $P$ in jurisdictions 1 and 2 and $W_{j P 01}$ and $W_{j P 02}$ are the weights, or relative electoral importance, that candidate $j$ of party $P$ assigns to the corresponding ideal policies of voters participating in the nationwide primary election in jurisdictions 1 and 2. For the analysis that follows $W_{j P 0 i}=\beta_{j P 0 i} i=1,2$ where $\beta_{j P 0 i}$ is the change in the nationwide plurality of votes that candidate $j$ of party $P$ expects to receive in the primary election from jurisdiction $i$.

In addition, $\hat{g}_{1}^{*}$ and $\hat{g}_{2}^{*}$ are the socially optimal policies in jurisdictions 1 and 2 and $W_{j P 1}$ and $W_{j P 2}$ are the weights that candidate $j$ of party $P$ assigns to the socially optimal policies in jurisdictions 1 and 2 (or equivalently the ideal policies of general election voters). For the 
analysis that follows $W_{j P 1}$ and $W_{j P 2}$ are the change in the nationwide plurality of votes that candidate $j$ of party $P$ expects to receive in the general election from jurisdictions 1 and 2 , respectively. Recall that in the nationwide general election, candidate $j$ of party $P$ runs against candidates 1 or 2 of the competing party. Hence the weight $W_{j P 1}=\beta_{j P 11}+\beta_{j P 21}$ reflects the sum of $\beta_{j P 11}$ which is the expected plurality of votes from jurisdiction 1 when candidate $j$ of party $P$ runs against candidate 1 of the competing party and $\beta_{j P 21}$ which is the plurality of expected votes from jurisdiction 1 when this candidate runs against candidate 2 of the competing party. A similar interpretation is given to $W_{j P 2}=\beta_{j P 12}+\beta_{j P 22}$ for the expected plurality of votes in the general election from jurisdiction 2. In what follows, Lemma 3 shows the equilibrium policy $G_{j P c}^{*}$ :

Lemma 3. For economies with non-integrated parties and democratic centralization, a candidate $j$ of party $P$ proposes a uniform and Pareto efficient local public good $G_{j P c}^{*}$ in jurisdictions 1 and 2 satisfying the following:

$$
G_{j P c}^{*}=\Upsilon_{j P c}\left(W_{j P 01} G_{P 01}^{*}+W_{j P 02} G_{P 02}^{*}+W_{j P 1} \hat{g}_{1}^{*}+W_{j P 2} \hat{g}_{2}^{*}\right)(6)
$$

Where $\Upsilon_{j P c}$ is a proportionality parameter given by:

$$
\Upsilon_{j P c}=\frac{1}{2\left(\Theta_{j P c}+\Gamma_{j P c}\right)-\frac{\operatorname{Cov}_{0}+\operatorname{Cov}_{G E}}{q}}(7)
$$

And

$$
\Theta_{j P c}=\frac{m_{1}+m_{2}}{\left(\beta_{j P 01} m_{1}+\beta_{j P 02} m_{2}\right)} \text { and } \Gamma_{j P c}=\frac{n_{1}+n_{2}}{\left(\beta_{j P 11}+\beta_{j P 21}\right) n_{1}+\left(\beta_{j P 12}+\beta_{j P 22}\right) n_{2}}
$$


Moreover, $\mathrm{Cov}_{0}$ is a weighted covariance of the marginal probability of the vote of candidate $j$ of party $P$ in the primary election, $\frac{\partial F_{j P 0 h i}}{\partial \varepsilon_{J P 0 h i}}$, and $\frac{\partial \varepsilon_{J P O h i}}{\partial G_{j P c}}$ which is the change in welfare of each individual voter due in jurisdiction i to a marginal change in $G_{j P c}^{*}$. In addition, $\frac{\partial \Phi_{j P}}{\partial \rho_{j P 0}}$ is the candidate's marginal change in the probability of winning the primary election:

$$
\operatorname{Cov}_{0}=\frac{\partial \Phi_{j P}}{\partial \rho_{j P 0}} \sum_{i=1}^{2} m_{i} \operatorname{Cov}_{j P 0 i}\left(\frac{\partial F_{j P 0 h i}}{\partial \varepsilon_{J P 0 h i}}, \frac{\partial \varepsilon_{J P 0 h i}}{\partial G_{j P c}}\right)
$$

And $\operatorname{Cov}_{j P 0 i}$ is the covariance of the marginal probability of voters in jurisdiction i for candidate $j$ of party $P$ in the primary and the change in welfare of each resident of jurisdiction $i$ due to a marginal change in $G_{j P C}^{*}$.

Moreover, $\operatorname{Cov}_{G E}$ is a weighted covariance of the marginal probability of the vote of candidate $j$ of party $P$ in the general election, $\frac{\partial F_{j P s h i}}{\partial \varepsilon_{J P S h i}}$, and $\frac{\partial \varepsilon_{J P 0 h i}}{\partial G_{j P c}}$ which is the change in the welfare of each resident in jurisdiction i due to a marginal change in $G_{j P c}^{*}$. Moreover, $\frac{\partial \Phi_{j P}}{\partial \rho_{j P s}}$ is the candidate's marginal change in the probability of winning the general election, hence:

$$
\operatorname{Cov}_{G E}=\sum_{s=1}^{2} \frac{\partial \Phi_{j P}}{\partial \rho_{j P s}}\left(\sum_{i=1}^{2} n_{i} \operatorname{Cov}_{j P s i}\left(\frac{\partial F_{j P s h i}}{\partial \varepsilon_{J P s h i}}, \frac{\partial \varepsilon_{J P s h i}}{\partial G_{j P c}}\right)\right)
$$

And $\operatorname{Cov}_{j P s i}$ is the covariance of the marginal probability of voters in jurisdiction i for candidate $j$ of party $P$ in the general election and the change in welfare of each resident of jurisdiction $i$ due to a marginal change in $G_{j P c}^{*}$.

\section{Proof}

See the appendix. 
Lemma 3 says that $G_{j P c}^{*}$ is proportional to a linear combination of the ideal policies of all voters participating in the primary election of party $P$ in jurisdictions 1 and 2 determined by $W_{j P 01} G_{P 01}^{*}+W_{j P 02} G_{P 02}^{*}$ and a linear combination of the socially optimal policies in jurisdictions 1 and 2 determined by $W_{j P 1} \hat{g}_{1}^{*}+W_{j P 2} \hat{g}_{2}^{*} .{ }^{22}$ The parameters $W_{j P 01}>0, W_{j P 02}>0$ represent the relative electoral influence of primary voters in jurisdictions 1 and 2 . The higher $W_{j P 01}$, the higher is the change in the expected number of votes that candidate $j$ of party $P$ expects to receive from residents of jurisdiction 1 in the primary election and candidates have electoral incentives to choose a policy closer to the ideal policy of residents of jurisdiction 1 who participate in the primary election. A similar interpretation is given to the weights of electoral influence of voters in the general election in jurisdictions 1 and 2 given by $W_{j P 1}>0, W_{j P 2}>0$.

Moreover, it is relevant to point out that the relative plurality gain between the primary and general election is determined by the relative values of $W_{j P 01}, W_{j P 02}$ vis-à-vis $W_{j P 1}, W_{j P 2}$. For instance if $W_{j P 01}+W_{j P 02}>W_{j P 1}+W_{j P 2}$ then primary voters in jurisdictions 1 and 2 have a higher electoral weight than general election voters in jurisdictions 1 and 2 . The higher the difference the higher is the electoral incentive for candidate $j$ of party $P$ to propose the ideal policy of the average nationwide primary voter. Another example is that in the case in which $W_{j P 01}>W_{j P 1}$ then primary voters in jurisdiction 1 have a higher electoral weight than general election voters in jurisdiction 1. In this case, parties' weigh more heavily the preferences of primary voters in jurisdiction 1 versus general election voters of jurisdiction 1 and the higher

\footnotetext{
${ }^{22}$ Recall that the institution of democratic centralization induces parties to take into account the marginal benefits and costs of public goods of all residents of all jurisdictions, which explains why parties have electoral incentives to consider a linear combination of the socially optimal policies $\hat{g}_{1}^{*}, \hat{g}_{2}^{*}$ given by $W_{j P 1} \hat{g}_{1}^{*}+W_{j P 2} \hat{g}_{2}^{*}$.
} 
is the electoral incentive for candidates to focalize local public spending and propose the ideal policy of the average primary voter of jurisdiction 1 .

The equilibrium level of $G_{j P c}^{*}$ also depends on a proportionality parameter given by $\Upsilon_{j P c}=\frac{1}{2\left(\Theta_{j P C}+\Gamma_{j P C}\right)-\frac{\operatorname{Cov}_{0}+\operatorname{Cov}_{G E}}{q}}$ which depends on the cost of producing public goods $q$ and the parameters $\Theta_{j P c}$ and $\Gamma_{j P c}$ that explain how the distribution of electoral costs associated with the tax burden are aggregated through the political process. That is to say, the parameters $\Theta_{j P c}$ and $\Gamma_{j P C}$ show the distribution of burden of costs of producing public goods among primary and general election voters in jurisdictions 1 and 2. In particular, the higher is $\Theta_{j P c}$ the higher is the electoral cost associated with the burden of financing public goods for primary voters in jurisdictions 1 and 2. Similarly, the higher is $\Gamma_{j P c}$ the higher is the burden of costs of local public goods for general election voters in jurisdictions 1 and 2. In both cases, increases in $\Theta_{j P c}$ and $\Gamma_{j P c}$ lead to a lower provision of $G_{j P c}^{*}$.

In addition, $\operatorname{Cov}_{G E}$ is a weighted covariance between the marginal probability of voting for candidate $j$ of party $P$ from individual type $\alpha_{h i}$ in jurisdiction $i$ in the general election and the change in the well-being of each voter from an increase in the provision of the local public good. Candidates will have electoral incentives to increase the size of $G_{j P c}^{*}$ when $\operatorname{Cov}_{G E}$ is positive; that is, when the electorate is constituted by voters who simultaneously have higher than average marginal probabilities of voting for candidate $j$ of party $P$ and higher than average demands for local public goods. A similar interpretation is given to $\operatorname{Cov}_{0}$ which is a weighted covariance between the marginal probability of voting for candidate $j$ of party $P$ from individual type $\alpha_{P h i}$ in jurisdiction $i$ in the primary election of party $P$ and the change in wellbeing of the voter from an increase in the provision of the local public good. 
It is relevant to point out that positive and negative values of $\operatorname{Cov}_{G E}$ and $\operatorname{Cov}_{0}$ tend to move the design of public spending from the center of the distribution of ideal policies of general and primary voters towards a policy that is polarized, and leading towards too much government spending if $\operatorname{Cov}_{G E}$ and $\operatorname{Cov}_{0}$ are positive, and too little government spending if $\operatorname{Cov}_{G E}$ and $\operatorname{Cov}_{0}$ are negative.

It should be clear from our previous discussion that different political institutions such as party integration and decentralization lead to different processes of aggregating the conflicting preferences of voters into policy platforms. For this reason, the equilibrium level of government spending in party integrated versus non-integrated regimes will be, in general, different. To provide a contrast for the results of this section, Figure 2 shows the marginal electoral benefits for parties from public goods in economies with party integration and democratic centralization, which leads to a policy given by $g_{c}^{*}$ (see Lemma 2 and the curve given by $\frac{\chi_{1}+\chi_{2}}{2}$ ), and the marginal electoral benefits when parties are non-integrated and there is democratic centralization (see the dashed red line), which leads to policy $G_{j P c}^{*}$.

Figure 2. Integrated versus Non-Integrated Party Systems and Democratic Centralization

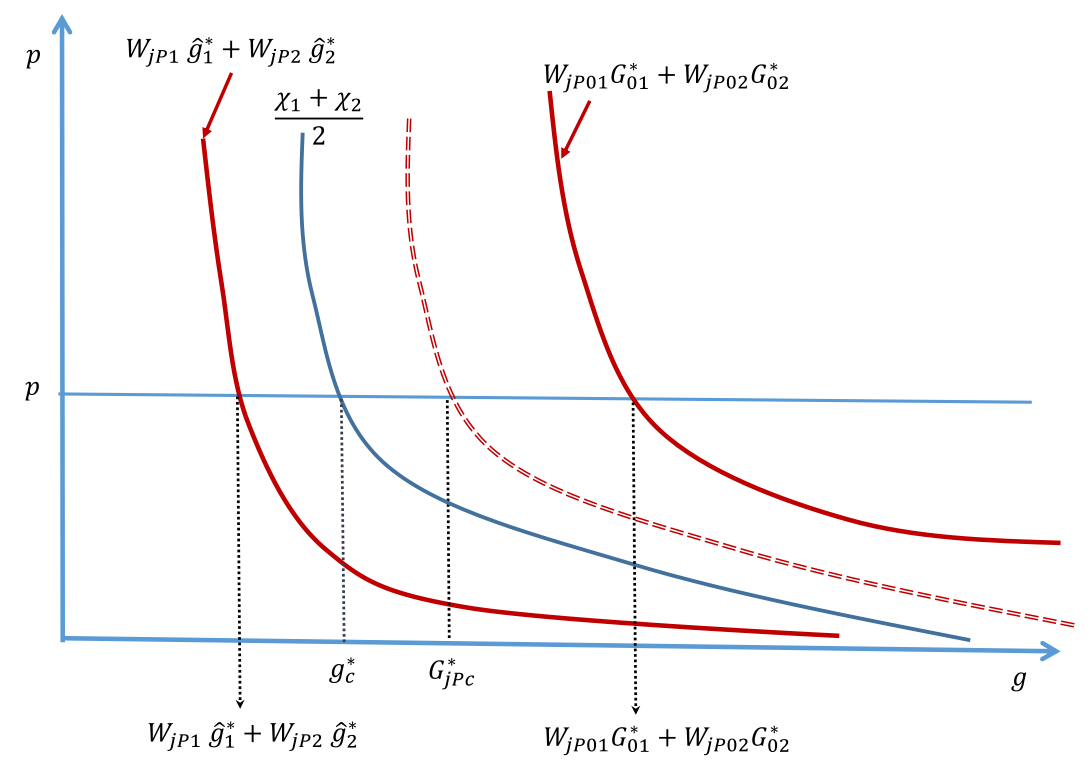


In Figure 2, the marginal electoral benefits for parties in the primary and general election are defined, respectively, by the marginal utility of the public good of the nationwide weighted average primary voter, $W_{j P 01} G_{P 01}^{*}+W_{j P 02} G_{P 02}^{*}$, and the marginal utility of the nationwide weighted average general voter $W_{j P 1} \hat{g}_{1}^{*}+W_{j P 2} \hat{g}_{2}^{*}$. For purposes of exposition, Figure 2 shows the case in which the ideal policy of the weighted average voter of the general election in systems with non-integrated parties, $W_{j P 1} \hat{g}_{1}^{*}+W_{j P 2} \hat{g}_{2}^{*}$, is smaller than the ideal policy of the average voter in systems with integrated parties, $\frac{\chi_{1}+\chi_{2}}{2}$, which, in turn, is also assumed to be smaller than the ideal policy of the weighted average primary voter. That is to say, $W_{j P 1} \hat{g}_{1}^{*}+$ $W_{j P 2} \hat{g}_{2}^{*}<\frac{\chi_{1}+\chi_{2}}{2}<W_{j P 01} G_{P 01}^{*}+W_{j P 02} G_{P 02}^{*}$. Therefore, Figure 2 shows the particular case in which parties have incentives to select more government spending in systems with nonintegrated parties relative to the equilibrium policy of systems with integrated parties, that is to say, $G_{j P c}^{*}>g_{c}^{*}$.

\section{Non-Integrated Parties and Democratic Decentralization}

In this section, we characterize the provision of local public goods for an economy with sequential primary and general elections and democratic decentralization (voters elect public officials at the local level). The structure of the game is easily extended from our previous discussion: Local public goods are chosen by the local government and expenditure is financed by a uniform tax on residents in each jurisdiction. To form local governments, primary and general elections take place in each jurisdiction.

In the first stage, candidates $j=\{1,2\}$ of each party in jurisdiction $i$, announce policy platforms that maximize the joint probability of candidate $j$ of party $P=\{A, B\}$ of winning the local primary and general elections $\Phi_{j P i}=\Phi_{j P i}\left(\rho_{j P 0 i}, \rho_{j P 1 i}, \rho_{j P 2 i}\right)$ that depends on the plurality 
of the candidate in states $s=0,1,2$ given by $\rho_{j P O i}, \rho_{j P 1 i}$ and $\rho_{j P 2 i}$. In the second stage, residents of jurisdiction $i$ observe the candidates' policies but only qualified voters vote in the primary election. Nature selects the set of qualified voters who can participate in the primary of each party. In the third stage of the game, the candidate who receives the majority of votes in the jurisdiction wins the nomination of his or her party. In the fourth stage, the general election takes place and all voters of the jurisdiction vote from the set of nominated candidates to elect a public official. Voting is sincere at the different stages of the electoral contest. In the fifth stage, votes are counted and the party with a majority of votes wins the general election, forms the local government and implements its proposal on public spending in the jurisdiction.

For the analysis that follows, we define the following concepts: Let $G_{j P i}^{*}$ be the equilibrium policy of candidate $j$ of party $P$ in jurisdiction $i$ for a democracy with non-integrated parties and democratic decentralization. We also denote $G_{0 i}^{*}$ and $G_{i}^{*}$ as the ideal policies of voters participating, respectively, in the primary and in the general election of jurisdiction $i$ and $W_{j P 0 i}$ and $W_{j P S i}$ are the electoral weights of primary and general election voters in jurisdiction $i$. For the analysis that follows, $W_{j P 0 i}$ is the change in the plurality of votes that candidate $j$ of party $P$ expects to receive in the primary election, and $W_{j P i}=\beta_{j P 1 i}+\beta_{j P 2 i}$ is the change in the nationwide plurality of votes that candidate $j$ of party $P$ expects to receive in the local general election.

For a formal characterization of the electoral game see Definition 4 in the appendix, and Lemma 4 provides a general characterization of local public goods for economies with blanket and closed primary elections. Lemma 5 shows a special case of Lemma 4 in which nominations are conducted through a blanket primary election. Theorem 2 shows that the strong 
decentralization theorem is not satisfied for economies with non-integrated parties and local elections, and Theorem 3 shows that Oates' conventional decentralization theorem holds in the case of blanket primaries but fails to hold in the case of closed primaries.

Lemma 4. For economies with non-integrated parties and democratic decentralization, a candidate $j$ of party $P$ in jurisdiction i proposes a local public good $G_{j P i}^{*}$ satisfying the following:

$$
G_{j P i}^{*}=\Upsilon_{j P i}\left(W_{j P 0 i} G_{P 0 i}^{*}+W_{j P i} G_{i}^{*}\right)
$$

Where $\Upsilon_{j P i}$ is a proportionality parameter given by:

$$
\Upsilon_{j P i}=\frac{1}{\left(\Theta_{j P i}+\Gamma_{j P i}\right)-\frac{\psi_{j P 0 i}+\psi_{j p G E i}}{q}}
$$

And

$$
\Theta_{j P i}=\frac{\beta_{j P 0 i} m_{i}}{n_{i}} \text { and } \Gamma_{j P i}=\beta_{j P 1 i}+\beta_{j P 2 i}
$$

Moreover, $\psi_{j \mathrm{POi}}$ is a weighted covariance of the change in the marginal probability of the vote of candidate $j$ of party $P$ in the local primary election of jurisdiction $i, \frac{\partial F_{j P 0 h i}}{\partial \varepsilon_{j P O h i}}$, and $\frac{\partial \varepsilon_{j P 0 h i}}{\partial G_{j P i}}$ which is the change in welfare of each individual voter due to a marginal change in $G_{j P i}^{*}$. In addition, $\frac{\partial \Phi_{j P} i}{\partial \rho_{j P 0}}$ is the candidate's change in the marginal probability of winning the primary election in jurisdiction $i$, where

$$
\psi_{j p 0 i}=\frac{\partial \Phi_{j P i}}{\partial \rho_{j P 0 i}} m_{i} \operatorname{Cov}_{j P 0 i}\left(\frac{\partial F_{j P 0 h i}}{\partial \varepsilon_{J P 0 h i}}, \frac{\partial \varepsilon_{J P 0 h i}}{\partial G_{j P i}}\right)
$$


Where $\operatorname{Cov}_{j P 0 i}$ is the covariance of the marginal probability of voters in jurisdiction ifor candidate $j$ of party $P$ in the primary and the change in welfare of each resident of jurisdiction $i$ due to a marginal change in $G_{j P c}^{*}$

And define $\psi_{j p G E i}$ is a weighted covariance of the change in the marginal probability of the vote of candidate $j$ of party $P$ in the local general election of jurisdiction $i, \frac{\partial F_{j P s h i}}{\partial \varepsilon_{J P s} h i}$, and $\frac{\partial \varepsilon_{J P S h i}}{\partial G_{j P i}}$ is the change in the welfare of voter due to a change in $G_{j P i}^{*}$. Moreover, $\frac{\partial \Phi_{j P i}}{\partial \rho_{j P S i}}$ is the candidate's change in the marginal probability of winning the general local election in jurisdiction $i$, hence

$$
\psi_{j p G E i}=\sum_{s=1}^{2} \frac{\partial \Phi_{j P}}{\partial \rho_{j P s i}} n_{i} \operatorname{Cov}_{j P s i}\left(\frac{\partial F_{j P s h i}}{\partial \varepsilon_{J P s h i}}, \frac{\partial \varepsilon_{J P s h i}}{\partial G_{j P i}}\right)
$$

Where $\operatorname{Cov}_{j P S i}$ is the covariance of the marginal probability of voters in jurisdiction ifor candidate $j$ of party $P$ in the general election in the electoral state $s=1,2$ and the change in welfare of each resident of jurisdiction $i$ due to a marginal change in $G_{j P c}^{*}$

\section{Proof}

See the appendix.

Lemma 4 says that sequential elections with a primary and a general elections along with democratic decentralization create incentives for candidates of all parties to select a policy $G_{j P i}^{*}$ that is proportional to a linear combination of the ideal policy of all participating primary voters of jurisdiction $i$ determined by $G_{P 0 i}^{*}$ and the ideal policy of all residents of the general election of the jurisdiction determined by $G_{i}^{*} \cdot{ }^{23}$ The parameters $W_{j P 0 i}>0$ and $W_{j P i}>0$ represent the

\footnotetext{
${ }^{23}$ The ideal policy of general election voters maximizes the net fiscal incidence from local public goods for the average voter in the jurisdiction, therefore $G_{i}^{*}=\sum_{h=1}^{n_{i}} \alpha_{h i} / q$. And the ideal policy of primary election voters maximizes the net fiscal incidence of public goods for the average primary voter, therefore $G_{P 0 i}^{*}=\sum_{h=1}^{m_{i}} \alpha_{P h i} / q$.
} 
relative electoral influence of primary and general election voters in jurisdiction $i$. Hence, the higher $W_{j P 0 i}$ the higher is the change in the number of votes that candidate $j$ of party $P$ expects to receive in the primary of jurisdiction $i$ and candidates have incentives to choose a policy closer to the ideal policy of primary voters of that jurisdiction.

A similar interpretation is given to the weight of electoral influence of voters participating in the general election, given by $W_{j P i}>0$. Hence, the higher $W_{j P i}>0$ the higher is the change in the expected number of votes from general election voters in the jurisdiction and candidates have incentives to choose a policy closer to the ideal policy of general election voters of the jurisdiction, which is given by $G_{i}^{*}$. Hence the relative electoral influence of primary versus general election votes are determined by the relative values of $W_{j P 0 i}$ and $W_{j P i}$. If $W_{j P 0 i}>W_{j P i}$, then primary voters of jurisdiction $i$ have a higher electoral weight than general election voters in the jurisdiction and the stronger the electoral incentive for candidates to propose the ideal policy of the average local primary voter of the jurisdiction. Of particular interest is the case of closed primaries in which primary voters might have significant electoral weight (that is $W_{j P 0 i}>W_{j P i}$ ) and therefore, local elections might not lead to middle of the road policies but polarized government spending with too much or too little government spending.

As we discussed in our previous section, the equilibrium level of $G_{j P i}^{*}$ also depends on a proportionality parameter given by $\Upsilon_{j P i}=\frac{1}{\left(\Theta_{j P i}+\Gamma_{j P i}\right)-\frac{\psi_{j P 0 i}+\psi_{j p G E i}}{q}}$ which depends on the cost of producing public goods $q$ and the parameters $\Theta_{j P i}$ and $\Gamma_{j P i}$ that explain how the distribution of electoral costs associated with the tax burden are aggregated through the political process.

Note that $m_{i}$ is the number of participating primary voters and $n_{i}$ the number of general election voters. In a closed primary $m_{i}<n_{i}$ and in a blanket primary $m_{i}=n_{i}$. 
Higher levels of $\Theta_{j P i}$ and $\Gamma_{j P i}$ lead to higher electoral costs for primary and general election voters associated with the burden of raising taxes in the jurisdiction and lead to a lower provision of $G_{j P i}^{*}$

In addition, $\psi_{j p G E i}$ and $\psi_{j p 0 i}$ are weighted covariances between the marginal probability of voting for candidate $j$ of party $P$ in the general and primary election of jurisdiction $i$ and the change in the well-being of each voter from an increase in the provision of the local public good. As we discussed in the previous section, positive and negative values of $\psi_{j p G E i}$ and $\psi_{j p 0 i}$ tend to move the design of public spending from the center of the distribution of ideal policies of general and primary voters in the jurisdiction towards a policy that is polarized and leading towards too much government spending if $\psi_{j p G E i}$ and $\psi_{j p 0 i}$ are positive and too little government spending if $\psi_{j p G E i}$ and $\psi_{j p 0 i}$ are negative.

In what follows, Lemma 5 distinguishes the equilibrium policies for an economy with non-integrated parties and blanket primaries.

Lemma 5. For economies with non-integrated parties, blanket primaries and democratic centralization $G_{j P c}^{*}$ is given by:

$$
G_{j P c}^{*}=\frac{\hat{g}_{1}^{*}+\hat{g}_{2}^{*}}{2}
$$

Where $\hat{g}_{1}^{*}, \hat{g}_{2}^{*}$ represent the Pareto efficient local public goods that maximize the social welfare gains from inter-regional policy differentiation.

For economies with non-integrated parties, blanket primaries and democratic decentralization $G_{j P i}^{*}=G_{i}^{*}$ which is the ideal policy of residents of jurisdiction $i$ and it is given by: 


$$
G_{j P i}^{*}=\frac{\sum_{h=1}^{n_{i}} \alpha_{h i}}{q}=\frac{\alpha_{i}}{q} \text { for } i=1,2
$$

\section{Proof}

See the appendix.

Lemma 5 shows the spending policies for an economy with non-integrated parties, blanket primaries and democratic centralization and decentralization. Under these institutions, democratic centralization produces the ideal policy of the nationwide average general election voter, $G_{j P c}^{*}$, and under democratic decentralization the ideal policy of the average voter in each jurisdiction, $G_{j P i}^{*}$. These outcomes provides several insights: first, our model predicts that party integration with a unitary government (see Lemma 2 and condition 3) and party non-integration with blanket primaries and a unitary government (see Lemma 5 and condition 16) produce the same policies. That is $g_{c}^{*}=G_{j P c}^{*}$. However, under local elections, integrated and non-integrated parties with blanket primaries do not produce the same policies, that is, $g_{L i}^{*} \neq G_{j P i}^{*}$ (see the equilibrium policies of Lemma 2 and Lemma 5). Hence, the institutions of party integration versus non-integration produce different outcomes under national versus local elections.

Second, in terms of the efficiency properties and the degree of policy differentiation of the equilibrium for economies with non-integrated parties, the implications of Lemma 4 and Lemma 5 are the following: for economies with blanket primaries and democratic centralization, local public goods with and without spillovers are uniform and Pareto efficient (see condition 16 of Lemma 5). That is, blanket primaries create electoral incentives for candidates to recognize the nationwide distribution of benefits and costs of local public goods. Hence, local public goods with and without spillovers are Pareto efficient. 
In addition, for economies with non-integrated parties, blanket primaries and democratic decentralization, local public goods with inter-regional spillovers are not Pareto efficient; in general, $G_{j P i}^{*}<\hat{g}_{i}^{*}$, for either type of primary, blanket or closed. That is, local sequential elections do not create incentives to internalize the benefits of local public goods across jurisdictions.

Third, if local public goods do not have spillovers, then the political institutions of the primary election determine whether the decentralized provision of local public goods is Pareto efficient or not. In our economy, in blanket primaries all voters participate in the primary and general election. Therefore, the average primary voter is also the average general election voter in each jurisdiction. Since parties select the ideal policy of the average voter in the jurisdiction, local public goods without externalities are Pareto efficient. However, for closed primaries, local public goods are not Pareto efficient if the electoral weight of general election voters is sufficiently low, that is if $W_{j P i} \rightarrow 0$. In this case, local governments provide a local public good that maximizes the well-being of the average primary voter of jurisdiction $i$. This means that local spending is focalized to benefit a local minoritarian coalition of voters in the jurisdiction and therefore public goods are not Pareto efficient.

Fourth, the political institutions of primaries also produce different results on the ability of local governments to maximize the gains from inter-regional policy differentiation. Under blanket primary elections, democratic decentralization produces the ideal policy of the average voter in each jurisdiction and maximizes the gains of the society from inter-regional policy differentiation. If the primary is closed, then the gains from policy differentiating can be maximized only if the electoral weight of primary voters is sufficiently low (that is if $W_{j P 0 i} \rightarrow 0$, see condition 11 in Lemma 4). If, in contrast, the electoral weight of primary voters is 
sufficiently high, local governments provide a local public good that maximizes the well-being of the average primary voter of jurisdiction $i$, which implies that the political process fails to take into account the full extent of preferences of all residents in each jurisdiction. As a result, the extent of inter-regional policy differentiation achieved by local governments is sub-optimal.

\section{Non-Integrated Parties with National and Local Elections and Oates' Decentralization}

\section{Theorem}

On what follows we develop the comparative analysis between national elections and local elections in economies with non-integrated parties. Theorem 2 shows that the strong decentralization theorem does not hold and Theorem 3 shows that Oates' decentralization theorem is satisfied when primaries are blanket but it is not satisfied if primaries are closed.

Theorem 2. In democracies with non-integrated parties and blanket primaries, the strong decentralization theorem does not hold but the conventional decentralization theorem holds.

\section{Proof}

See the appendix.

Lemma 5 shows that, in systems with non-integrated parties and blanket primaries, parties propose the size of public spending that maximizes a unanimous utilitarian social welfare function of local residents in each jurisdiction. That is, parties propose the ideal policy of the average voter of the jurisdiction and, therefore, the resulting policies are Pareto efficient but only for local public goods without spillovers. With spillovers, local spending is not Pareto efficient and, therefore, the strong decentralization theorem does not hold for these economies. In addition, under blanket primaries, the local provision of public goods maximizes the welfare 
gains associated with differentiating local policy to the heterogeneous preferences of voters across jurisdictions.

If the government is democratically centralized and uses blanket primaries, local public goods with and without spillovers are uniform and Pareto efficient. In this case, local public goods reflect the ideal size on public spending of the average voter of all jurisdictions. Lastly, Theorem 2 shows that if local public goods do not display spillovers then democratic decentralization dominates centralization because the Pareto efficient and heterogeneous provision of local public goods in a democratically decentralized system maximizes the welfare gains from policy differentiation, while democratic centralization leads to suboptimal interregional policy differentiation. Consequently, the conventional decentralization theorem of Oates (1972) holds for democracies with non-integrated parties and blanket primaries.

Theorem 3. The strong and the conventional decentralization theorems do not hold in democracies with non-integrated parties and closed primaries.

\section{Proof}

See the appendix.

In general, the strong and the conventional decentralization theorems do not hold for a democracy with closed primaries. ${ }^{24}$ As we mentioned before, sequential elections induce candidates to propose a policy that reflects a compromise between the ideal policy of the average voter of the primary and the ideal policy of the average voter of the general election (see

\footnotetext{
${ }^{24}$ A comparison of (2) and (6) shows that the optimal policy for candidates in a nationwide sequential election with closed primaries is, in general, different from the spending policy that maximizes the fiscal surplus for all residents in the economy. A similar conclusion is reached for local elections in a federation (see conditions 2 and 12). As a result, the strong and the conventional decentralization theorems do not hold in with a system of non-integrated parties and closed primaries.
} 
expressions of Lemmas 3 and 4). In the case of closed primaries, it is likely that minority coalitions could have strong electoral influence over local governments that is translated into policies that are closer to their preferences. In this case, electoral competition might produce extreme policy positions (too much or too little local public spending) instead of the policy that maximizes the net fiscal incidence of local public goods for the society.

For instance, in condition 6 of Lemma 3 , if $W_{j P 1}=W_{j P 2} \cong 0$, then local elections produce the size of public spending in the vicinity of the ideal policy of primary voters in each jurisdiction, instead of the ideal policy of all residents in each jurisdiction. ${ }^{25}$ Simultaneously, we can find parametric values of the weight of the electoral influence of primary voters - in which democratic centralization averages the political influence of local coalitions of voters- to produce a more moderate provision of local public goods that could be welfare superior to the less moderate provision of public goods in the democratically decentralized system of local governments. This is likely true for an economy with many localities in which the political influence of local coalitions is significant over local governments, but the influence of local minority groups fades away in the nationwide election. In this setting, the provision of a uniform public good by a democratically centralized government could be welfare superior to the differentiated but with extreme policy positions produced by a system of democratically decentralized local governments.

\footnotetext{
${ }^{25}$ In particular, significantly low values of $W_{j P 1}$ and $W_{j P 2}$ imply that the marginal change of the joint probability of winning the primary and the general election due to a marginal gain from the plurality of the primary is sufficiently high (maybe because the candidate who wins the primary would win with almost certainty the general election) and therefore candidates will select the ideal policy of a minority of the electorate (i.e. the ideal policy of the average voter of the primary voters).
} 


\section{Conclusion}

In this paper, we analyze how political institutions condition the outcomes of fiscal federalism. We develop a formal extension and refinement of Oates' (1972) decentralization theorem, which has provided the basis for much of the research on fiscal decentralization over the past five decades. In particular, we provide a political economy analysis of local public good provision by incorporating the joint influence of democratic (de)centralization and party (non)integration. Our theory generates a number of new insights: first, we show that for democracies with integrated parties, a system of elected local governments welfare-dominates a centralized government even if local public goods show inter-jurisdictional spillovers. We call this result the strong decentralization theorem. When our new theorem is satisfied, the conventional decentralization theorem developed by Oates (1972), where local public goods do not show spillovers, is also satisfied. Indeed, an important implication of our theoretical model is that the combination of democratic decentralization and party integration tends to produce the highest welfare gains from the provision of public goods. Democratic decentralization ensures that local governments are responsive to the desires of their constituents while party integration incentivizes local leaders to pay for goods that may have spillover benefits.

Second, we show that the strong decentralization theorem does not hold for countries with non-integrated parties, whether they have blanket or closed primaries. For countries with non-integrated parties and blanket primaries, Oates' conventional decentralization theorem (without spillovers) holds since the political institutions of blanket primaries promote the participation of voters and the representation of their preferences into policies. However, countries with non-integrated parties and closed primaries, even the conventional decentralization theorem does not generally hold. The participation rules of closed primaries 
induce parties to propose a policy that reflects a compromise between the ideal policy of a weighted average voter of the primary and the ideal policy of a weighted average voter of the general election. This last finding has particularly important implications for much of the past literature. In the case of countries with closed primaries, it is likely that minority coalitions (i.e. primary voters) will have strong political influence over central and local governments that is translated into policies closer to their preferences. When this happens, electoral competition will not necessarily produce Pareto efficient local public goods (even if local public goods do not show spillovers). Parties might adopt extreme policy positions with too much or too little local public spending compared with the policy that maximizes the surplus from the net fiscal exchange for the society as a whole. Another important consequence is that the degree of policy differentiation might be suboptimal and might not exhaust the gains from matching the preferences of voters across jurisdictions if primary elections are closed.

In summary, we show that creating locally elected governments can only be expected to improve public goods allocation either when parties are integrated or when there are no interjurisdictional spillovers. Local governments controlled by non-integrated parties are not likely to provide efficient levels of public goods that spill over into adjacent jurisdictions. Therefore, the outcomes from fiscal and democratic decentralization are closely intertwined with the design of political parties. All of these institutions must be studied jointly if we are to understand better the factors that make local government and fiscal federalism produce superior outcomes. 


\section{References}

Bardhan, P. and D. Mookherjee. 2000. Capture and Governance at Local and National levels. American Economic Review 90(2), 135-139.

Bardhan, P. and D. Mookherjee. 2002. Relative Capture of Local and Central Governments: An Essay in the Political Economy of Decentralization, Working Paper, Institute for Economic Development, Boston University, 1-45.

Besley, T., and S. Coate. 2003. Centralized versus Decentralized Provision of Local Public Goods: A Political Economy Approach. Journal of Public Economics 87: 2611-2637.

Bordignon, M., L. Colombo, and U. Galmarini. (2008). Fiscal Federalism and Lobbying. Journal of Public Economics, 92(12), 2288-2301

Carey, John M and Matthew Soberg Shugart. 1995. Incentives to Cultivate a Personal Vote: A Rank Ordering of Electoral Formulas. Electoral Studies 14(4): 417-439.

Chhibber, Pradeep and Ken Kollman. 2004. The Formation of National Party Systems: Federalism and Party Competition in Canada, Great Britain, India, and the United States. New York: Princeton University Press.

Coughlin, P.J., 1992. Probabilistic Voting Theory. Cambridge University Press.

Enikolopov, Ruben and Ekaterina Zhuravskaya. 2007. Decentralization and Political Institutions. Journal of Public Economics 91: 2261-2290.

Fabre, Elodie, Bart Maddens, Wilfried Swenden, and Robertas Pogorelis. 2005. Partis politiques nationaux en crise? Organisation des partis et décentralisation. Une comparaison de l'Espagne et du Royaume Uni. Res Publica 2005/1.

Filippov, Mikhail, Peter C. Ordeshook, and Olga Shvetsova. 2004. Designing Federalism: A Theory of Self-Sustainable Federal Institutions. New York: Cambridge University Press.

Keefe, William J. 1998. Parties, politics and public policy in America. Washington DC. CQ Press.

Haggard, Stephan and Robert R. Kaufman. 1995. The Political Economy of Democratic Transitions. Princeton: Princeton University Press. 
Hankla, Charles R., Jorge Martinez-Vazquez, and Raul Ponce Rodriguez. 2019. Local Accountability and National Coordination in Fiscal Federalism: A Fine Balance. Edward Elgar Publishers. Series: Studies in Fiscal Federalism and State-Local Finance.

Hallerberg, Mark and Patrik Marier. 2004. Executive Authority, the Personal Vote, and Budget Discipline in Latin American and Caribbean Countries. American Journal of Political Science 48 (3): 571-587.

Kaufman, K.M. , J.G Gimpel, and A.H. Hoffman 2003. A Promise Fulfilled? Open Primaries and Representation. The Journal of Politics, Vol. 65, No. 2, pp. 457-476.

Lockwood, B. 2015. The Political Economy of Decentralization, in Ahmad, E. and G. Brosio, (Ed), Handbook of Multilevel Finance. Edward Elgar Publishing, (pp. 37-65).

Lockwood, B. 2008. Voting, Lobbying and the Decentralization Theorem. Economics \& Politics, 20(3), 416- 431 .

McKelvey, R.D and J.W. Patty. 2006. A Theory of Voting in Large Elections. Games and Economic Behavior, 57(1):155-180, 20

Martinez-Vazquez, Jorge. 1982. Fiscal Incidence at the Local Level. Econometrica 50 (5): 12071218.

Martinez-Vazquez, Jorge, Santiago Lago-Peñas, and Agnese Sacchi. 2016. The Impact of Fiscal Decentralization: A Survey. Journal of Economic Surveys, (on line version) 7 November 2016.

Myerson, Roger B. 2006. Federalism and Incentives for Success of Democracy. Quarterly Journal of Political Science 1: 3-23.

Nielson, Daniel L. 2003. Supplying Trade Reform: Political Institutions and Liberalization in Middle-Income Presidential Democracies. American Journal of Political Science 47 (3): 470491.

Oates, Wallace E. 1972. Fiscal Federalism. New York: Harcourt, Brace, Jovanovich.

Oates, Wallace E. 2005. Towards a Second-Generation Theory of Fiscal Federalism. Journal of International Tax and Public Finance 12: 349-373. 
O’Halloran, Sharyn. 1994. Politics, Process, and American Trade Policy. Ann Arbor: University of Michigan Press.

Persson, T. And G. Tabellini. 2002. Political Economics: Explaining Economic Policy. Cambridge, MA, The MIT Press.

Persson, T. And G. Tabellini. 2003. The Economic Effects of Constitutions, Munich Lectures in Economics. Cambridge, MA, The MIT Press.

Ponce-Rodriguez, Raul, Charles R. Hankla, Jorge Martinez-Vazquez, and Eunice Heredia-Ortiz. 2018. Rethinking the Political Economy of Decentralization: How Elections and Parties Shape the Provision of Local Public Goods. Publius: The Journal of Federalism 48 (4): 523-558.

Riker, William H. 1987. The Development of American Federalism. Boston: Kluwer Academic Publishers.

Roubini, Nouriel and Jeffrey Sachs. 1989. Government Spending and Budget Deficits: Industrial Democracies. Working Paper No. 2919. National Bureau of Economic Research, Cambridge, MA.

Seabright, P. 1996. Accountability and Decentralisation in Government: An Incomplete Contracts Model. European Economic Review, 40 (1), 61- 89.

Volden, Craig. 2004. Origin, Operation, and Significance: The Federalism of William H. Riker. Publius: The Journal of Federalism 34 (4): 89-107.

Volkerink, Bjørn and Jakob de Haan. 2001. Fragmented Government Effects of Fiscal Policy: New Evidence. Public Choice 109: 221-242.

Weingast, Barry R. 2009. Second Generation Fiscal Federalism: The Implications of Fiscal Incentives. Journal of Urban Economics 65: 279-293.

Weingast, Barry R. 2014. Second Generation Fiscal Federalism: Political Aspects of Decentralization and Economic Development. World Development 53: 14-25. 


\section{Appendix - For Online Publication}

Definition 1. Define policy platform of candidate $j=\{1,2\}$ of party $P=\{A, B\}$ in district $i=$ $\{1,2\}$ by $g_{j P i}$. The equilibrium for an economy with party centralization and democratic centralization is constituted as follows:

In the first stage, candidates $j$ of party $P$ announce policy platforms $g_{j P 1}^{*}=g_{j P 2}^{*}=g_{c P}^{*}$ :

$$
g_{c P}^{*} \in \operatorname{argmax} \pi_{P} \text { subject to } g_{j P 1}=g_{j P 2}
$$

Where $\pi_{P}$ is the probability of party $P$ of winning the national election and $g_{j P 1}=g_{j P 2}$ is the constraint that candidates announce uniform policy platforms in all districts.

Party Leaders nominate a candidate by selecting a candidate $j=1$ or 2 to the nomination set $N S_{P}$ if

$$
g_{j P i}^{*}=g_{c P}^{*} \in \operatorname{argmax} \pi_{P} \Rightarrow j \in N S_{P}
$$

Otherwise the candidate does not get the nomination and $j \notin N S_{P}$

The nomination process implies that all candidates of all parties $P=\{A, B\}$ select policies $g_{c P}^{*}$ in all districts.

In the second stage, a voter of district $i=\{1,2\}$ with preference $\alpha_{h i}$ for $h=1,2 \ldots n_{i}$ votes for party $A$ if

$$
\Psi_{h i}\left(\alpha_{h i}\right)=\left\{v_{h i}\left(\alpha_{h i}, g_{c A}^{*}, g_{c A}^{*}\right)-\tau_{A}+\sigma_{A h i}\right\}-\left\{v_{h i}\left(\alpha_{h i}, g_{c B}^{*}, g_{c B}^{*}\right)-\tau_{B}+\sigma_{B h i}\right\} \geq 0
$$

Otherwise, she votes for party $B$.

We define $\mathbf{\Omega}$ as a non-decreasing cumulative distribution of the sequence $\left\{\Psi_{A h i}\left(\alpha_{h i}\right)\right\}_{\forall h, \forall i}$, hence $\mathbf{\Omega} \in[\mathbf{0}, \mathbf{1}]$. In the third stage, if $\mathbf{\Omega}\left(\forall \alpha_{h i}, i=\{1,2\}: \Psi_{h i}\left(\alpha_{h i}\right)>0\right)>\frac{1}{2}$ then partyA wins the election and implements $g_{c A}^{*}$. Otherwise, party $B$ wins and implements $g_{c B}^{*}$.

Lemma 1. Local public goods with and without spillovers are Pareto efficient for an economy with a majoritarian electoral system, single member jurisdictions, a democratically centralized 
government and integrated parties. All parties converge in providing a uniform local public good across jurisdictions, $g_{1}^{*}=g_{2}^{*}=g_{c}^{*}$ where $g_{c}^{*}$ is defined as follows

$$
g_{c}^{*}=\frac{\hat{g}_{1}^{*}+\hat{g}_{2}^{*}}{2}
$$

Where

$$
\left[\hat{g}_{1}^{*}, \hat{g}_{2}^{*}\right]=\left[\frac{\alpha_{1}+k_{1} \alpha_{2}}{q}, \frac{\alpha_{2}+k_{2} \alpha_{1}}{q}\right]
$$

Where $\alpha_{1}=\sum_{h=1}^{n_{1}} \alpha_{h 1}$ is the aggregate intensity of preferences for local public goods of all residents in district 1 and $\alpha_{2}=\sum_{h=1}^{n_{2}} \alpha_{h 2}$ is the corresponding aggregate intensity of preferences of all residents of district 2.

\section{Proof}

The problem of policy design for parties $P=\{A, B\}$ is $\delta_{P}=\pi_{P}$ subject to $g_{P 1}=g_{P 2}=g_{P}$. We impose the equality constraint in the objective function of party $P$. The first order condition is

$$
\frac{\partial \delta_{P}}{\partial g_{P}}=\frac{\partial \pi_{P}}{\partial \rho_{P}} \frac{\partial \rho_{P}}{\partial \phi_{P}} \frac{\partial \phi_{P}}{\partial g_{P}}=0 \Rightarrow \frac{\partial \delta_{P}}{\partial g_{P}}=\frac{\partial \phi_{P}}{\partial g_{P}}=0 \forall g_{P}^{*}>0
$$

Since the nationwide expected votes for party $P$ is given by $\phi_{P}=\sum_{i=1}^{2} \phi_{P i}$ then

$$
\Rightarrow \frac{\partial \delta_{P}}{\partial g_{P}}=\frac{\partial \phi_{P 1}}{\partial g_{P}}+\frac{\partial \phi_{P 1}}{\partial g_{P}}=0 \forall g_{P}^{*}>0(A .4)
$$

Where $\frac{\partial \phi_{P i}}{\partial g_{P}}$ is the marginal expected votes from jurisdiction $i$. Hence, the first order condition in (A.4) can be stated as follows:

$$
\frac{\partial \delta_{P}}{\partial g_{P}}=\sum_{h=1}^{n_{1}} \frac{\partial F_{P h 1}}{\partial \varepsilon_{h 1}} \frac{\partial \varepsilon_{h 1}}{\partial g_{P}}+\sum_{h=1}^{n_{2}} \frac{\partial F_{P h 2}}{\partial \varepsilon_{h 2}} \frac{\partial \varepsilon_{h 2}}{\partial g_{P}}=0 \forall g_{P}^{*}>0
$$

The parties' policies converge in probabilistic voting models with homogeneous parties (see Coughlin 1992) and we denote the equilibrium policy as $g_{A}^{*}=g_{B}^{*}=g_{c}^{*}$. Therefore, $\frac{\partial F_{P h 1}(0)}{\partial \Psi_{P h 1}}=$ $\frac{\partial F_{P h 2}(0)}{\partial \Psi_{P h 2}} \forall h$ which implies that the first order condition in (A.5) becomes

$$
\frac{\partial \delta_{P}}{\partial g_{P}}=\sum_{h=1}^{n_{1}} \frac{\partial \varepsilon_{h 1}}{\partial g_{P}}+\sum_{h=1}^{n_{2}} \frac{\partial \varepsilon_{h 2}}{\partial g_{P}}=0 \forall g_{c}^{*}>0
$$


Recall $v_{A h 1}\left(\alpha_{h i}, g_{A 1}, g_{A 2}\right)=\alpha_{h 1}\left[\ln \left(g_{A 1}\right)+k_{2} \ln \left(g_{A 2}\right)\right]$ and use the fact $g_{A 1}=g_{A 2}=g_{A c}$ and the budget constraint of the central government given by $\tau_{A}=\frac{2 p\left(g_{A c}\right)}{\left(n_{1}+n_{2}\right)}$ to state $\varepsilon_{h 1}$ as follows: $\varepsilon_{h 1}=\left\{\alpha_{h 1}\left[\ln \left(g_{A c}\right)+k_{2} \ln \left(g_{A c}\right)\right]-\frac{2 p\left(g_{A c}\right)}{\left(n_{1}+n_{2}\right)}\right\}-\left\{\alpha_{h 1}\left[\ln \left(g_{B c}\right)+k_{2} \ln \left(g_{B c}\right)\right]-\frac{2 p\left(g_{B c}\right)}{\left(n_{1}+n_{2}\right)}\right\}$. Note that $g_{A c}$ is the only choice variable for party $A$. Similarly, $\varepsilon_{h 2}$ can be written as follows $\varepsilon_{h 2}=\left\{\alpha_{h 2}\left[\ln \left(g_{A c}\right)+k_{1} \ln \left(g_{A c}\right)\right]-\frac{2 p\left(g_{A c}\right)}{\left(n_{1}+n_{2}\right)}\right\}-\left\{\alpha_{h 2}\left[\ln \left(g_{B c}\right)+k_{1} \ln \left(g_{B c}\right)\right]-\frac{2 p\left(g_{B c}\right)}{\left(n_{1}+n_{2}\right)}\right\}$.

Considering that $g_{A}^{*}=g_{c}^{*}$ the first order condition becomes

$$
\sum_{h=1}^{n_{1}} \frac{\partial \varepsilon_{h 1}}{\partial g_{P}}=\frac{\sum_{h=1}^{n_{1}} \alpha_{h 1}}{g_{c}^{*}}+k_{2} \frac{\sum_{h=1}^{n_{1}} \alpha_{h 1}}{g_{c}^{*}}-\frac{2 n_{1} q}{\left(n_{1}+n_{2}\right)}=0 \forall g_{c}^{*}>0(A .7)
$$

And

$$
\sum_{h=1}^{n_{2}} \frac{\partial \varepsilon_{h 2}}{\partial g_{P}}=\frac{\sum_{h=1}^{n_{2}} \alpha_{h 2}}{g_{c}^{*}}+k_{1} \frac{\sum_{h=1}^{n_{2}} \alpha_{h 2}}{g_{c}^{*}}-\frac{2 n_{2} q}{\left(n_{1}+n_{2}\right)}=0 \forall g_{c}^{*}>0
$$

Use (A.7) and (A.8) into the first order conditions (A.6) to show

$$
\frac{\partial \delta_{P}}{\partial g_{P}}=\frac{\sum_{h=1}^{n_{1}} \alpha_{h 1}}{g_{c}^{*}}+k_{2} \frac{\sum_{h=1}^{n_{1}} \alpha_{h 1}}{g_{c}^{*}}+\frac{\sum_{h=1}^{n_{2}} \alpha_{h 2}}{g_{c}^{*}}+k_{1} \frac{\sum_{h=1}^{n_{2}} \alpha_{h 2}}{g_{c}^{*}}-2 q=0 \forall g_{c}^{*}>0 \text { (A.9) }
$$

Define $\alpha_{1}=\sum_{h=1}^{n_{1}} \alpha_{h 1}$ as the aggregate intensity of preferences for local public goods of all residents in district 1 and $\alpha_{2}=\sum_{h=1}^{n_{2}} \alpha_{h 2}$ is the corresponding aggregate intensity of preferences of all residents of district 2 , then $g_{c}^{*}$ is given by:

$$
g_{c}^{*}=\frac{\alpha_{1}+k_{1} \alpha_{2}}{2 q}+\frac{\alpha_{2}+k_{2} \alpha_{1}}{2 q}
$$

Since, $\hat{g}_{1}^{*}=\frac{\alpha_{1}+k_{1} \alpha_{2}}{q}$ and $\hat{g}_{2}^{*}=\frac{\alpha_{2}+k_{2} \alpha_{1}}{q}, g_{c}^{*}$ can also be expressed as follows:

$$
g_{c}^{*}=\frac{\hat{g}_{1}^{*}+\hat{g}_{2}^{*}}{2}
$$

Definition 2. Define policy platform of candidate $j=\{1,2\}$ of party $P=\{A, B\}$ in the local election of district $i=\{1,2\}$ by $g_{j P i}$. The equilibrium for an economy with party integration and democratic decentralization is constituted as follows: 
In the first stage, candidates $j$ of party $P$ announce local policy platforms $g_{L P i}^{*}$ :

$$
g_{L P i}^{*} \in \operatorname{argmax} \pi_{L P}
$$

Where $\pi_{L P}$ is the joint probability that party $P$ wins elections in districts 1 and 2.

Party Leaders nominate a candidate to run in the local election of each jurisdiction by selecting a candidate $j=1$ or 2 to the nomination set $N S_{L P i} \forall i$ if

$$
g_{j P i}^{*}=g_{L P i}^{*} \in \operatorname{argmax} \pi_{L P} \Rightarrow j \in N S_{L P i} \forall i
$$

Otherwise the candidate does not get the nomination and $j \notin N S_{L P i}$

The nomination process implies that parties $P=\{A, B\}$ nominate a candidate who adopts a policy on local public spending of jurisdiction $i, g_{L P i}^{*}$, that maximizes the joint probability that party $P$ wins elections in all jurisdictions.

In the second stage, a voter of jurisdiction $i$ with preference $\alpha_{h i}$ for $h=1,2 \ldots n_{i}$ votes for party $A$ if

$$
\Psi_{h i}\left(\alpha_{h i}\right)=\left\{v_{h i}\left(\alpha_{h i}, g_{L A 1}^{*}, g_{L A 2}^{*}\right)-\tau_{A i}+\sigma_{A h i}\right\}-\left\{v_{h i}\left(\alpha_{h i}, g_{L B 1}^{*}, g_{L B 2}^{*}\right)-\tau_{B i}+\sigma_{B h i}\right\} \geq 0
$$

Otherwise, he or she, votes for party $B$.

We define $\boldsymbol{\Omega}_{\boldsymbol{i}}$ as a non-decreasing cumulative distribution of the sequence $\left\{\Psi_{A h i}\left(\alpha_{h i}\right)\right\}_{\forall h, \forall i}$, hence $\boldsymbol{\Omega}_{\boldsymbol{i}} \in[\mathbf{0}, \mathbf{1}]$. In the third stage, if in jurisdiction $i$ it is satisfied that $\boldsymbol{\Omega}_{\boldsymbol{i}}\left(\forall \alpha_{h i}: \Psi_{h i}\left(\alpha_{h i}\right)>\right.$ $0)>\frac{1}{2}$ then party $A$ wins the election in the jurisdiction and implements $g_{L A i}^{*}$. Otherwise, party $B$ wins and implements $g_{L B i}^{*}$.

Lemma 2. Party integration and democratic decentralization lead to a set of Pareto efficient local public goods with and without spillovers $\mathbf{g}_{\mathrm{L}}^{*}=\left[g_{L 1}^{*}, g_{L 2}^{*}\right]$. At the equilibrium, $g_{L 1}^{*}, g_{L 2}^{*}$, satisfy the following:

$$
\left[g_{L 1}^{*}, g_{L 2}^{*}\right]=\left[\frac{\alpha_{1}+k_{1} \alpha_{2}}{q}, \frac{\alpha_{2}+k_{2} \alpha_{1}}{q}\right]
$$




\section{Proof}

For convenience assume party label is $P=A$. In the local election of district $i$ party $A$ selects $g_{L i}^{*} \in \arg \max \pi_{L A}=\pi_{L A}\left(\rho_{L A 1}, \rho_{L A 2}\right)$. The first order condition for an interior maximizer of local government spending in jurisdiction $i=1$ is $\frac{\partial \pi_{L A}}{\partial \rho_{L A 1}} \frac{\rho_{L A 1}}{\partial g_{L A 1}}+\frac{\partial \pi_{L A}}{\partial \rho_{L A 2}} \frac{\rho_{L A 2}}{\partial g_{L A 1}}=0$. By definition $\rho_{L A i}=\phi_{L A i}-\phi_{L B i} \forall i$ and the sum of the expected votes in jurisdiction $i$ for parties $A$ and $B$ is $\phi_{L A i}+\phi_{L B i}=n_{i} \forall i$, therefore $\frac{\rho_{L A i}}{\partial g_{L A i}}=2 \frac{\partial \phi_{L A i}}{\partial g_{L A 1}} \forall i$.

The parties' policies converge in probabilistic voting models with homogeneous parties (see Coughlin 1992). The convergence of the parties' policies $g_{L A i}^{*}=g_{L B i}^{*}=g_{L i}^{*}$ implies $\frac{\partial \pi_{L A}(0)}{\partial \rho_{L A 1}}=$ $\frac{\partial \pi_{L A}(0)}{\partial \rho_{L A 2}}$, therefore the first order condition becomes

$$
\frac{\partial \phi_{L 1}}{\partial g_{L 1}}+\frac{\partial \phi_{L 2}}{\partial g_{L 1}}=0 \forall g_{L 1}^{*}>0(A .13)
$$

Where $\frac{\partial \phi_{L 1}}{\partial g_{L 1}}$ and $\frac{\partial \phi_{L 2}}{\partial g_{L 1}}$ are the marginal expected votes for the party in jurisdictions 1 and 2 when there is a marginal change in policy $g_{L 1}^{*}$. Since $\frac{\partial \phi_{L 1}}{\partial g_{L 1}}=\sum_{h=1}^{n_{1}} \frac{\partial F_{P h 1}}{\partial \varepsilon_{h 1}} \frac{\partial \varepsilon_{h 1}}{\partial g_{L 1}}$ and $\frac{\partial \phi_{L 2}}{\partial g_{L 1}}=$ $\sum_{h=1}^{n_{2}} \frac{\partial F_{P h 2}}{\partial \varepsilon_{h 2}} \frac{\partial \varepsilon_{h 2}}{\partial g_{L 1}}$, the first order conditions in (A.13) can be stated as follows

$$
\sum_{h=1}^{n_{1}} \frac{\partial F_{P h 1}}{\partial \varepsilon_{h 1}} \frac{\partial \varepsilon_{h 1}}{\partial g_{L 1}}+\sum_{h=1}^{n_{2}} \frac{\partial F_{P h 2}}{\partial \varepsilon_{h 2}} \frac{\partial \varepsilon_{h 2}}{\partial g_{L 1}}=0 \forall g_{L 1}^{*}>0(A
$$

The convergence of the parties' policies also implies that $\frac{\partial F_{P h 1}(0)}{\partial \varepsilon_{h 1}}=\frac{\partial F_{P h 2}(0)}{\partial \varepsilon_{h 2}}$ therefore, the first order conditions in (A.14) is equivalent to:

$$
\sum_{h=1}^{n_{1}} \frac{\partial \varepsilon_{h 1}}{\partial g_{L 1}}+\sum_{h=1}^{n_{2}} \frac{\partial \varepsilon_{h 2}}{\partial g_{L 1}}=0 \forall g_{L 1}^{*}>0
$$

Use $\sum_{h=1}^{n_{1}} \frac{\partial \varepsilon_{h 1}}{\partial g_{L 1}}=\frac{\sum_{h=1}^{n_{1}} \alpha_{h 1}}{g_{L 1}^{*}}-q$ and $\sum_{h=1}^{n_{2}} \frac{\partial \varepsilon_{h 2}}{\partial g_{L 1}}=k_{1} \frac{\sum_{h=1}^{n_{2}} \alpha_{h 2}}{g_{L 1}^{*}}$ into (A.15) to show

$$
g_{L 1}^{*}=\frac{\sum_{h=1}^{n_{1}} \alpha_{h 1}+k_{1} \frac{\sum_{h=1}^{n_{2}} \alpha_{h 2}}{g_{c}^{*}}}{q}=\frac{\alpha_{1}+k_{1} \alpha_{2}}{q}
$$

Where $\alpha_{1}=\sum_{h=1}^{n_{1}} \alpha_{h 1}$ and $\alpha_{2}=\sum_{h=1}^{n_{2}} \alpha_{h 2}$ are respectively the aggregate intensities of preferences for local public goods of all residents in district 1 and 2 . 
Following similar steps, it can be shown that $g_{L 2}^{*}$ in district 2 is given by:

$$
g_{L 2}^{*}=\frac{\alpha_{2}+k_{2} \alpha_{1}}{q}
$$

Theorem 1. If parties are integrated, then the provision of local public goods with and without inter-regional spillovers by a system of democratically elected local governments welfaredominates the democratically centralized provision.

\section{Proof}

It is simple to verify that conditions (2), (3) (4), and (5) imply that for $\hat{\mathbf{g}}^{*}, \mathbf{g}_{\mathbf{c}}^{*}, \mathbf{g}_{\mathbf{L}}^{*} \in \mathbb{R}^{2}: \hat{\mathbf{g}}^{*}=$ $\left[\hat{g}_{1}^{*}, \hat{g}_{2}^{*}\right], \mathbf{g}_{\mathbf{c}}^{*}=\left[g_{c}^{*}, g_{c}^{*}\right]$ and, $\mathbf{g}_{\mathbf{L}}^{*}=\left[g_{L 1}^{*}, g_{L 2}^{*}\right]$ it is satisfied that $\hat{\mathbf{g}}^{*}=\mathbf{g}_{\mathbf{L}}^{*} \neq \mathbf{g}_{\mathbf{c}}^{*}$. Recall that $\hat{g}_{1}^{*}, \hat{g}_{2}^{*} \in \operatorname{argmax} \operatorname{NSW}\left(g_{1}, g_{2}\right)$ where $N S W=\sum_{h=1}^{n_{1}} v_{h 1}\left(\alpha_{h 1}, g_{1}, g_{2}\right)+$ $\sum_{h=1}^{n_{2}} v_{h 2}\left(\alpha_{h 2}, g_{2}, g_{1}\right)-p\left(g_{1}+g_{2}\right)$. By the strict concavity of $N S W\left(g_{1}, g_{2}\right)$ it is satisfied that $N S W\left(\hat{g}_{1}^{*}, \hat{g}_{2}^{*}\right)>N S W\left(\left(g_{1}, g_{2}\right)\right) \forall \hat{g}_{i}^{*} \neq g_{i} \forall i(A .18)$

Since $g_{L 1}^{*}=\hat{g}_{i}^{*} \forall i$ and $g_{c}^{*} \neq \hat{g}_{i}^{*} \forall i$ then $N S W\left(g_{L 1}^{*}, g_{L 2}^{*}\right)>N S W\left(g_{c}^{*}, g_{c}^{*}\right)$. This means that democratic decentralization welfare dominates democratic centralization even if local public goods show spillovers.

Definition 3. The equilibrium for an economy with primary and general elections and democratic centralization is constituted as follows:

In the first stage, candidates $j=\{1,2\}$ of party $P=\{A, B\}$ announce policy platforms in jurisdictions $i=1,2$ given by $G_{j P 1}^{*}=G_{j P 2}^{*}=G_{j P c}^{*}$ where

$$
G_{j P c}^{*} \in \operatorname{argmax} \Phi_{j P} \text { subject to } G_{j P 1}^{*}=G_{j P 2}^{*}
$$

Where $\Phi_{j P}$ is the joint cumulative probability that candidate $j$ of party $P$ will win the nationwide primary and general elections. 
In the second stage of the game, Nature selects a set of voters who can participate in the primary. In each jurisdiction, Nature selects the distribution of qualified voters given by $\left\{\alpha_{A 1 i}, \alpha_{A 2 i} \ldots \ldots \ldots \alpha_{A m_{i} i}\right\}$ and $\left\{\alpha_{B 1 i}, \alpha_{B 2 i} \ldots \ldots . \alpha_{B m_{i} i}\right\}$ for $i=1,2 .{ }^{26}$

The primary election takes place and only qualified primary voters choose between policies of candidate 1 and candidate 2 of party $P$. Denote $G_{1 P 1}^{*}=G_{1 P 2}^{*}=G_{1 P c}^{*}$ as the policies of candidate 1 of party $P$ in districts 1 and 2 and $G_{2 P 1}^{*}=G_{2 P 2}^{*}=G_{2 P c}^{*}$ are the corresponding policies of candidate 2 of party $P$.

Thus, primary voters with preference $\alpha_{P h i}$ for $h=1,2 \ldots m_{i}$ vote for candidate 1 of party $P$ in jurisdiction $i$ if: 27

$$
\begin{gathered}
\Psi_{P h i}\left(\alpha_{P h i}\right)=\left\{v_{P h i}\left(\alpha_{P h i}, G_{1 P 1}^{*}, G_{1 P 2}^{*}\right)-\tau_{1 P}+\sigma_{1 P h i}\right\} \\
-\left\{v_{P h i}\left(\alpha_{P h i}, G_{2 P 1}^{*}, G_{2 P 2}^{*}\right)-\tau_{2 P}+\sigma_{2 P h i}\right\} \geq 0
\end{gathered}
$$

Otherwise they vote for candidate 2 of party $P$.

We define $\boldsymbol{\Omega}_{\boldsymbol{p}}$ as a non-decreasing cumulative distribution of the sequence $\left\{\Psi_{P h i}\left(\alpha_{P h i}\right)\right\}_{\forall h, \forall i}$, hence $\boldsymbol{\Omega}_{\boldsymbol{p}} \in[\mathbf{0}, \mathbf{1}]$. In the third stage, if $\mathbf{\Omega}_{\boldsymbol{p}}\left(\forall \alpha_{P h i}: \Psi_{P h i}\left(\alpha_{P h i}\right) \geq 0\right)>\frac{1}{2}$ then candidate 1 of party $P$ is nominated. Otherwise, candidate 2 of party $P$ is nominated.

The nomination process means that the candidates' policies are now adopted by parties. Hence, policies of the nominated candidate of party $P$ in jurisdictions 1 and $2, G_{j P 1}^{*}, G_{j P 2}^{*}$, become respectively the parties' policies in jurisdictions 1 and 2 denoted by $G_{P 1}^{*}, G_{P 2}^{*}$.

In the fourth stage, the nationwide general election takes place and voters vote from the set of nominated candidates in each party. Parties $A$ and $B$ postulate policies, $G_{A 1}^{*}, G_{A 2}^{*}$ and $G_{B 1}^{*}, G_{B 2}^{*}$ in jurisdictions 1 and 2. Hence voters with preference for local public goods $\alpha_{h i}$ for $h=1,2 \ldots n_{i}$ in jurisdictions $i=1,2$ vote for party $A$ if

\footnotetext{
${ }^{26}$ Where the preference parameter $\alpha_{P h i}$ depicts a voter who can participate in the primary election of party $P$, indexed by $h=1, \ldots m_{i}$ in district $i$.

${ }^{27}$ In the utility function $v_{h 1}\left(\alpha_{h i}, G_{1 P 1}^{*}, G_{1 P 2}^{*}\right)$, the subscripts $h i$ denote $h=1, \ldots m$ voters and $i=1,2$ jurisdictions. Hence $v_{h 1}$ depends on policies $G_{J P i}^{*}$ where $j P i$ stands for $J=1,2$ candidates, $P=A, B$ parties and $i=1,2$ jurisdictions.
} 


$$
\Psi_{h i}\left(\alpha_{h i}\right)=\left\{v_{h i}\left(\alpha_{h i}, G_{A 1}^{*}, G_{A 2}^{*}\right)-\tau_{A}+\sigma_{A h i}\right\}-\left\{v_{h i}\left(\alpha_{h i}, G_{B 1}^{*}, G_{B 2}^{*}\right)-\tau_{B}+\sigma_{B h i}\right\} \geq 0
$$

Otherwise they vote for party $B$.

Define $\Omega$ as a non-decreasing cumulative distribution of the sequence $\left\{\Psi_{h i}\left(\alpha_{h i}\right)\right\}_{\forall h, \forall i}$, hence $\boldsymbol{\Omega} \in[\mathbf{0}, \mathbf{1}]$.In the fifth stage, if $\boldsymbol{\Omega}\left(\forall \alpha_{h i}: \Psi_{h i}\left(\alpha_{h i}\right) \geq 0\right)>\frac{1}{2}$ then party $A$ wins and implements $G_{A 1}^{*}, G_{A 2}^{*}$. Otherwise, party $B$ wins and implements $G_{B 1}^{*}, G_{B 2}^{*}$. 


\section{For the purpose of exposition, we include the extensive form of the game with primary and general elections and democratic}

centralization.

First Stage: Candidates announce policies

Second Stage:

Nature selects voters participating in primary

Voters vote to nominate a candidate

Third Stage: The candidate with majority of votes win the nomination

\section{Fourth Stage}

Voters vote from the set of

Nominated candidates

Fifth Stage

A candidate from some party wins and forms the government
In the first stage, candidates $j=\{1,2\}$ of party $P=\{A, B\}$ announce policy platforms $G_{j p 1}^{*}=$ $G_{j P 2}^{*}=G_{j P c}^{*}$ where

$$
G_{j P c}^{*} \in \operatorname{argmax} \Phi_{j P} \quad \text { subject to } G_{j P 1}^{*}=G_{j P 2}^{*}
$$

In the second stage of the game, in each jurisdiction, Nature selects the distribution of qualified voters given by $\left\{\alpha_{A 1 i}, \alpha_{A 2 i} \ldots \ldots . \alpha_{A m_{i} i}\right\}$ and $\left\{\alpha_{B 1 i}, \alpha_{B 2 i} \ldots \ldots . \alpha_{B m_{i} i}\right\}$ for jurisdictions $i=1,2$.

Thus, qualified primary voters with preference $\alpha_{P h i}$ for $h=1,2 \ldots m_{i}$ vote for candidate 1 of party $P$ in jurisdiction $i$ if

$$
\Psi_{h i}\left(\alpha_{P h i}\right)=\left\{v_{h i}\left(\alpha_{P h i}, G_{1 P i}^{*}\right)-\tau_{1 P i}+\sigma_{1 P h i}\right\}-\left\{v_{h i}\left(\alpha_{P h i}, G_{2 P i}^{*}\right)-\tau_{2 P i}+\sigma_{2 P h i}\right\} \geq 0
$$

Otherwise voters vote for candidate 2 of party $P$.

In the third stage, if $\boldsymbol{\Omega}_{P 0 i}\left(\forall \alpha_{h i}: \Psi_{h i}\left(\alpha_{P h i}\right) \geq 0\right)>\frac{1}{2}$ then candidate 1 of party $P$ is nominated by majority of the votes in the primary and the party's platform in jurisdiction $i, G_{P i}^{*}$, takes the value of $G_{P i}^{*}=G_{1 P i}^{*}$. Otherwise, candidate 2 is nominated and the party's platform takes the

$$
\text { value } G_{P i}^{*}=G_{2 P i}^{*}
$$

Candidate 2

In the fourth stage, the nationwide general election takes place and voters vote from the set of Candidate 1 of competing party

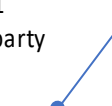

\section{of competing party}

\begin{abstract}
i. Hence voters with preference for local public goods $\alpha_{h i}$ for $h=1,2 \ldots n_{i}$ in jurisdiction $i$ votes
\end{abstract} for party $A$ if

$$
\Psi_{h i}\left(\alpha_{h i}\right)=\left\{v_{h i}\left(\alpha_{h i}, G_{A i}^{*}\right)-\tau_{A i}+\sigma_{A h i}\right\}-\left\{v_{h i}\left(\alpha_{h i}, G_{B i}^{*}\right)-\tau_{B i}+\sigma_{B h i}\right\} \geq 0
$$

Otherwise they vote for party $B$.

In the fifth stage, if $\boldsymbol{\Omega}_{i}\left(\forall \alpha_{h i}: \Psi_{h i}\left(\alpha_{h i}\right) \geq 0\right)>\frac{1}{2}$ then party $A$ wins by majority and implements $G_{A i}^{*}$. Otherwise, party $B$ wins and implements $G_{B i}^{*}$. 
Lemma 3. For economies with non-integrated parties and democratic centralization, a candidate $j$ of party $P$ proposes a uniform and Pareto efficient local public good $G_{j P c}^{*}$ in jurisdictions 1 and 2 satisfying the following:

$$
G_{j P c}^{*}=\Upsilon_{j P c}\left(W_{j P 01} G_{P 01}^{*}+W_{j P 02} G_{P 02}^{*}+W_{j P 1} \hat{g}_{1}^{*}+W_{j P 2} \hat{g}_{2}^{*}\right)(A
$$

Where $\Upsilon_{j P c}$ is a proportionality parameter given by:

$$
\Upsilon_{j P c}=\frac{1}{2\left(\Theta_{j P c}+\Gamma_{j P c}\right)-\frac{\operatorname{Cov}_{0}+\operatorname{Cov}_{G E}}{q}}
$$

And

$$
\Theta_{j P c}=\frac{m_{1}+m_{2}}{\left(\beta_{j P 01} m_{1}+\beta_{j P 02} m_{2}\right)} \text { and } \Gamma_{j P c}=\frac{n_{1}+n_{2}}{\left(\beta_{j P 11}+\beta_{j P 21}\right) n_{1}+\left(\beta_{j P 12}+\beta_{j P 22}\right) n_{2}}
$$

Moreover, $\operatorname{Cov}_{0}$ is a weighted nationwide covariance of the marginal probability of the vote of candidate $j$ of party $P$ in the nationwide primary election, $\frac{\partial F_{j P 0 h i}}{\partial \varepsilon_{J P 0 h i}}$, and $\frac{\partial \varepsilon_{J P 0 h i}}{\partial G_{j P c}}$ which is the change in welfare of each individual voter due to a marginal change in $G_{j P c}^{*}$. In addition, $\frac{\partial \Phi_{j P}}{\partial \rho_{j P 0}}$ is the candidate's marginal change in the probability of winning the primary election:

$$
\operatorname{Cov}_{0}\left(\frac{\partial F_{j P 0 i}}{\partial \varepsilon_{J P 0 i}}, \frac{\partial \varepsilon_{J P 0 i}}{\partial G_{j P c}}\right)=\frac{\partial \Phi_{j P}}{\partial \rho_{j P 0}} \sum_{i=1}^{2} m_{i} \operatorname{Cov}_{j P 0 i}
$$

And $\operatorname{Cov}_{j P 0}$ is the covariance of the marginal probability of voters in jurisdiction i for candidate $j$ of party $P$ in the primary and the change in welfare of each resident of jurisdiction $i$ due to a marginal change in $G_{j P c}^{*}$.

Moreover, $\operatorname{Cov}_{G E}$ is a weighted nationwide covariance of the marginal probability of the vote of candidate $j$ of party $P$ in the general election, $\frac{\partial F_{j P s i}}{\partial \varepsilon_{J P S i}}$, and $\frac{\partial \varepsilon_{J P 0 i}}{\partial G_{j P c}}$ which is the change in the welfare of each individual voter due to a marginal change in $G_{j P c}^{*}$. Moreover, $\frac{\partial \Phi_{j P}}{\partial \rho_{j P s}}$ is the candidate's marginal change in the probability of winning the general election, hence: 


$$
\operatorname{Cov}_{G E}\left(\frac{\partial F_{j P s h i}}{\partial \varepsilon_{J P S h i}}, \frac{\partial \varepsilon_{J P s h i}}{\partial G_{j P c}}\right)=\sum_{s=1}^{2} \frac{\partial \Phi_{j P}}{\partial \rho_{j P s}}\left(\sum_{i=1}^{2} n_{i} \operatorname{Cov}_{j P s i}\right)
$$

And $\operatorname{Cov}_{j P s i}$ is the covariance of the marginal probability of voters in jurisdiction i for candidate $j$ of party $P$ in the general election in the electoral state $s=1,2$ and the change in welfare of each resident of jurisdiction $i$ due to a marginal change in $G_{j P c}^{*}$.

\section{Proof}

For an economy with party non-integration and a single government, candidate $j$ of party $P$ designs public spending to maximize $\Phi_{j P}$ subject to $G_{j P 1}=G_{j P 2}=G_{j P c}$. We impose the equality restriction in the objective function of party $P$. The first order condition for the party's problem is

$$
\frac{\partial \Phi_{j P}}{\partial \rho_{j P 0}} \frac{\partial \rho_{j P 0}}{\partial G_{j P c}}+\frac{\partial \Phi_{j P}}{\partial \rho_{j P 1}} \frac{\partial \rho_{j P 1}}{\partial G_{j P c}}+\frac{\partial \Phi_{j P}}{\partial \rho_{j P 2}} \frac{\partial \rho_{j P 2}}{\partial G_{j P c}}=0 \forall G_{j P c}^{*}>0
$$

Where $\frac{\partial \Phi_{j P}}{\partial \rho_{j P s}} \frac{\partial \rho_{j P s}}{\partial G_{j P c}}$ for $s=0,1,2$ is the marginal change in the candidate's plurality in the primary and the general election due to a marginal change in $G_{j P c}^{*}$. By definition, the plurality of each party and the sum of expected votes implies

$$
\frac{\partial \rho_{j P s}}{G_{j P c}}=2 \frac{\partial \phi_{j P s}}{\partial G_{j P c}}=2\left(\frac{\partial \phi_{j P s 1}}{\partial G_{j P c}}+\frac{\partial \phi_{j P s 2}}{\partial G_{j P c}}\right) A(A
$$

In (A.25), $\frac{\partial \phi_{j P s i}}{\partial G_{j P C}}$ is the marginal expected vote for candidate $j$ of party $P$ in the state of the electoral contest $s=0,1,2$ in jurisdiction $i$.

Since $G_{j P 1}=G_{j P 2}=G_{j P c}$ then the nationwide expected votes in the primary election, with $s=$ 0 , are given by

$$
\frac{\partial \rho_{j P 0}}{\partial G_{j P c}}=2\left(\frac{\partial \phi_{j P o 1}}{\partial G_{j P c}}+\frac{\partial \phi_{j P o 2}}{\partial G_{j P c}}\right)
$$

And the nationwide expected votes in the general election if candidate $j$ faces candidate $s=1$ or $s=2$ of the competing party are 


$$
\begin{aligned}
& \frac{\partial \rho_{j P 1}}{\partial G_{j P c}}=\frac{\partial \phi_{j P 11}}{\partial G_{j P c}}+\frac{\partial \phi_{j P 12}}{\partial G_{j P c}} \\
& \frac{\partial \rho_{j P 2}}{\partial G_{j P c}}=\frac{\partial \phi_{j P 21}}{\partial G_{j P c}}+\frac{\partial \phi_{j P 22}}{\partial G_{j P c}}
\end{aligned}
$$

In equation (A.27), $\frac{\partial \phi_{j P 11}}{\partial G_{j P c}}$ and $\frac{\partial \phi_{j P 12}}{\partial G_{j P C}}$ are, respectively, the expected votes from candidate $j$ of party $P$ if candidate $j$ faces candidate 1 of the competing party in jurisdictions 1 and 2 . Condition (A.28) is the expected votes from candidate $j$ of party $P$ if candidate $j$ faces candidate 2 of the competing party in jurisdictions 1 and 2.

It follows that the first order condition (A.24) is given by

$$
\begin{gathered}
\frac{\partial \Phi_{j P}}{\partial \rho_{j P 0}}\left(\frac{\partial \phi_{j P o 1}}{\partial G_{j P c}}+\frac{\partial \phi_{j P o 2}}{\partial G_{j P c}}\right)+\frac{\partial \Phi_{j P}}{\partial \rho_{j P 1}}\left(\frac{\partial \phi_{j P 11}}{\partial G_{j P c}}+\frac{\partial \phi_{j P 12}}{\partial G_{j P c}}\right) \\
+\frac{\partial \Phi_{j P}}{\partial \rho_{j P 2}}\left(\frac{\partial \phi_{j P 21}}{\partial G_{j P c}}+\frac{\partial \phi_{j P 22}}{\partial G_{j P c}}\right)=0 \forall G_{j P c}^{*}>0(A .29)
\end{gathered}
$$

In each jurisdiction, Nature selects the distribution of qualified voters given by $\left\{\alpha_{A 1 i}, \alpha_{A 2 i} \ldots \ldots \ldots \alpha_{A m_{i} i}\right\}$ and $\left\{\alpha_{B 1 i}, \alpha_{B 2 i} \ldots \ldots . \alpha_{B m_{i} i}\right\}$ for $i=1,2$. In the primary election $h=$ $1,2 \ldots . m_{i} \leq n_{i}$ where $m_{i}$ is the number of voters voting in the primary election of jurisdiction $i$, and $n_{i}$ is the number of residents of jurisdiction $i$. In a blanket primary election $m_{i}=n_{i}$ and in a closed primary election $m_{i}<n_{i}$.

The expected votes of candidate $j$ of party $P$ in the primary election (for $s=0$ ) in jurisdiction $i$ can be stated as follows ${ }^{28}$

$$
\frac{\partial \phi_{j P s i}}{\partial G_{j P c}}=\sum_{h=1}^{m_{i}} \frac{\partial F_{j P s h i}\left(\varepsilon_{J P s h i}\right)}{\partial G_{j P c}} \text { for } s=0, i=\{1,2\}(A .30)
$$

In (A.30) the expression $F_{j P s h}$ is the marginal probability of the vote for candidate $j$ of party $P$ of electoral state $s$ from voter $h$ in district $i$.

\footnotetext{
${ }^{28}$ In condition (A.30) the subscripts in $F_{j P s h}$ refer to the joint probability of the vote for candidate $j$ of party $P$ of electoral state $s$ from voter $h$ in district $i$.
} 
And the marginal expected votes of candidate $j$ of party $P$ in state of election $s=\{1,2\}$ in jurisdiction $i, \frac{\partial \phi_{j P s i}}{\partial G_{j P c}}$, can be stated as follows

$$
\frac{\partial \phi_{j P s i}}{\partial G_{j P c}}=\sum_{h=1}^{n_{i}} \frac{\partial F_{j P s h i}\left(\varepsilon_{J P s h i}\right)}{\partial G_{j P c}} \text { for } s=\{1,2\}, i=\{1,2\}
$$

Therefore, the first order condition in (A.29) becomes

$$
\begin{gathered}
\frac{\partial \Phi_{j P}}{\partial \rho_{j P 0}}\left(\sum_{h=1}^{m_{1}} \frac{\partial F_{j P 0 h 1}\left(\varepsilon_{J P 0 h 1}\right)}{\partial G_{j P c}}+\sum_{h=1}^{m_{2}} \frac{\partial F_{j P 0 h 2}\left(\varepsilon_{J P 0 h 2}\right)}{\partial G_{j P c}}\right) \\
+\frac{\partial \Phi_{j P}}{\partial \rho_{j P 1}}\left(\sum_{h=1}^{n_{1}} \frac{\partial F_{j P 1 h 1}\left(\varepsilon_{J P 1 h 1}\right)}{\partial G_{j P c}}+\sum_{h=1}^{n_{2}} \frac{\partial F_{j P 12}\left(\varepsilon_{J P 1 h 2}\right)}{\partial G_{j P c}}\right) \\
+\frac{\partial \Phi_{j P}}{\partial \rho_{j P 2}}\left(\sum_{h=1}^{n_{1}} \frac{\partial F_{j P 2 h 1}\left(\varepsilon_{J P 2 h 1}\right)}{\partial G_{j P c}}+\sum_{h=1}^{n_{2}} \frac{\partial F_{j P 2 h 2}\left(\varepsilon_{J P 2 h 2}\right)}{\partial G_{j P c}}\right)=0 \forall G_{j P c}^{*}>0
\end{gathered}
$$

In the previous condition $\frac{\partial \Phi_{j P}}{\partial \rho_{j P 0}}$ is the change in the marginal nationwide probability of candidate $j$ of party $P$ of winning the primary election when it chooses $G_{j P c}^{*}$ and $\sum_{h=1}^{m_{1}} \frac{\partial F_{j P 0 h 1}\left(\varepsilon_{J P 0 h 1}\right)}{\partial G_{j P c}}$ is the expected vote of candidate $j$ of party $P$ in the primary election in jurisdiction 1 and $\sum_{h=1}^{m_{2}} \frac{\partial F_{j P 0 h 2}\left(\varepsilon_{J P 0 h 2}\right)}{\partial G_{j P c}}$ is the corresponding expected vote of candidate in the primary election in jurisdiction 2 .

Similarly, $\frac{\partial \Phi_{j P}}{\partial \rho_{j P 1}}$ is the marginal probability of candidate $j$ of party $P$ when it chooses $G_{j P c}$ of winning the general election when candidate $j$ faces candidate 1 of the competing party and $\sum_{h=1}^{n_{1}} \frac{\partial F_{j P 1 h 1}\left(\varepsilon_{J P 1 h 1}\right)}{\partial G_{j P c}}$ is the expected vote of candidate $j$ of party $P$ in the general election in jurisdiction 1 when facing candidate 1 of the competing party and $\sum_{h=1}^{n_{2}} \frac{\partial F_{j P 1 h 2}\left(\varepsilon_{J P 1 h 2}\right)}{\partial G_{j P c}}$ is the expected vote of candidate $j$ of party $P$ in the general election in jurisdiction 2 when facing candidate 1 of the competing party. A similar interpretation is given to the general election when candidate $j$ faces candidate 2 of the competing party for the expressions

$$
\frac{\partial \Phi_{j P}}{\partial \rho_{j P 2}}, \sum_{h=1}^{n_{1}} \frac{\partial F_{j P 2 h 1}\left(\varepsilon_{J P 2 h 1}\right)}{\partial G_{j P c}}, \text { and } \sum_{h=1}^{n_{2}} \frac{\partial F_{j P 2 h 2}\left(\varepsilon_{J P 2 h 2}\right)}{\partial G_{j P c}}
$$


From condition (A.30) express $\frac{\partial F_{j P s h i}\left(\varepsilon_{J P s h i}\right)}{\partial G_{j P c}}$ as follows:

$$
\frac{\partial F_{j P s i}\left(\varepsilon_{J P s h i}\right)}{\partial G_{j P c}}=\frac{\partial F_{j P s h i}}{\partial \varepsilon_{J P s h i}} \frac{\partial \varepsilon_{J P s h i}}{\partial G_{j P c}}
$$

From the definition of the covariance between $A$ and $B, \operatorname{Cov}(A, B)=E[A B]-E[A] E[B]$. Redefine $A=\left\{\frac{\partial F_{j P s h i}}{\partial \varepsilon_{J P s h i}}\right\}$ and $B=\left\{\frac{\partial \varepsilon_{J P s h i}}{\partial G_{j P c}}\right\}$ to sate the following:

For $\mathrm{s}=0$

$$
\begin{gathered}
\sum_{h=1}^{m_{i}} \frac{\partial F_{j P 0 h i}}{\partial \varepsilon_{J P 0 h i}} \frac{\partial \varepsilon_{J P 0 h i}}{\partial G_{j P c}}=m_{i} \operatorname{Cov}_{j P 0 i}\left(\frac{\partial F_{j P 0 h i}}{\partial \varepsilon_{j P 0 h i}}, \frac{\partial \varepsilon_{J P 0 h i}}{\partial G_{j P c}}\right) \\
+\left(\sum_{h=1}^{m_{i}} \frac{\partial F_{j P 0 h i}}{\partial \varepsilon_{j P 0 h i}}\right)\left(\sum_{h=1}^{m_{i}} \frac{\partial \varepsilon_{j P 0 h i}}{\partial G_{j P c}}\right)(A .34)
\end{gathered}
$$

For $\mathrm{s}=1,2$

$$
\begin{gathered}
\sum_{h=1}^{n_{i}} \frac{\partial F_{j P s h i}}{\partial \varepsilon_{J P s h i}} \frac{\partial \varepsilon_{J P s h i}}{\partial G_{j P c}}=n_{i} \operatorname{Cov}_{j P s i}\left(\frac{\partial F_{j P s h i}}{\partial \varepsilon_{j P s h i}}, \frac{\partial \varepsilon_{J P s h i}}{\partial G_{j P c}}\right) \\
+\left(\sum_{h=1}^{n_{i}} \frac{\partial F_{j P s h i}}{\partial \varepsilon_{j P s h i}}\right)\left(\sum_{h=1}^{n_{i}} \frac{\partial \varepsilon_{j P s h i}}{\partial G_{j P c}}\right)\left(A .34^{\prime}\right)
\end{gathered}
$$

Use (A.34), (A.34') into (A.32) to show that

$$
\begin{gathered}
\frac{\partial \Phi_{j P}}{\partial \rho_{j P 0}}\left(\sum_{i=1}^{2}\left(m_{i} \operatorname{Cov}_{j P 0 i}\left(\frac{\partial F_{j P 0 h i}}{\partial \varepsilon_{j P 0 h 1}}, \frac{\partial \varepsilon_{j P 0 h i}}{\partial G_{j P c}}\right)+\left(\sum_{h=1}^{m_{i}} \frac{\partial F_{j P 0 h i}}{\partial \varepsilon_{j P 0 h i}}\right)\left(\sum_{h=1}^{m_{i}} \frac{\partial \varepsilon_{J P 0 h i}}{\partial G_{j P c}}\right)\right)\right) \\
+\frac{\partial \Phi_{j P}}{\partial \rho_{j P 1}}\left(\sum_{i=1}^{2}\left(n_{i} \operatorname{Cov}_{j P 1 i}\left(\frac{\partial F_{j P 1 h i}}{\partial \varepsilon_{j P 1 h i}}, \frac{\partial \varepsilon_{j P 1 h i}}{\partial G_{j P c}}\right)+\left(\sum_{h=1}^{n_{i}} \frac{\partial F_{j P 1 h i}}{\partial \varepsilon_{j P 1 h i}}\right)\left(\sum_{h=1}^{n_{i}} \frac{\partial \varepsilon_{j P 1 h i}}{\partial G_{j P c}}\right)\right)\right) \\
+\frac{\partial \Phi_{j P}}{\partial \rho_{j P 2}}\left(\sum_{i=1}^{2}\left(n_{i} \operatorname{Cov}_{j P 2 i}\left(\frac{\partial F_{j P 2 h i}}{\partial \varepsilon_{j P 2 h i}}, \frac{\partial \varepsilon_{J P 2 h i}}{\partial G_{j P c}}\right)+\left(\sum_{h=1}^{n_{i}} \frac{\partial F_{j P 2 h i}}{\partial \varepsilon_{J P 2 h i}}\right)\left(\sum_{h=1}^{n_{i}} \frac{\partial \varepsilon_{j P 2 h i}}{\partial G_{j P c}}\right)\right)\right) \\
=0(A .35)
\end{gathered}
$$

Equivalent to: 


$$
\begin{aligned}
& \frac{\partial \Phi_{j P}}{\partial \rho_{j P 0}}\left(\sum_{i=1}^{2}\left(m_{i} \operatorname{Cov}_{j P 0 i}\left(\frac{\partial F_{j P 0 h i}}{\partial \varepsilon_{j P 0 h 1}}, \frac{\partial \varepsilon_{j P 0 h i}}{\partial G_{j P c}}\right)\right)\right) \\
&+ \frac{\partial \Phi_{j P}}{\partial \rho_{j P 1}}\left(\sum_{i=1}^{2}\left(n_{i} \operatorname{Cov}_{j P 1 i}\left(\frac{\partial F_{j P 1 h i}}{\partial \varepsilon_{j P 1 h i}}, \frac{\partial \varepsilon_{j P 1 h i}}{\partial G_{j P c}}\right)\right)\right) \\
&+ \frac{\partial \Phi_{j P}}{\partial \rho_{j P 2}}\left(\sum_{i=1}^{2}\left(n_{i} \operatorname{Cov}_{j P 2 i}\left(\frac{\partial F_{j P 2 h i}}{\partial \varepsilon_{j P 2 h i}}, \frac{\partial \varepsilon_{J P 2 h i}}{\partial G_{j P c}}\right)\right)\right) \\
&+ \frac{\partial \Phi_{j P}}{\partial \rho_{j P 0}}\left(\sum_{i=1}^{2}\left(\sum_{h=1}^{m_{i}} \frac{\partial F_{j P 0 h i}}{\partial \varepsilon_{j P 0 h i}}\right)\left(\sum_{h=1}^{m_{i}} \frac{\partial \varepsilon_{j P 0 h i}}{\partial G_{j P c}}\right)\right) \\
&+ \frac{\partial \Phi_{j P}}{\partial \rho_{j P 1}}\left(\sum_{i=1}^{2}\left(\sum_{h=1}^{n_{i}} \frac{\partial F_{j P 1 h i}}{\partial \varepsilon_{j P 1 h i}}\right)\left(\sum_{h=1}^{n_{i}} \frac{\partial \varepsilon_{j P 1 h i}}{\partial G_{j P c}}\right)\right) \\
&+\frac{\partial \Phi_{j P}}{\partial \rho_{j P 2}}\left(\sum_{i=1}^{2}\left(\sum_{h=1}^{n_{i}} \frac{\partial F_{j P 2 h i}}{\partial \varepsilon_{j P 2 h i}}\right)\left(\sum_{h=1}^{n_{i}} \frac{\partial \varepsilon_{j P 2 h i}}{\partial G_{j P c}}\right)\right)=0(A .)
\end{aligned}
$$

Let define $\beta_{j P s i}$ as follows

$$
\begin{gathered}
\beta_{j P 0 i}=\frac{\partial \Phi_{j P}}{\partial \rho_{j P 0}} \sum_{h=1}^{m_{i}} \frac{\partial F_{j P 0 h i}}{\partial \varepsilon_{J P 0 h i}} \text { for } s=0, i=1,2(A .37) \\
\beta_{j P s i}=\frac{\partial \Phi_{j P}}{\partial \rho_{j P s}} \sum_{h=1}^{n_{i}} \frac{\partial F_{j P s h i}}{\partial \varepsilon_{J P S h i}} \text { for } s=1,2, i=1,2(A .38)
\end{gathered}
$$

Use (A.37) and (A.38) into (A.36) to express the first order conditions as follows

$$
\begin{gathered}
\frac{\partial \Phi_{j P}}{\partial \rho_{j P 0}}\left(\sum_{i=1}^{2}\left(m_{i} \operatorname{Cov}_{j P 0 i}\right)\right)+\sum_{s=1}^{2} \frac{\partial \Phi_{j P}}{\partial \rho_{j P s}}\left(\sum_{i=1}^{2} n_{i} \operatorname{Cov}_{j P s i}\right) \\
+\left(\sum_{i=1}^{2} \beta_{j P 0 i}\left(\sum_{h=1}^{m_{i}} \frac{\partial \varepsilon_{j P 0 h i}}{\partial G_{j P c}}\right)\right) \\
+\left(\sum_{i=1}^{2} \beta_{j P 1 i}\left(\sum_{h=1}^{n_{i}} \frac{\partial \varepsilon_{j P 1 h i}}{\partial G_{j P c}}\right)\right) \\
+\left(\sum_{i=1}^{2} \beta_{j P 2 i}\left(\sum_{h=1}^{n_{i}} \frac{\partial \varepsilon_{j P 2 h i}}{\partial G_{j P c}}\right)\right)=0 \forall G_{j P c}^{*}>0(A .39)
\end{gathered}
$$


The expected votes of candidate $j$ of party $P$ in the primary election in jurisdictions 1 and 2 , are correspondingly, given by:

$$
\begin{aligned}
& \sum_{h=1}^{m_{1}} \frac{\partial \varepsilon_{J P 0 h 1}}{\partial G_{j P c}}=\frac{\sum_{h=1}^{m_{1}} \alpha_{P h 1}}{G_{j P c}^{*}}+k_{2} \frac{\sum_{h=1}^{m_{1}} \alpha_{P h 1}}{G_{j P C}^{*}}-\frac{2 m_{1} q}{\left(n_{1}+n_{2}\right)} \\
& \sum_{h=1}^{m_{2}} \frac{\partial \varepsilon_{J P 0 h 2}}{\partial G_{j P c}}=\frac{\sum_{h=1}^{m_{2}} \alpha_{P h 2}}{G_{j P c}^{*}}+k_{1} \frac{\sum_{h=1}^{m_{2}} \alpha_{P h 2}}{G_{j P c}^{*}}-\frac{2 m_{2} q}{\left(n_{1}+n_{2}\right)}
\end{aligned}
$$

The expected votes of candidate $j$ of party $P$ when this candidate faces candidates $s=1,2$ of the competing party in the general election in jurisdictions 1 and 2, are correspondingly, given by:

$$
\begin{aligned}
& \sum_{h=1}^{n_{1}} \frac{\partial \varepsilon_{J P s h 1}}{\partial G_{j P c}}=\frac{\sum_{h=1}^{n_{1}} \alpha_{h 1}}{G_{j P c}^{*}}+k_{2} \frac{\sum_{h=1}^{n_{1}} \alpha_{h 1}}{G_{j P c}^{*}}-\frac{2 n_{1} q}{\left(n_{1}+n_{2}\right)} \text { for } s=\{1,2\} \\
& \sum_{h=1}^{n_{2}} \frac{\partial \varepsilon_{J P s h 2}}{\partial G_{j P c}}=\frac{\sum_{h=1}^{n_{2}} \alpha_{h 2}}{G_{j P c}^{*}}+k_{1} \frac{\sum_{h=1}^{n_{2}} \alpha_{h 2}}{G_{j P c}^{*}}-\frac{2 n_{2} q}{\left(n_{1}+n_{2}\right)} \text { for } s=\{1,2\}
\end{aligned}
$$

From condition (A.39), the expression $\sum_{i=1}^{2} \beta_{j P 0 i}\left(\sum_{h=1}^{n_{i}} \frac{\partial \varepsilon_{j P 0 h i}}{\partial G_{j P c}}\right)$ can be stated as follows:

$$
\begin{gathered}
\sum_{i=1}^{2} \beta_{j P 0 i}\left(\sum_{h=1}^{m_{i}} \frac{\partial \varepsilon_{j P 0 h i}}{\partial G_{j P c}}\right)= \\
\beta_{j P 01}\left(\frac{\sum_{h=1}^{m_{1}} \alpha_{P h 1}}{G_{j P c}^{*}}+k_{2} \frac{\sum_{h=1}^{m_{1}} \alpha_{P h 1}}{G_{j P c}^{*}}\right)+ \\
\beta_{j P 02}\left(\frac{\sum_{h=1}^{m_{2}} \alpha_{P h 2}}{G_{j P c}^{*}}+k_{1} \frac{\sum_{h=1}^{m_{2}} \alpha_{P h 2}}{G_{j P c}^{*}}\right)-\frac{2\left(\beta_{j P 01} m_{1}+\beta_{j P 02} m_{2}\right) q}{\left(n_{1}+n_{2}\right)}
\end{gathered}
$$

And from condition (A.39), the expression $\sum_{i=1}^{2} \beta_{j P s i}\left(\sum_{h=1}^{n_{i}} \frac{\partial \varepsilon_{j P s h i}}{\partial G_{j P c}}\right)$ is also equivalent to:

$$
\begin{gathered}
\sum_{i=1}^{2} \beta_{j P s i}\left(\sum_{h=1}^{n_{i}} \frac{\partial \varepsilon_{j P s h i}}{\partial G_{j P c}}\right)=\beta_{j P s 1}\left(\frac{\sum_{h=1}^{n_{1}} \alpha_{h 1}}{G_{j P c}^{*}}+k_{2} \frac{\sum_{h=1}^{n_{1}} \alpha_{h 1}}{G_{j P c}^{*}}\right) \\
+\beta_{j P s 2}\left(\frac{\sum_{h=1}^{n_{2}} \alpha_{h 2}}{G_{j P c}^{*}}+k_{1} \frac{\sum_{h=1}^{n_{2}} \alpha_{h 2}}{G_{j P c}^{*}}\right) \\
-\frac{2\left(\beta_{j P s 1} n_{1}+\beta_{j P s 2} n_{2}\right) q}{\left(n_{1}+n_{2}\right)} \text { for } s=\{1,2\}(A .45)
\end{gathered}
$$


Use expressions (A.40) to (A.45) into (A.39) to show that the first order condition $G_{j P c}^{*}>0$ satisfies the following

$$
\begin{gathered}
\frac{\partial \Phi_{j P}}{\partial \rho_{j P 0}}\left(\sum_{i=1}^{2}\left(m_{i} \operatorname{Cov}_{j P 0 i}\right)\right)+\sum_{s=1}^{2} \frac{\partial \Phi_{j P}}{\partial \rho_{j P s}}\left(\sum_{i=1}^{2} n_{i} \operatorname{Cov}_{j P s i}\right) \\
+\beta_{j P 01}\left(\frac{\sum_{h=1}^{m_{1}} \alpha_{P h 1}}{G_{j P c}^{*}}+k_{2} \frac{\sum_{h=1}^{m_{1}} \alpha_{P h 1}}{G_{j P c}^{*}}\right) \\
+\beta_{j P 02}\left(\frac{\sum_{h=1}^{m_{2}} \alpha_{P h 2}}{G_{j P c}^{*}}+k_{1} \frac{\sum_{h=1}^{m_{2}} \alpha_{P h 2}}{G_{j P c}^{*}}\right)-\frac{2\left(\beta_{j P 01} m_{1}+\beta_{j P 02} m_{2}\right) q}{\left(m_{1}+m_{2}\right)} \\
+\left(\beta_{j P 11}+\beta_{j P 21}\right)\left(\frac{\sum_{h=1}^{n_{1}} \alpha_{h 1}}{G_{j P c}^{*}}+k_{2} \frac{\sum_{h=1}^{n_{1}} \alpha_{h 1}}{G_{j P c}^{*}}\right) \\
+\left(\beta_{j P 12}+\beta_{j P 22}\right)\left(\frac{\sum_{h=1}^{n_{2}} \alpha_{h 2}}{G_{j P c}^{*}}+k_{1} \frac{\sum_{h=1}^{n_{2}} \alpha_{h 2}}{G_{j P c}^{*}}\right) \\
-\frac{2\left(\left(\beta_{j P 11}+\beta_{j P 21}\right) n_{1}+\left(\beta_{j P 12}+\beta_{j P 22}\right) n_{2}\right) q}{\left(n_{1}+n_{2}\right)}=0(A .46)
\end{gathered}
$$

Define $\operatorname{Cov}_{0}\left(\frac{\partial F_{j P 0 i}}{\partial \varepsilon_{J P S i}}, \frac{\partial \varepsilon_{J P 0 i}}{\partial G_{j P c}}\right)$ as a weighted covariance of the marginal probability of the vote in the nationwide primary election of candidate $j$ of party $P, \frac{\partial F_{j P 0 i}}{\partial \varepsilon_{J P 0 i}}$, and $\frac{\partial \varepsilon_{J P 0 i}}{\partial G_{j P c}}$ is the change in the welfare of voter due to a marginal change in $G_{j P c}^{*}$. In addition, $\frac{\partial \Phi_{j P}}{\partial \rho_{j P 0}}$ is the candidate's marginal change in the probability of winning the primary election:

$$
\operatorname{Cov}_{0}\left(\frac{\partial F_{j P 0 i}}{\partial \varepsilon_{J P 0 i}}, \frac{\partial \varepsilon_{J P 0 i}}{\partial G_{j P c}}\right)=\frac{\partial \Phi_{j P}}{\partial \rho_{j P 0}} \sum_{i=1}^{2} m_{i} \operatorname{Cov}_{j P 0 i}(A .47)
$$

And $\operatorname{Cov}_{G E}$ is a weighted covariance of the marginal probability of the vote in the general election of candidate $j$ of party $P, \frac{\partial F_{j P S i}}{\partial \varepsilon_{J P S i}}$, and $\frac{\partial \varepsilon_{J P 0 i}}{\partial G_{j P C}}$ is the change in the welfare of voter due to a marginal change $G_{j P c}^{*}$. Moreover, $\frac{\partial \Phi_{j P}}{\partial \rho_{j P S}}$ is the candidate's marginal change in the probability of winning the general election, hence: 


$$
\operatorname{Cov}_{G E}\left(\frac{\partial F_{j P s i}}{\partial \varepsilon_{J P s i}}, \frac{\partial \varepsilon_{J P s i}}{\partial G_{j P c}}\right)=\sum_{s=1}^{2} \frac{\partial \Phi_{j P}}{\partial \rho_{j P s}}\left(\sum_{i=1}^{2} n_{i} \operatorname{Cov}_{j P s i}\right)
$$

Use, the former definitions in (A.47) and (A.48) and solve for the equilibrium policy $G_{j P c}^{*}$ to show:

$$
\begin{gathered}
G_{j P c}^{*}=\frac{\beta_{j P 01}\left(\sum_{h=1}^{m_{1}} \alpha_{P h 1}+k_{2} \sum_{h=1}^{m_{1}} \alpha_{P h 1}\right)+\beta_{j P 02}\left(\sum_{h=1}^{m_{1}} \alpha_{P h 2}+k_{1} \sum_{h=1}^{m_{1}} \alpha_{P h 2}\right)}{q\left(2\left(\Theta_{j P c}+\Gamma_{j P c}\right)-\frac{1}{q}\left(\operatorname{Cov}_{0}+\operatorname{Cov}_{G E}\right)\right)} \\
+\frac{\left(\beta_{j P 11}+\beta_{j P 21}\right)\left(\sum_{h=1}^{n_{1}} \alpha_{h 1}+k_{2} \sum_{h=1}^{n_{1}} \alpha_{h 1}\right)}{q\left(2\left(\Theta_{j P c}+\Gamma_{j P c}\right)-\frac{1}{q}\left(\operatorname{Cov}_{0}+\operatorname{Cov}_{G E}\right)\right)} \\
+\frac{\left(\beta_{j P 12}+\beta_{j P 22}\right)\left(\sum_{h=1}^{n_{2}} \alpha_{h 2}+k_{1} \sum_{h=1}^{n_{2}} \alpha_{h 2}\right)}{q\left(2(\Theta+\Gamma)-\frac{1}{q}\left(\operatorname{Cov}_{0}+\operatorname{Cov}_{G E}\right)\right)}(A .49)
\end{gathered}
$$

And define

$$
\Theta_{j P c}=\frac{m_{1}+m_{2}}{\left(\beta_{j P 01} m_{1}+\beta_{j P 02} m_{2}\right)} \text { and } \Gamma_{j P c}=\frac{n_{1}+n_{2}}{\left(\beta_{j P 11}+\beta_{j P 21}\right) n_{1}+\left(\beta_{j P 12}+\beta_{j P 22}\right) n_{2}}
$$

In addition, define $G_{P 01}^{*}$ and as $G_{P 02}^{*}$ as the ideal policies of voters participating in the primary election of party $P$ in jurisdictions 1 and 2 as follows:

$$
\begin{aligned}
G_{P 01}^{*} & =\frac{\sum_{h=1}^{m_{1}} \alpha_{P h 1}+k_{2} \sum_{h=1}^{m_{1}} \alpha_{P h 1}}{q} \\
G_{P 02}^{*} & =\frac{\sum_{h=1}^{m_{2}} \alpha_{P h 2}+k_{1} \sum_{h=1}^{m_{2}} \alpha_{P h 2}}{q}
\end{aligned}
$$

Recall that the socially optimal policies in jurisdictions 1 and 2 are, correspondingly, given by $\hat{g}_{1}^{*}$ and $\hat{g}_{2}^{*}$ with

$$
\begin{aligned}
& \hat{g}_{1}^{*}=\frac{\sum_{h=1}^{n_{1}} \alpha_{h 1}+k_{2} \sum_{h=1}^{n_{1}} \alpha_{h 1}}{q} \\
& \hat{g}_{2}^{*}=\frac{\sum_{h=1}^{n_{2}} \alpha_{h 2}+k_{1} \sum_{h=1}^{n_{2}} \alpha_{h 2}}{q}
\end{aligned}
$$

Use (A.50) to (A.54) into (A.49) to express the equilibrium condition $G_{j P c}^{*}$ as follows 


$$
\begin{gathered}
G_{j P c}^{*}=\frac{\beta_{j P 01} G_{P 01}^{*}+\beta_{j P 02} G_{P 02}^{*}}{2\left(\Theta_{j P c}+\Gamma_{j P c}\right)-\frac{1}{q}\left(\operatorname{Cov}_{0}+\operatorname{Cov}_{G E}\right)} \\
+\frac{\left(\beta_{j P 11}+\beta_{j P 21}\right) \hat{g}_{1}^{*}+\left(\beta_{j P 12}+\beta_{j P 22}\right) \hat{g}_{2}^{*}}{2\left(\Theta_{j P c}+\Gamma_{j P c}\right)-\frac{1}{q}\left(\operatorname{Cov}_{0}+\operatorname{Cov}_{G E}\right)}(A
\end{gathered}
$$

For further simplification, define

$$
\begin{gathered}
W_{j P 0 i}=\beta_{j P 0 i}>0(A .56) \\
W_{j P 1}=\beta_{j P 11}+\beta_{j P 21}>0(A .57) \\
W_{j P 2}=\beta_{j P 12}+\beta_{j P 22}>0(A .58)
\end{gathered}
$$

Use (A.56) to (A.58) to state the equilibrium spending policy in jurisdictions 1 and 2 as follows:

$$
G_{j P c}^{*}=\Upsilon_{j P c}\left(W_{j P 01} G_{P 01}^{*}+W_{j P 02} G_{P 02}^{*}+W_{j P 1} \hat{g}_{1}^{*}+W_{j P 2} \hat{g}_{2}^{*}\right)(A
$$

Where

$$
\Upsilon_{j P c}=\frac{1}{2\left(\Theta_{j P c}+\Gamma_{j P c}\right)-\frac{\operatorname{Cov}_{0}+\operatorname{Cov}_{G E}}{q}}
$$

Definition 4. The equilibrium for an economy with primary and general elections and democratic decentralization is constituted as follows:

In the first stage, candidates $j=\{1,2\}$ of party $P=\{A, B\}$ announce policy platforms in jurisdiction $i, G_{j P i}^{*}$ where

$$
G_{j P i}^{*} \in \operatorname{argmax} \Phi_{j P i}
$$

Where $\Phi_{j P i}$ is the joint cumulative probability that candidate $j$ of party $P$ wins the primary and general local elections of jurisdiction $i$.

In the second stage of the game, in each jurisdiction, Nature selects the distribution of qualified voters given by $\left\{\alpha_{A 1 i}, \alpha_{A 2 i} \ldots \ldots . \alpha_{A m_{i}}\right\}$ and $\left\{\alpha_{B 1 i}, \alpha_{B 2 i} \ldots \ldots . \alpha_{B m_{i} i}\right\}$ for jurisdictions $i=1,2$. 
The primary election of jurisdiction i takes place and only qualified primary voters choose between policies of candidate 1 and candidate 2 of party $P$. Denote $G_{1 P i}^{*}$ as the policy of candidate 1 of party $P$ in jurisdiction $i$ and $G_{2 P i}^{*}$ as the corresponding policy of candidate 2 of party $P$ in jurisdiction $i$.

Thus, qualified primary voters with preference $\alpha_{\text {Phi }}$ for $h=1,2 \ldots m_{i}$ vote for candidate 1 of party $P$ in jurisdiction $i$ if ${ }^{29}$

$$
\Psi_{h i}\left(\alpha_{P h i}\right)=\left\{v_{h i}\left(\alpha_{P h i}, G_{1 P i}^{*}\right)-\tau_{1 P i}+\sigma_{1 P h i}\right\}-\left\{v_{h i}\left(\alpha_{P h i}, G_{2 P i}^{*}\right)-\tau_{2 P i}+\sigma_{2 P h i}\right\} \geq 0
$$

Otherwise voters vote for candidate 2 of party $P$.

Define $\boldsymbol{\Omega}_{\boldsymbol{P 0 i}}$ as a non-decreasing cumulative distribution of the sequence $\left\{\Psi_{h i}\left(\alpha_{P h i}\right)\right\}_{\forall h, \forall i}$, hence $\boldsymbol{\Omega}_{\boldsymbol{P 0} i} \in[\mathbf{0}, \mathbf{1}]$. In the third stage, if $\boldsymbol{\Omega}_{\boldsymbol{P 0 i}}\left(\forall \alpha_{h i}: \Psi_{h i}\left(\alpha_{P h i}\right) \geq 0\right)>\frac{1}{2}$ then candidate 1 of party $P$ is nominated by majority of the votes in the primary and the party's platform in jurisdiction $i, G_{P i}^{*}$, takes the value of $G_{P i}^{*}=G_{1 P i}^{*}$. Otherwise, candidate 2 is nominated and the party's platform takes the value $G_{P i}^{*}=G_{2 P i}^{*}$.

In the fourth stage, the nationwide general election takes place and voters vote from the set of nominated candidates in each party. Parties $A$ and $B$ postulate policies, $G_{A i}^{*}$ and $G_{B i}^{*}$ in jurisdiction $i$. Hence voters with preference for local public goods $\alpha_{h i}$ for $h=1,2 \ldots n_{i}$ in jurisdiction $i$ votes for party $A$ if

$$
\Psi_{h i}\left(\alpha_{h i}\right)=\left\{v_{h i}\left(\alpha_{h i}, G_{A i}^{*}\right)-\tau_{A i}+\sigma_{A h i}\right\}-\left\{v_{h i}\left(\alpha_{h i}, G_{B i}^{*}\right)-\tau_{B i}+\sigma_{B h i}\right\} \geq 0
$$

Otherwise they vote for party $B$.

Define $\boldsymbol{\Omega}_{\boldsymbol{i}}$ as a non-decreasing cumulative distribution of the sequence $\left\{\Psi_{h i}\left(\alpha_{h i}\right)\right\}_{\forall h, \forall i}$, hence $\boldsymbol{\Omega}_{\boldsymbol{i}} \in[\mathbf{0}, \mathbf{1}]$. In the fifth stage, if $\boldsymbol{\Omega}_{\boldsymbol{i}}\left(\forall \alpha_{h i}: \Psi_{h i}\left(\alpha_{h i}\right) \geq 0\right)>\frac{1}{2}$ then party $A$ wins by majority and implements $G_{A i}^{*}$. Otherwise, party $B$ wins and implements $G_{B i}^{*}$

\footnotetext{
${ }^{29}$ In the net payoff $\Psi_{h i}\left(\alpha_{P h i}\right)$ of voter with preference $\alpha_{P h i}$, the expression $\sigma_{1 P h i}$ refers to a stochastic factor of candidate 1 of party $\mathrm{P}$ that is specific to voter $h$ in district $i$. A similar interpretation is given to $\sigma_{2 P h i}$.
} 
Lemma 4. For economies with non-integrated parties and democratic decentralization, a candidate $j$ of party $P$ in jurisdiction $i$ proposes a local public good $G_{j P i}^{*}$ satisfying the following:

$$
G_{j P i}^{*}=\Upsilon_{j P i}\left(W_{j P 01} G_{0 i}^{*}+W_{j P i} G_{i}^{*}\right)(
$$

Where $\Upsilon_{j P i}$ is a proportionality parameter given by:

$$
\Upsilon_{j P i}=\frac{1}{\left(\Theta_{j P i}+\Gamma_{j P i}\right)-\frac{\psi_{j P 0 i}+\psi_{j p G E i}}{q}}
$$

And

$$
\Theta_{j P i}=\frac{\beta_{j P 0 i} m_{i}}{n_{i}} \text { and } \Gamma_{j P i}=\beta_{j P 1 i}+\beta_{j P 2 i}
$$

Moreover, $\psi_{j P O i}$ is a weighted covariance of the change in the marginal probability of the vote of candidate $j$ of party $P$ in the local primary election of jurisdiction $i, \frac{\partial F_{j P 0 i}}{\partial \varepsilon_{J P 0 i}}$, and $\frac{\partial \varepsilon_{j P 0 i}}{\partial G_{j P i}}$ which is the change in welfare of each individual voter due to a marginal change in $G_{j P i}^{*}$. In addition, $\frac{\partial \Phi_{j P} i}{\partial \rho_{j P 0}}$ is the candidate's change in the marginal probability of winning the primary election in jurisdiction $i$ :

$$
\psi_{j p 0 i}\left(\frac{\partial F_{j P 0 i}}{\partial \varepsilon_{J P 0 i}}, \frac{\partial \varepsilon_{J P 0 i}}{\partial G_{j P i}}\right)=\frac{\partial \Phi_{j P i}}{\partial \rho_{j P 0 i}} m_{i} \operatorname{Cov}_{j P 0 i}
$$

Where $\operatorname{Cov}_{j P 0 i}$ is the covariance of the marginal probability of voters in jurisdiction ifor candidate $j$ of party $P$ in the primary and the change in welfare of each resident of jurisdiction $i$ due to a marginal change in $G_{j P c}^{*}$

And $\psi_{\text {jpGEi }}$ is a weighted covariance of the change in the marginal probability of the vote of candidate $j$ of party $P$ in the local general election of jurisdiction $i, \frac{\partial F_{j P s i}}{\partial \varepsilon_{j P s i}}$, and $\frac{\partial \varepsilon_{J P s i}}{\partial G_{j P s i}}$ is the change in the welfare of voter due to a change in $G_{j P c}^{*}$. Moreover, $\frac{\partial \Phi_{j P i}}{\partial \rho_{j P s i}}$ is the candidate's change in the marginal probability of winning the general local election in jurisdiction $i$, hence

$$
\psi_{j p G E i}\left(\frac{\partial F_{j P s i}}{\partial \varepsilon_{J P s i}}, \frac{\partial \varepsilon_{J P s i}}{\partial G_{j P i}}\right)=\sum_{s=1}^{2} \frac{\partial \Phi_{j P}}{\partial \rho_{j P s i}} n_{i} \operatorname{Cov}_{j P s i}
$$


Where $\operatorname{Cov}_{j P s i}$ is the covariance of the marginal probability of voters in jurisdiction ifor candidate $j$ of party $P$ in the general election in the electoral state $s=1,2$ and the change in welfare of each resident of jurisdiction i due to a marginal change in $G_{j P c}^{*}$

\section{Proof}

In a federation with party non-integration, the spending policy of candidate $j$ of party $P$ in district $i$ is

$$
G_{j P i}^{*} \in \operatorname{argmax} \Phi_{j P i}(A .66)
$$

Where $\Phi_{j P i}$ is the joint probability of candidate $j$ of party $P$ of winning the local primary and general elections in jurisdiction $i$ The first order condition of the candidate's problem is

$$
\frac{\partial \Phi_{j P i}}{\partial \rho_{j P o i}} \frac{\partial \rho_{j P o i}}{\partial G_{j P i}^{*}}+\frac{\partial \Phi_{j P i}}{\partial \rho_{j P 1 i}} \frac{\partial \rho_{P 1 i}}{\partial G_{j P i}^{*}}+\frac{\partial \Phi_{j P i}}{\partial \rho_{j P 2 i}} \frac{\partial \rho_{j P 2 i}}{\partial G_{j P i}^{*}}=0 \forall G_{j P i}^{*}>0(A .67)
$$

Where $\frac{\partial \Phi_{j P i}}{\partial \rho_{j P s i}} \frac{\partial \rho_{j P s i}}{\partial G_{j P i}^{*}}$ for $s=0,1,2$ is the marginal change in the candidate's plurality in the local primary (for $s=0$ ) and the general election (for $s=1,2$ ) of jurisdiction $i$ due to a marginal change in $G_{j P i}^{*}$.

Nature selects the distribution of qualified voters given by $\left\{\alpha_{A 1 i}, \alpha_{A 2 i} \ldots \ldots \ldots \alpha_{A m_{i} i}\right\}$ and $\left\{\alpha_{B 1 i}, \alpha_{B 2 i} \ldots \ldots \ldots \alpha_{B m_{i} i}\right\}$ for jurisdictions $i=1,2$. Recall that in the local primary election $h=$ $1,2 \ldots m_{i} \leq n_{i}$ where $m_{i}$ is the number of voters voting in the primary election of jurisdiction $i$, and $n_{i}$ is the number of residents of jurisdiction $i$. In a blanket primary election $m_{i}=n_{i}$ and in a closed primary election $m_{i}<n_{i}$.

By definition the plurality of each party and the sum of expected votes in the local primary implies

$$
\frac{\partial \rho_{j P s i}}{G_{j P i}}=2 \frac{\partial \phi_{j P 0 i}}{\partial G_{j P i}}=2 \sum_{h=1}^{m_{i}} \frac{\partial F_{j P 0 h i}\left(\varepsilon_{j P 0 h i}\right)}{\partial G_{j P i}}
$$

Where $F_{j P 0 h i}\left(\varepsilon_{j P 0 h i}\right)$ is the probability of candidate $j$ of party $P$ in the primary election, $s=0$, that voter with preference $\alpha_{P h i}$ votes for her(him) in jurisdiction $i$. 
And in the general local election of jurisdiction $i$ the relative plurality of candidate $j$ of party $P$ is given by:

$$
\frac{\partial \rho_{j P s i}}{G_{j P i}}=2 \frac{\partial \phi_{j P s i}}{\partial G_{j P i}}=2 \sum_{h=1}^{n_{i}} \frac{\partial F_{j P s h i}\left(\varepsilon_{j P s h i}\right)}{\partial G_{j P i}} \text { for } s=\{1,2\}
$$

Use (A.68) and (A.69) to state the first order condition of the candidate's problem of policy design as follows:

$$
\begin{gathered}
\frac{\partial \Phi_{j P i}}{\partial \rho_{j P o i}}\left(\sum_{h=1}^{m_{i}} \frac{\partial F_{j P 0 h i}\left(\varepsilon_{j P 0 h i}\right)}{\partial G_{j P i}}\right)+\frac{\partial \Phi_{j P i}}{\partial \rho_{j P 1 i}}\left(\sum_{h=1}^{n_{i}} \frac{\partial F_{j P 1 h i}\left(\varepsilon_{j P 1 h i}\right)}{\partial G_{j P i}}\right) \\
+\frac{\partial \Phi_{j P i}}{\partial \rho_{j P 2 i}}\left(\sum_{h=1}^{n_{i}} \frac{\partial F_{j P 2 h i}\left(\varepsilon_{j P 2 h i}\right)}{\partial G_{j P i}}\right)=0 \forall G_{j P i}^{*}>0(A .70)
\end{gathered}
$$

Express $\frac{\partial F_{j P s h i}\left(\varepsilon_{j P s h i}\right)}{\partial G_{j P i}}$ for $s=\{0,1,2\}$ as follows:

$$
\frac{\partial F_{j P s h i}\left(\varepsilon_{j P s h i}\right)}{\partial G_{j P i}}=\frac{\partial F_{j P s h i}}{\partial \varepsilon_{j P s h i}} \frac{\partial \varepsilon_{j P s h i}}{\partial G_{j P i}}
$$

From the definition of the covariance between $A$ and $B, \operatorname{Cov}(A, B)=E[A B]-E[A] E[B]$. Redefine $A=\frac{\partial F_{j P s h i}}{\partial \varepsilon_{j P s h i}}$ and $B=\frac{\partial \varepsilon_{j P s h i}}{\partial G_{j P i}}$ to express the following

$$
\begin{gathered}
\sum_{h=1}^{m_{i}} \frac{\partial F_{j P 0 h i}}{\partial \varepsilon_{j P 0 h i}} \frac{\partial \varepsilon_{j P 0 h i}}{\partial G_{j P i}}=m_{i} \operatorname{Cov}_{j P 0 i}\left(\frac{\partial F_{j P 0 h i}}{\partial \varepsilon_{j P 0 h i}}, \frac{\partial \varepsilon_{j P 0 h i}}{\partial G_{j P i}}\right) \\
+\left(\sum_{h=1}^{m_{i}} \frac{\partial F_{j P 0 h i}}{\partial \varepsilon_{j P 0 h i}}\right)\left(\sum_{h=1}^{m_{i}} \frac{\partial \varepsilon_{j P 0 h i}}{\partial G_{j P i}}\right)(A .72)
\end{gathered}
$$

And for states $s=1,2$ in the general election

$$
\begin{gathered}
\sum_{h=1}^{n_{i}} \frac{\partial F_{j P s h i}}{\partial \varepsilon_{j P s h i}} \frac{\partial \varepsilon_{j P s h i}}{\partial G_{j P i}}=n_{i} \operatorname{Cov}_{j P s i}\left(\frac{\partial F_{j P s h i}}{\partial \varepsilon_{j P s h i}}, \frac{\partial \varepsilon_{j P s h i}}{\partial G_{j P i}}\right) \\
+\left(\sum_{h=1}^{n_{i}} \frac{\partial F_{j P s h i}}{\partial \varepsilon_{j P s h i}}\right)\left(\sum_{h=1}^{n_{i}} \frac{\partial \varepsilon_{j P s h i}}{\partial G_{j P i}}\right)(A .73)
\end{gathered}
$$

Use (A.72) and (A.73) to state the first order condition of the candidate $j$ of party $P$ as follows: 


$$
\begin{array}{r}
\frac{\partial \Phi_{j P i}}{\partial \rho_{j P o i}}\left(m_{i} \operatorname{Cov}_{j P 0 i}\left(\frac{\partial F_{j P 0 h i}}{\partial \varepsilon_{j P 0 h i}}, \frac{\partial \varepsilon_{j P 0 h i}}{\partial G_{j P i}}\right)+\left(\sum_{h=1}^{m_{i}} \frac{\partial F_{j P 0 h i}}{\partial \varepsilon_{j P 0 h i}}\right)\left(\sum_{h=1}^{m_{i}} \frac{\partial \varepsilon_{j P 0 h i}}{\partial G_{j P i}}\right)\right) \\
+\frac{\partial \Phi_{j P i}}{\partial \rho_{j P 1 i}}\left(n_{i} \operatorname{Cov}_{j P 1 i}\left(\frac{\partial F_{j P 1 h i}}{\partial \varepsilon_{j P 1 h i}}, \frac{\partial \varepsilon_{j P 1 h i}}{\partial G_{j P i}}\right)+\left(\sum_{h=1}^{n_{i}} \frac{\partial F_{j P 1 h i}}{\partial \varepsilon_{j P 1 h i}}\right)\left(\sum_{h=1}^{n_{i}} \frac{\partial \varepsilon_{j P 1 h i}}{\partial G_{j P i}}\right)\right) \\
+\frac{\partial \Phi_{j P i}}{\partial \rho_{j P 2 i}}\left(n_{i} \operatorname{Cov}_{j P 2 i}\left(\frac{\partial F_{j P 2 h i}}{\partial \varepsilon_{j P 2 h i}}, \frac{\partial \varepsilon_{j P 2 h i}}{\partial G_{j P i}}\right)+\left(\sum_{h=1}^{n_{i}} \frac{\partial F_{j P 2 h i}}{\partial \varepsilon_{j P 2 h i}}\right)\left(\sum_{h=1}^{n_{i}} \frac{\partial \varepsilon_{j P 2 h i}}{\partial G_{j P i}}\right)\right)=0
\end{array}
$$

Let define $\beta_{j P S i}$ for $s=\{0,1,2\}$ as follows

$$
\begin{gathered}
\beta_{j P 0 i}=\frac{\partial \Phi_{j P i}}{\partial \rho_{j P 0 i}} \sum_{h=1}^{m_{i}} \frac{\partial F_{j P 0 h i}}{\partial \varepsilon_{J P 0 h i}}(A .75) \\
\beta_{j P S i}=\frac{\partial \Phi_{j P i}}{\partial \rho_{j P S i}} \sum_{h=1}^{n_{i}} \frac{\partial F_{j P S i}}{\partial \varepsilon_{j P S i}} \text { for } s=1,2(A .76)
\end{gathered}
$$

Use (A.75) and (A.76) to express the first order condition (A.74) as follows

$$
\begin{gathered}
\frac{\partial \Phi_{j P i}}{\partial \rho_{j P o i}}\left(m_{i} \operatorname{Cov}_{j P 0 i}\left(\frac{\partial F_{j P 0 h i}}{\partial \varepsilon_{j P 0 h i}}, \frac{\partial \varepsilon_{j P 0 h i}}{\partial G_{j P i}}\right)\right)+\sum_{S=1}^{2} \frac{\partial \Phi_{j P i}}{\partial \rho_{j P S i}}\left(n_{i} \operatorname{Cov}_{j P S i}\left(\frac{\partial F_{j P S h i}}{\partial \varepsilon_{j P s h i}}, \frac{\partial \varepsilon_{j P S h i}}{\partial G_{j P i}}\right)\right) \\
\beta_{j P 0 i}\left(\sum_{h=1}^{m_{i}} \frac{\partial \varepsilon_{j P 0 h i}}{\partial G_{j P i}}\right)+\beta_{j P 1 i}\left(\sum_{h=1}^{n_{i}} \frac{\partial \varepsilon_{j P 1 h i}}{\partial G_{j P i}}\right)+\beta_{j P 2 i}\left(\sum_{h=1}^{n_{i}} \frac{\partial \varepsilon_{j P 2 h i}}{\partial G_{j P i}}\right)(A .77)
\end{gathered}
$$

The expected votes of candidate $j$ of party $P$ in the primary election in jurisdictions 1 and 2 , are correspondingly:

$$
\sum_{h=1}^{m_{i}} \frac{\partial \varepsilon_{J P 0 h i}}{\partial G_{j P c}}=\frac{\sum_{h=1}^{m_{i}} \alpha_{P h i}}{G_{j P i}^{*}}-\frac{m_{i} q}{n_{i}}
$$

The expected votes of candidate $j$ of party $P$ when this candidate faces candidates $s=1,2$ of the competing party in the general election in jurisdictions 1 and 2 are correspondingly given by:

$$
\sum_{h=1}^{n_{i}} \frac{\partial \varepsilon_{J P s h i}}{\partial G_{j P c}}=\frac{\sum_{h=1}^{n_{i}} \alpha_{h i}}{G_{j P i}^{*}}-q \text { for } s=\{1,2\}
$$

Therefore, the following is satisfied: 


$$
\beta_{j P 0 i}\left(\sum_{h=1}^{m_{i}} \frac{\partial \varepsilon_{J P 0 h i}}{\partial G_{j P i}}\right)=\beta_{j P 0 i}\left(\frac{\sum_{h=1}^{m_{i}} \alpha_{P h i}}{G_{j P i}^{*}}-\frac{m_{i} q}{n_{i}}\right)
$$

And

$$
\beta_{j P s i}\left(\sum_{h=1}^{n_{i}} \frac{\partial \varepsilon_{j P 1 h i}}{\partial G_{j P i}}\right)=\beta_{j P s i}\left(\frac{\sum_{h=1}^{n_{i}} \alpha_{h i}}{G_{j P i}^{*}}-q\right) \text { for } s=\{1,2\}
$$

Use expressions (A.80) to (A.81) into (A.77) to show that the first order condition $G_{j P i}^{*}>0$ satisfies the following

$$
\begin{gathered}
\frac{\partial \Phi_{j P i}}{\partial \rho_{j P o i}}\left(m_{i} \operatorname{Cov}_{j P 0 i}\left(\frac{\partial F_{j P 0 h i}}{\partial \varepsilon_{j P 0 h i}}, \frac{\partial \varepsilon_{j P 0 h i}}{\partial G_{j P i}}\right)\right)+\sum_{S=1}^{2} \frac{\partial \Phi_{j P i}}{\partial \rho_{j P s i}}\left(n_{i} \operatorname{Cov}_{j P s i}\left(\frac{\partial F_{j P s h i}}{\partial \varepsilon_{j P s h i}}, \frac{\partial \varepsilon_{j P s h i}}{\partial G_{j P i}}\right)\right) \\
\beta_{j P 0 i}\left(\frac{\sum_{h=1}^{m_{i}} \alpha_{h i}}{G_{j P i}^{*}}-\frac{m_{i} q}{n_{i}}\right) \\
+\left(\beta_{j P 1 i}+\beta_{j P 2 i}\right)\left(\frac{\sum_{h=1}^{n_{i}} \alpha_{h i}}{G_{j P i}^{*}}-2 q\right)=0(A .82)
\end{gathered}
$$

The equilibrium policy $G_{j P c}^{*}$ can be expressed as follows:

$$
G_{j P c}^{*}=\frac{\beta_{j P 01}\left(\sum_{h=1}^{m_{i}} \alpha_{h i}\right)+\left(\beta_{j P 1 i}+\beta_{j P 2 i}\right)\left(\sum_{h=1}^{n_{i}} \alpha_{h i}\right)}{p\left(\left(\Theta_{j p i}+\Gamma_{j P i}\right)-\frac{1}{q}\left(\frac{\partial \Phi_{j P i}}{\partial \rho_{j P o i}}\left(m_{i} \operatorname{Cov}_{j P 0 i}\right)+\sum_{S=1}^{2} \frac{\partial \Phi_{j P i}}{\partial \rho_{j P s i}}\left(n_{i} \operatorname{Cov}_{j P s i}\right)\right)\right)}
$$

Define $\Theta_{j P i}$ and $\Gamma_{j P i}$ as follows:

$$
\Theta_{j P i}=\frac{\beta_{j P 0 i} m_{i}}{n_{i}} \text { and } \Gamma_{j P i}=\beta_{j P 1 i}+\beta_{j P 2 i}(A .83)
$$

In addition, define $G_{0 i}^{*}$ as the ideal policy of primary voters in jurisdiction $i$ :

$$
G_{0 i}^{*}=\frac{\sum_{h=1}^{m_{i}} \alpha_{h i}}{q}
$$

Moreover, define $G_{i}^{*}$ as the ideal policy of voters participating in the general election (that is all residents) in jurisdiction $i$ as follows:

$$
G_{i}^{*}=\frac{\sum_{h=1}^{n_{i}} \alpha_{h i}}{q}
$$


For further simplification, define

$$
\begin{gathered}
W_{j P 0 i}=\beta_{j P 0 i}>0(A .86) \\
W_{j P i}=\beta_{j P 1 i}+\beta_{j P 2 i}>0(A .87)
\end{gathered}
$$

In addition, define, $\psi_{j P 0 i}$ as a weighted covariance of the marginal probability of the vote of candidate $j$ of party $P$ in the local primary election of jurisdiction $i, \frac{\partial F_{j P 0 i}}{\partial \varepsilon_{j P 0 i}}$, and $\frac{\partial \varepsilon_{j P 0 i}}{\partial G_{j P i}}$ which is the change in welfare of each individual voter due to a marginal change in $G_{j P i}^{*}$. In addition, $\frac{\partial \Phi_{j P} i}{\partial \rho_{j P 0}}$ is the candidate's change in the marginal probability of winning the primary election in jurisdiction $i$ :

$$
\psi_{j p 0 i}\left(\frac{\partial F_{j P 0 h i}}{\partial \varepsilon_{J P 0 h i}}, \frac{\partial \varepsilon_{J P 0 h i}}{\partial G_{j P i}}\right)=\frac{\partial \Phi_{j P i}}{\partial \rho_{j P 0 i}} m_{i} \operatorname{Cov}_{j P 0 i}(A
$$

And define $\psi_{j p G E i}$ as a weighted covariance of the change in the probability of the vote of candidate $j$ of party $P$ in the local general election of jurisdiction $i, \frac{\partial F_{j P s h i}}{\partial \varepsilon_{J P S h i}}$, and $\frac{\partial \varepsilon_{J P s h i}}{\partial G_{j P s i}}$ is the change in the welfare of voter due to a marginal change $G_{j P c}^{*}$. Moreover, $\frac{\partial \Phi_{j P i}}{\partial \rho_{j P S i}}$ is the candidate's change in the marginal probability of winning the general local election in jurisdiction $i$, hence

$$
\psi_{j p G E i}\left(\frac{\partial F_{j P s h i}}{\partial \varepsilon_{J P S h i}}, \frac{\partial \varepsilon_{J P S h i}}{\partial G_{j P i}}\right)=\sum_{s=1}^{2} \frac{\partial \Phi_{j P}}{\partial \rho_{j P S i}} n_{i} \operatorname{Cov}_{j P s i}
$$

Use (A.84) to (A.89) to state the equilibrium spending policy in jurisdiction $i$ is:

$$
G_{j P i}^{*}=\Upsilon_{j P i}\left(W_{j P 01} G_{0 i}^{*}+W_{j P i} G_{i}^{*}\right)(A .90)
$$

Where

$$
\Upsilon_{j P i}=\frac{1}{\left(\Theta_{i}+\Gamma_{i}\right)-\frac{\psi_{j p 0 i}+\psi_{j p G E i}}{q}}
$$

Lemma 5. For economies with non-integrated parties with blanket primaries and democratic centralization $G_{j P c}^{*}$ is given by: 


$$
G_{j P c}^{*}=\frac{\hat{g}_{1}^{*}+\hat{g}_{2}^{*}}{2}
$$

Where $\hat{g}_{1}^{*}, \hat{g}_{2}^{*}$ represent the Pareto efficient local public goods that maximize the social welfare gains from inter-regional policy differentiation.

For economies with non-integrated parties, blanket primaries and democratic decentralization $G_{j P i}^{*}=G_{i}^{*}$ which is the ideal policy of residents of jurisdiction $i$ and it is given by:

$$
G_{j P i}^{*}=\frac{\sum_{h=1}^{n_{i}} \alpha_{h i}}{q}=\frac{\alpha_{i}}{q} \text { for } i=1,2
$$

\section{Proof}

For an economy with party non-integration and a single government, candidate $j$ of party $P$ designs public spending to maximize $\Phi_{j P}$ subject to $G_{j P 1}=G_{j P 2}=G_{j P c}$. We impose the equality restriction in the objective function. The first order condition for the party's problem is

$$
\frac{\partial \Phi_{j P}}{\partial \rho_{j P 0}} \frac{\partial \rho_{j P 0}}{\partial G_{j P c}}+\frac{\partial \Phi_{j P}}{\partial \rho_{j P 1}} \frac{\partial \rho_{j P 1}}{\partial G_{j P c}}+\frac{\partial \Phi_{j P}}{\partial \rho_{j P 2}} \frac{\partial \rho_{j P 2}}{\partial G_{j P c}}=0 \forall G_{j P C}^{*}>0(A .94)
$$

Where $\frac{\partial \Phi_{j P}}{\partial \rho_{j P s}} \frac{\partial \rho_{j P s}}{\partial G_{j P c}}$ for $s=0,1,2$ is the marginal change in the candidate's plurality in the primary and the general election due to a marginal change in $G_{j P c}^{*}$.

With blanket primaries the distribution of primary and general election voters is the same. Therefore, all candidates of all parties converge in selecting $G_{j P c}^{*} \in \operatorname{argmax} \Phi_{j P}$ since they maximize a continuous and strictly concave probability function of winning the joint primary and general election based on a common system of beliefs and strategy policy set. Therefore,

$$
\frac{\partial \Phi_{j P}}{\partial \rho_{j P 0}} \frac{\partial \rho_{j P 0}}{\partial G_{j P c}}=\frac{\partial \Phi_{j P}}{\partial \rho_{j P 1}} \frac{\partial \rho_{j P 1}}{\partial G_{j P c}}=\frac{\partial \Phi_{j P}}{\partial \rho_{j P 2}} \frac{\partial \rho_{j P 2}}{\partial G_{j P c}}
$$

Let's define

$$
\frac{\partial \Phi_{j P}}{\partial \rho_{j P S}} \frac{\partial \rho_{j P s}}{\partial G_{j P c}}=\frac{\partial \Phi_{j P}}{\partial \rho_{j P}} \frac{\partial \rho_{j P}}{\partial G_{j P c}} \text { for } s=0,1,2(\text { A.96) }
$$

Which in turn implies that the first order condition of the problem of policy design can be written as follows: 


$$
\frac{\partial \rho_{j P}}{G_{j P c}}=2 \frac{\partial \phi_{j P}}{\partial G_{j P c}}=0 \Rightarrow\left(\frac{\partial \phi_{j P 1}}{\partial G_{j P c}}+\frac{\partial \phi_{j P 2}}{\partial G_{j P c}}\right)=0
$$

Where $\frac{\partial \phi_{j P 1}}{\partial G_{j P c}}$ and $\frac{\partial \phi_{j P 2}}{\partial G_{j P c}}$ correspond to the expected votes in jurisdictions 1 and 2 that policy $G_{j P c}^{*}$ can be delivered in the primary and general nationwide elections.

The expected votes of any candidate $j$ of any party $P$ in the primary and general election in jurisdiction $i$ can be stated as follows

$$
\frac{\partial \phi_{j P i}}{\partial G_{j P c}}=\sum_{h=1}^{n_{i}} \frac{\partial F_{j P h i}}{\partial \varepsilon_{j P h i}} \frac{\partial \varepsilon_{j P h i}}{\partial G_{j P c}} \text { for } i=1,2(A .98)
$$

The convergence of the candidates' policies implies $\frac{\partial F_{j P i}}{\partial \varepsilon_{j P i}}$ is a constant. Hence the first order condition is given by:

$$
\frac{\partial \phi_{j P 1}}{\partial G_{j P c}}+\frac{\partial \phi_{j P 2}}{\partial G_{j P c}}=\sum_{h=1}^{n_{1}} \frac{\partial \varepsilon_{j P h}}{\partial G_{j P c}}+\sum_{h=1}^{n_{2}} \frac{\partial \varepsilon_{j P h}}{\partial G_{j P c}}=0
$$

In addition, it follows that:

$$
\begin{aligned}
& \sum_{h=1}^{n_{1}} \frac{\partial \varepsilon_{J P h}}{\partial G_{j P c}}=\frac{\sum_{h=1}^{n_{1}} \alpha_{h 1}}{G_{j P c}^{*}}+k_{2} \frac{\sum_{h=1}^{n_{1}} \alpha_{h 1}}{G_{j P c}^{*}}-\frac{2 n_{1} q}{\left(n_{1}+n_{2}\right)} \\
& \sum_{h=1}^{n_{2}} \frac{\partial \varepsilon_{J P h}}{\partial G_{j P c}}=\frac{\sum_{h=1}^{n_{2}} \alpha_{h 2}}{G_{j P c}^{*}}+k_{1} \frac{\sum_{h=1}^{n_{2}} \alpha_{h 2}}{G_{j P c}^{*}}-\frac{2 n_{2} q}{\left(n_{1}+n_{2}\right)}
\end{aligned}
$$

The equilibrium policy $G_{j P c}^{*}$ can be expressed as follows:

$$
G_{j P c}^{*}=\frac{\left(\sum_{h=1}^{n_{1}} \alpha_{h 1}+k_{2} \sum_{h=1}^{n_{2}} \alpha_{h 1}\right)+\left(\sum_{h=1}^{n_{2}} \alpha_{h 2}+k_{1} \sum_{h=1}^{n_{1}} \alpha_{h 2}\right)}{2 q}
$$

Recall $\alpha_{1}=\sum_{h=1}^{n_{1}} \alpha_{h 1}$ is the aggregate intensity of preferences for local public goods of all residents in district 1 and $\alpha_{2}=\sum_{h=1}^{n_{2}} \alpha_{h 2}$ is the corresponding aggregate intensity of preferences of all residents of district 2 . State the equilibrium policy $G_{j P c}^{*}$ as follows:

$$
G_{j P c}^{*}=\frac{\alpha_{1}+k_{1} \alpha_{2}}{2 q}+\frac{\alpha_{2}++k_{2} \alpha_{1}}{2 q}
$$


Since, $\hat{g}_{1}^{*}=\frac{\alpha_{1}+k_{1} \alpha_{2}}{p}$ and $\hat{g}_{2}^{*}=\frac{\alpha_{2}+k_{2} \alpha_{1}}{p}, G_{j P c}^{*}$ can also be expressed as follows:

$$
G_{j P c}^{*}=\frac{\hat{g}^{* i}+\hat{g}^{*-i}}{2}(A .104)
$$

\section{Blanket primaries and democratic decentralization}

For an economy with party non-integration and democratic decentralization, candidate $j$ of party $P$ in jurisdiction $i$ designs public spending to maximize $\Phi_{j P i}$. The first order condition for the candidate's problem is

$$
\frac{\partial \Phi_{j P i}}{\partial \rho_{j P o i}} \frac{\partial \rho_{j P o i}}{\partial G_{j P i}^{*}}+\frac{\partial \Phi_{j P i}}{\partial \rho_{j P 1 i}} \frac{\partial \rho_{P 1 i}}{\partial G_{j P i}^{*}}+\frac{\partial \Phi_{j P i}}{\partial \rho_{j P 2 i}} \frac{\partial \rho_{j P 2 i}}{\partial G_{j P i}^{*}}=0 \forall G_{j P i}^{*}>0(A
$$

With blanket primaries the distribution of primary and general election voters is the same and all candidates of all parties converge in selecting $G_{j P i}^{*} \in \operatorname{argmax} \Phi_{j P i}$ since they maximize a continuous and strictly concave probability function of winning the joint primary and general election based on a common system of beliefs and strategy policy set. Therefore,

$$
\frac{\partial \Phi_{j P i}}{\partial \rho_{j P o i}} \frac{\partial \rho_{j P o i}}{\partial G_{j P i}^{*}}=\frac{\partial \Phi_{j P i}}{\partial \rho_{j P 1 i}} \frac{\partial \rho_{P 1 i}}{\partial G_{j P i}^{*}}=\frac{\partial \Phi_{j P i}}{\partial \rho_{j P 2 i}} \frac{\partial \rho_{j P 2 i}}{\partial G_{j P i}^{*}}
$$

Therefore, the first order condition is equivalent to:

$$
\frac{\partial \phi_{j P i}}{\partial G_{j P i}}=\sum_{h=1}^{n_{i}} \frac{\partial F_{j P h i}}{\partial \varepsilon_{j P h i}} \frac{\partial \varepsilon_{j P h i}}{\partial G_{j P i}}=0
$$

The convergence of the candidates' policies implies $\frac{\partial F_{j P i}}{\partial \varepsilon_{j P i}}$ is constant, which means:

$$
\frac{\partial \phi_{j P i}}{\partial G_{j P i}}=\sum_{h=1}^{n_{i}} \frac{\partial \varepsilon_{j P h i}}{\partial G_{j P i}}=\frac{\sum_{h=1}^{n_{1}} \alpha_{h 1}}{G_{j P i}^{*}}-q=0
$$

Therefore, for economies with non-integrated parties, blanket primaries, and democratic decentralization, $G_{j P i}^{*}$ is given by:

$$
G_{j P i}^{*}=\frac{\sum_{h=1}^{n_{i}} \alpha_{h i}}{q} \forall i=1,2(A .109)
$$


Theorem 2. In democracies with non-integrated parties and blanket primaries, the strong decentralization theorem does not hold but the conventional decentralization theorem holds.

\section{Proof}

The equilibrium provision of local public goods for economies with party non-integration and local elections is not Pareto efficient for local public goods with spillovers. Therefore, the strong decentralization theorem does not hold.

\section{Conventional Decentralization Theorem}

Now we proceed to analyze whether the conventional decentralization theorem holds in economies with party non-integration and blanket primaries. To do so, consider the case in which local public goods do not show spillovers then $k_{1}=k_{2}=0$. Note that local spending for an economy with a nationwide primary and general elections $G_{j P c}^{*}$ is Pareto efficient and the equilibrium provision for economies with party non-integration and democratic centralization is

$$
G_{j P c}^{*}=\frac{\hat{g}_{1}^{*}+\hat{g}_{2}^{*}}{2}(A .110)
$$

where

$$
\left[\hat{g}_{1}^{*}, \hat{g}_{2}^{*}\right]=\left[\hat{g}_{1}^{*}, \hat{g}_{2}^{*}\right]=\left[\frac{\alpha_{1}}{q}, \frac{\alpha_{2}}{q}\right](
$$

By Lemma 5, for economies with non-integrated parties with blanket primaries and democratic decentralization $G_{j P i}^{*}$ is given by:

$$
G_{j P i}^{*}=\frac{\sum_{h=1}^{n_{i}} \alpha_{h i}}{q}=\frac{\alpha_{i}}{q} \text { for } i=1,2(A .112)
$$

Recall $\hat{g}_{1}^{*}, \hat{g}_{2}^{*} \in \operatorname{argmax} \operatorname{NSW}\left(g_{1}, g_{2}\right)$ where $N S W\left(g_{1}, g_{2}\right)$ is the nationwide welfare under the provision of public goods in jurisdictions 1 and 2 given by $g_{1}, g_{2}$.

By the strict concavity of $N S W\left(g_{1}, g_{2}\right)$ it is satisfied that $N S W\left(\hat{g}_{1}^{*}, \hat{g}_{2}^{*}\right)>N S W\left(g_{1}, g_{2}\right) \forall \hat{g}_{i}^{*} \neq$ $g_{i}$ for $i=1,2$. Since $G_{j P i}^{*}=\hat{g}_{i}^{*}$ for $i=1,2$ and $G_{j P c}^{*} \neq \hat{g}_{i}^{*}$ for $i=1,2$ then

$$
N S W\left(G_{j P 1}^{*}, G_{j P 2}^{*}\right)>N S W\left(G_{j P c}^{*}, G_{j P c}^{*}\right)
$$

This means that the provision of public goods under democratic decentralization $G_{j P 1}^{*}, G_{j P 2}^{*}$ is 
welfare superior than the provision under democratic centralization $G_{j P c}^{*}, G_{j P c}^{*}$, and therefore, the conventional decentralization is satisfied in economies with party non-integration and blanket primaries.

Theorem 3. The strong and the conventional decentralization theorems do not hold in democracies with non-integrated parties and closed primaries.

\section{Proof}

A candidate $j$ of party $P$ seeking to form a central government in party non-integrated regimes with closed primaries selects $G_{j P c}^{*} \in \operatorname{argmax} \Phi_{j P}$ subject to $G_{j P 1}^{*}=G_{j P 2}^{*}$ Moreover $\hat{g}_{1}^{*}, \hat{g}_{2}^{*} \in$ $\operatorname{argmax} N S W\left(g_{1}, g_{2}\right)$ where $\hat{g}_{1}^{*}, \hat{g}_{2}^{*}$ are the policies that maximize the nationwide surplus from the fiscal exchange associated with local public goods. Lemma 3 implies that $G_{j P c}^{*} \neq \hat{g}_{i}^{*}$ for $i=$ 1,2 .

Similarly, in a system of local governments with party non-integration and closed primaries, a candidate $j$ of party $P$ selects $G_{j P i}^{*} \in \operatorname{argmax} \Phi_{j P i}$ for $i=1,2$. Lemma 4 shows that, in general, $G_{j P i}^{*} \neq \hat{g}_{i}^{*}$ for $i=1,2$. As a result, the nationwide aggregate wellbeing of voters satisfies the following

$$
N S W\left(G_{j P c}^{*}, G_{j P c}^{*}\right) \frac{<}{>} N S W\left(G_{j P 1}^{*}, G_{j P 2}^{*}\right)(A .114)
$$

And the strong and conventional decentralization theorems, in general, do not hold. 